ANL- 6244

Reactors - General (TID-4500, 15th Ed.)

AEC Research and Development

ARGONNE NATIONAL LABORATORY

9700 South Cass Avenue

Argonne, Illinois

\title{
ON THE PROBLEM OF LIQUID ENTRAINMENT
}

by

Gordon C. K. Yeh and Novak Zuber

Ramo-Wooldridge a Division of

Thompson Ramo Wooldridge Inc.

Canoga Park, California

October 1960

Argonne National Laboratory Subcontract 31-109-38-1159

September 29, 1960

Operated by The University of Chicago

under

Contract $W-31-109-$ eng-38 


\section{DISCLAIMER}

This report was prepared as an account of work sponsored by an agency of the United States Government. Neither the United States Government nor any agency Thereof, nor any of their employees, makes any warranty, express or implied, or assumes any legal liability or responsibility for the accuracy, completeness, or usefulness of any information, apparatus, product, or process disclosed, or represents that its use would not infringe privately owned rights. Reference herein to any specific commercial product, process, or service by trade name, trademark, manufacturer, or otherwise does not necessarily constitute or imply its endorsement, recommendation, or favoring by the United States Government or any agency thereof. The views and opinions of authors expressed herein do not necessarily state or reflect those of the United States Government or any agency thereof. 


\section{DISCLAIMER}

Portions of this document may be illegible in electronic image products. Images are produced from the best available original document. 
ABSTRACT

NOMENCLATURE

INTRODUCTION

I. DROP FORMATION

I.1 The Mechanism 9

I.2 The Effect of Bubble Diameter on Drop Size Distribution i2

I.3 The Effect of Bubble Diameter on the Maximum Neight 18 Reached by an EJected Drop

I.4 The Effect of Bubble Diameter on Liquid Entrainment 21

I.5 Summary

II. THE CHARACTERISTICS OF RISING LIQUID JETS 24

II.I The Profile of a Rising Jet 24

II.2 The Velocity of Rising Jet 27

II.3 The Break-Up of a Jet 29

II.4 Conclusions 31

III. DROP TRAJECTORIES

II.I General Equations of Motion 34

III.2 Equations of Motion for Smal1 Drops 39

III.3 Equations of Motion for Large Drops 42

$\begin{array}{lll}\text { III. } 4 \text { Summary } & 47\end{array}$

IV. ANALYTICAL FORMULATIONS OF ENTRAINMENT 49

IV.1 The Formulation of Zenz and weil 49

IV.2 The Formulation of Andrews 56

IV.3 Conclusions 60 
V. SEMI-EMPIRICAL APPROACH TO LIQUID ENTRAINMENT

$\begin{array}{lll}\text { V.1 The Correlation of Rruzhilin } & 61\end{array}$

V.2 The Correlation of Panasenko and Antonov 64

V.3 The Correlation of Sterman, Antonov, and Surnov 71

V.4 The Correlation of Sterman 78

$\begin{array}{lll}\text { V.5 Conclusions } & 84\end{array}$

VI. TRANSPORTATION OF STEAM IN A BUBBLING TWO-PHASE MIXTURE 86

VI.1 The Correlation of Kurbatov 87

VI.2 The Correlation of Margulova 88

VI.3 The Correlation of Sterman 90

VI.4 The Experiments and the Correlation of Dementiev, 92 Lepilin, and Loginov

VI.5 The Expansion of a Bubbling Mixture and the True 95 Location of the Liquid Interface

$\begin{array}{ll}\text { VI.6 Summary } & 101\end{array}$

$\begin{array}{lr}\text { REFERENCES } & 103\end{array}$

APPENDIX A
IA

Experimental Data on Water Carryover from Boilers at High Pressures

APPENDIX B

Volumetric Vapor Fraction a as a Function of the Reduced Vapor Velocity uo" at High Pressures 


\section{ABSTRACT}

This report surveys the problem of liquid entrainment by a gas phase. It is written with the purpose of gathering, presenting and correlating avaliable incormation which may be useful for predicting the liquid cary over in boiling water reactor at high pressure.

Correlations which predict water carry over as a function of pressure, of the height of the vapor dome and of the vapor mass flow rate are presented and discussed. Because entraimment depends upon the hydrodynamic conditions and upon the expansion of a twophase bubbing mixture this report discusses also the transportation of vapor through such mixtures. Fquations which relate the volumetric vapor fraction to the reduced (superficial) vapor velocity in bubbling at high pressures are presented and some inconsistencies are noted. Experimental data and correlations which predict the 1ocation of the liquid-vapor interiace in bubbling at high pressures are also given. Ixperimental data on water carry over at high pressures reported in the Iiterature are summarized in the Appendix.

The problems of drop formation for bursting bubbles and of drop balligtics are discussed together with some analytical formulations of the entralnment problem. The bibliography may prove useful as a source of additional information on the problems of cary over, corrosion and on the purity of steam and of water at high pressures. 


\section{NOMENCLATURE}

\section{(Dimensions in the MT System)}

$\mathbf{A}=\mathbf{A}^{\prime}+\mathbf{A}^{n}=$ cross sectional area $\left(\mathbb{L}^{2}\right)$

$A^{\prime}$ - cross sectional area occupied by liquid (L $\left.{ }^{2}\right)$

$A^{* *}=$ cross sectional area occupied by vapor $\left(\mathbb{L}^{2}\right)$

$A_{r}=$ dimensionless group defined by $\mathbb{E q} \cdot(\mathrm{V}-29-\mathrm{b})$

$C=$ drag coeficient (dimensionless)

$D=$ drop dianeter $(\mathbb{L})$

$D_{j}=$ jet diameter (L)

d = diameter of a container (L)

$\mathrm{d}_{\boldsymbol{L}}=$ diameter given by $\mathrm{Eq} \cdot(\mathrm{VI}-13)(\mathrm{L})$

$E$ - liquid entrainment (mass flow rate of liquid/mass flow rate of vapor) (dimensionless)

e entrainment given by $\mathbb{E q} \cdot($ VI-10) (dimensionless)

$F=d r a g$ force $\left(M T^{-2}\right)$

$\mathbb{F}_{\mathbf{r}}=$ Froude number defined by $\mathbb{E} q \cdot(\mathrm{V}-29-2)$ (dimensionless)

$f_{1}=$ mass $f^{2}$ action of particles with energy $\epsilon_{i}\left(M^{-1} L^{-2} T^{2}\right)$

$G^{\prime}=$ flow rate of liquid leaving the interface $\left(M^{-2} \mathrm{~T}^{-1}\right.$ )

$\mathrm{G}^{\mathrm{w}}=$ vapor mass flow rate $\left(\mathrm{ML}^{-2} \mathrm{~T}^{-1}\right)$

$\mathrm{G}_{2}=$ dimensionless group defined by Eq. (V-22-a)

$g=$ gravitational acceleration $\left(\mathrm{LT}^{-2}\right)$

$H=$ height of the vapor dome (vapor space) in absence of bubbling ( $L$ )

HL = height of the liquid in absence of bubbling (L)

$\mathrm{H}_{\mathrm{m}}=$ height of the two phase bubbling mixture (L)

Hy = height of the vapor space during bubbling ( $L$ )

$\Delta H=$ expansion of the two phase bubbling mixture (I) 
$H_{T R}$ helght of the "transition region" defined in Chapter VI (I) $\mathrm{h}=$ hydrostatic head (L)

$\mathrm{h}=$ height of drop trajectory (L)

$\mathrm{h}_{\mathrm{m}}=$ maximum height of drop trajectory (L)

$h_{j}=$ maximum height of a jet (L)

$\mathrm{K}=$ parameter defined by $\mathrm{R} q \cdot(\operatorname{III}-36)\left(\mathrm{L}^{-0.4} \mathrm{~T}^{0.6}\right)$

$\mathbb{K}=$ constant in $E q \cdot(I I-3)\left(L^{2}\right)$

$\mathbb{K}_{0}=$ function defined by $\mathrm{Eq} .(\mathrm{V}-19)\left(\mathrm{L}^{-0.75} \mathrm{~T} 0.75\right)$

$I=$ wave length of jet deformation (L)

Lopt: most critical wave length for jet break-up (L)

$K=$ unbroken length of a jet (L)

$m$ mass of liquid drop (M) (Chapters I and IV)

$m$ - mass of liquid set in motion to fill a crater (M) (Chapter II)

$N=$ dimensionless group defined by E. (V-16)

$N$ - total number of drops thrown up from the interface per unit cross sectional area per second $\left(\mathbb{L}^{-2} \mathrm{~T}^{-1}\right)$

$n$ number of drops of a given size thrown up from the interface per unit cross sectional area per second $\left(\mathbb{L}^{-2} \mathrm{~T}^{-1}\right)$

$\bar{n}=$ number or weight percentage of a given drop size in total spectrum $\left(\mathrm{L}^{-2} \mathrm{~T}^{-1}\right)$

$P=$ pressure $\left(M^{-1} T^{-2}\right)$

$p_{i}=$ pressure inside a bubble $\left(m_{-}^{-I_{T}-2}\right)$

$p_{0}=$ pressure outside a bubble $\left(M_{-}^{-1} T^{-2}\right)$

$\Delta \mathrm{p}=\mathrm{p}_{1}-\mathrm{p}_{0}\left(\mathrm{M}^{-\mathrm{I}_{\mathrm{T}}-2}\right)$

$q=$ frequency in $\mathbb{E q} \cdot(\operatorname{II}-15)\left(\mathrm{T}^{-1}\right)$

$R_{1}, R_{2}=$ principal radil of curvature (L) 
$R_{e}=$ Reynolds number (dimensionless)

$r$ - depression of a bubble crater (L)

$\mathrm{r}_{\mathrm{m}}=$ maximum bubble $\mathrm{radius}(\mathrm{L})$

$\mathbf{r}_{\text {cr }}$ critical bubble radius defined in $\mathbb{E q} .(I-9)$ (L)

$S$ = suriace area which can eject drops (L2)

$t=\operatorname{time}(T)$

$\bar{\tau}$ - drop residence time above a given elevation (T)

$t_{m}$ time to reach the maximum height (T)

$U_{0}=$ initial velocity of a jet $\left(\mathrm{LT}^{-1}\right)$

$u^{\prime}=$ drop velocity $\left(\mathrm{LT}^{-1}\right)$

$u_{\mathrm{h}}^{\prime}=$ horizontal component of $\mathrm{u}^{\prime}\left(\mathrm{LT}^{-1}\right)$

$u_{v}^{\prime}=$ vertical component of $u^{\prime}\left(L^{-1}\right)$

$u_{1}=$ initial drop velocity (LT-1)

$u_{t}=$ terminal velocity of a liquid drop (LT-1)

$u_{t \xi}$ - terminal velocity of a liquid drop given by stokes' law Eq. (III-24) (LT $\left.T^{-1}\right)$

$u_{0}^{\prime}=V^{9} / A=G^{\prime} / \rho^{\prime} A$ reduced (superficial) velocity of liquid $\left(L T^{-1}\right.$ )

$u_{0}^{m}=V^{w} / \mathbb{A}=G^{m} / \rho^{m} \mathbb{A}=$ reduced (superficial) velocity of vapor $\left(L^{-1}\right.$ )

$V^{\prime}=$ volumetric flow rate of liquid $\left(\mathrm{L}^{3} \mathrm{~T}^{-1}\right)$

$V^{\prime \prime}=$ volumetric llow rate of vapor $\left(\mathbb{L}^{3} \mathrm{~T}^{-1}\right)$

$W$ - total rate of entrainment $\left(M^{-1}\right)$

$W_{1}=\frac{d w_{i}}{d t}$ entralament rate under steady conditions for particles with energy $\epsilon_{i}\left(L^{-2} \mathrm{~T}\right)$

$W_{e}=$ Weber number (dimensionless)

$w_{i}$ - vessel inventory of particles with energy $\varepsilon_{1}\left(L^{-2} x^{2}\right)$

$a=\frac{A^{a P}}{A^{2}+A^{m}}=\frac{A^{m}}{A}=$ volumetric vapor fraction (dimensionless)

a amplitude of the surface disturbance of a jet (L) (Chapter II) 
$B=$ reciprocal of average particle energy $\left(M^{-1}{ }_{L}^{-2} T^{2}\right)$

$\epsilon=$ entrained number of drops per unit volume of gas $\left(\mathrm{L}^{-3}\right)$

$\epsilon_{i}=$ escape energy defined by $E q \cdot(I V-13)\left(M^{2} T^{-2}\right)$

$\eta=$ number of drops per cross-sectional area above a given elevation $\left(\mathbb{L}^{-2}\right)$

$\lambda$ = dimensionless coefficient of conductance in Eq. (IV-20)

$\emptyset$ - function given by Eq. (III-34) (dimensionless)

$V=$ kinematic viscosity $\left(L^{2} \mathrm{~T}^{-1}\right)$

$\mu^{m}=$ viscosity of gas $\left(M_{-1}-I_{T}^{-1}\right)$

$\rho^{\prime}=$ liquid density $\left(M^{-3}\right)$

$p^{m}=$ vapor density $\left(M^{-3}\right)$

$\rho_{\mathrm{m}}=(1-\alpha) \rho^{\prime}+\alpha \rho^{m}=$ density of two phase mixture $\left(\mathrm{mL}^{-3}\right)$

$\theta=$ angle in $F 1 g$. II -1

$\sigma$ - surface tension (MT-2)

\section{Superscripts:}

- denotes 1iquid

* denotes vagor

* denotes that the data eroluated at the second transition point (Point B in Fig, 1) 


\section{ON THE PROBLEM OF LIQUID ENTRAINMENT}

\section{INTRODUCION}

The entrainment is a consequence of dynamic iateractions and may arise wherever two phases are brought into contact and are in relative motion. The entrainment of a liquid by a gas phase may occur in technical equipments such as boilers, evaporators, rectification columns, nuclear reactors, etc. The effects of entrainment are detrimental to the performance of most systems. In evaporation, distillation, and absorption, it may cause serious loss or contamination of the products, or it may diminish the effective separation of liquid components. The presence of water droplets in the stean may cause water hamer in pipes and superheaters, or it may cause damage to a reciprocating engine or a turbine. In direct cycle water boiling reactors droplets which leave the boiling interface carry volatile substances which are highly radioactive (Rer. 1), thus, the carry-over of radioactivity poses an additional problem. It is therefore of considerable interest to understand the processes which affect the entrainment and to be able to predict the amount of liquid which is carried by the gas or vapor phase as function of the design characteristics and operating conditions of the system.

The problem is complicated because the entrained liquid drops can result from three different processes: from bursting bubbles, from splashing, and from foaming. Fach process is in turn affected, to a different degree, by the design and operating characteristics of the system, as well as by the physical and chemical phenomena which occur at the intereace between the 1iquid 
and the vapor. Figure 1, which is reproduced from Reference 2 shows how, for a given design (cross-sectional area and height of the dome) and for given operating conditions (pressure, initial level of the liquid, salt content), the entrainment $\mathrm{E}$ varies with the reduced vapor velocity $u_{0}$ ". It can be seen from this figure that the experimental data can be approximated by power law expressions relating the entrainment to the reduced vapor velocity

$$
I=c\left(u_{0}\right)^{n}
$$

where the constant $c$, and the exponent $n$, assume different values for different regions (see Figure 1). It was proposed therefore, In Relerences 3, 4,5 , and 6, that the carryover problem could be simplified by considering three different regions, each of which could be described in terms of the dominant mechanism governing the entrainment of the Iiquid. A very idealized description of these mechanisms is shown on Figure 2, which is reproduced from Reference 6.

Consider vesse1 (see Figure $2-a$ ) with a liquid level $\mathrm{H}_{\mathrm{L}}$, and a vapor space which, in absence of bubbling, has a helght H. Once the process of bubbling starts, i.e., once the vapor volume fraction $a$, in the liquid is larger than zero (see rigure 2-b) the volume of the two-phase mixture will expand thereby increasing the height $H_{m}$, of the mixture and decreasing the height of the vapor space $\mathbb{H}_{V}$. At the 1 iquid vapor interface (at $\mathrm{H}_{\mathrm{m}}$ ) drops are generated by bursting bubbles. In order that a drop can be

\footnotetext{
*The abscissa on this 1 igure is equal to the reduced (superficial) vapor velocity uo", divided by the height $H_{1}$ of the done measured from the level of the liquid in absence of bubbling. For the data shown on Figure 1 , the value of II was constant and equal to $46.5 \mathrm{~cm}$.
} 


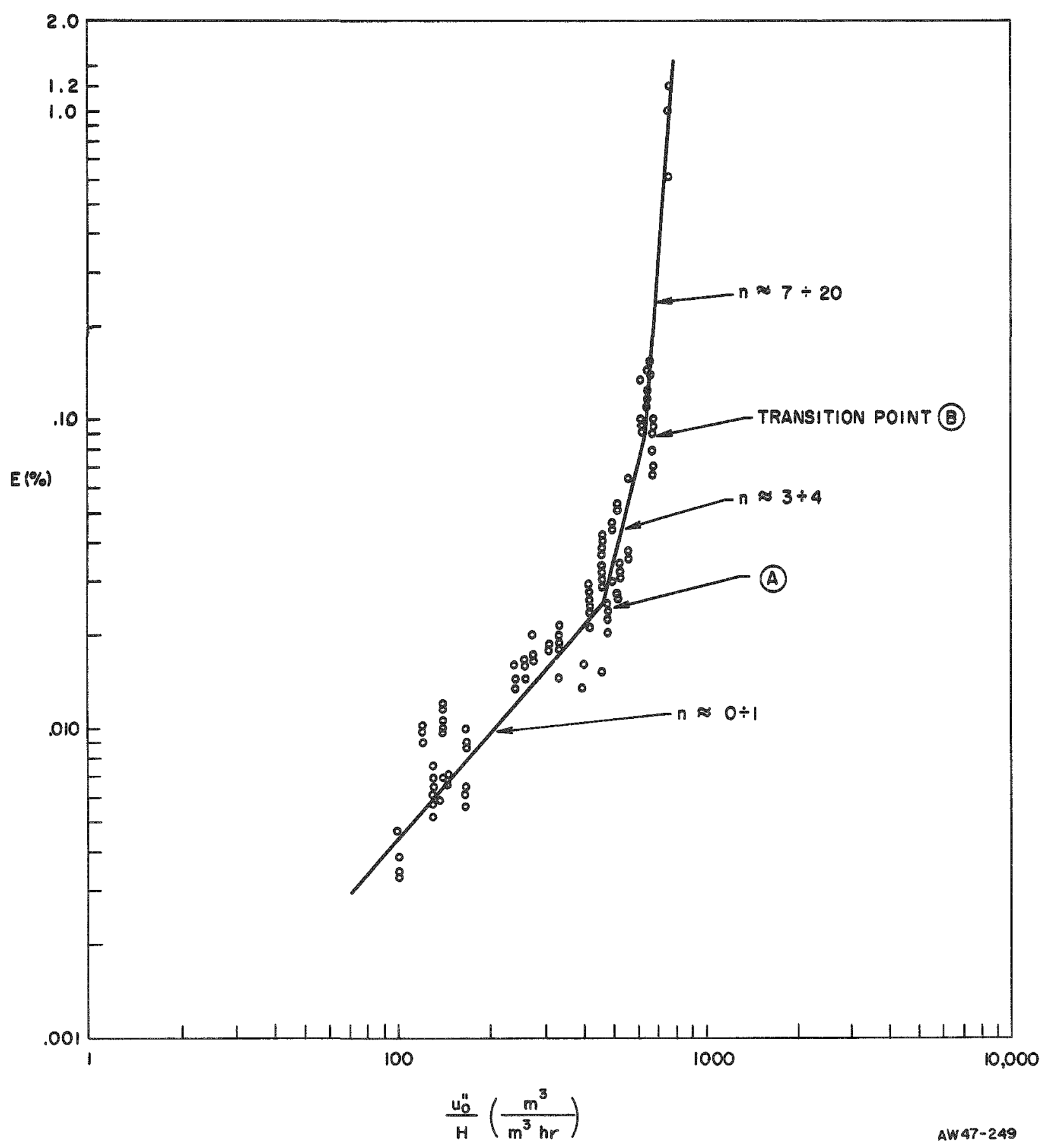

Figure 1. Entrainment as a Function of the Reduced (Supericial) Vapor Volocity for Vlater at 185 atm and for the Height of the Vapor Dome $H=0.465 \mathrm{~m}$. (Ref. 2). 

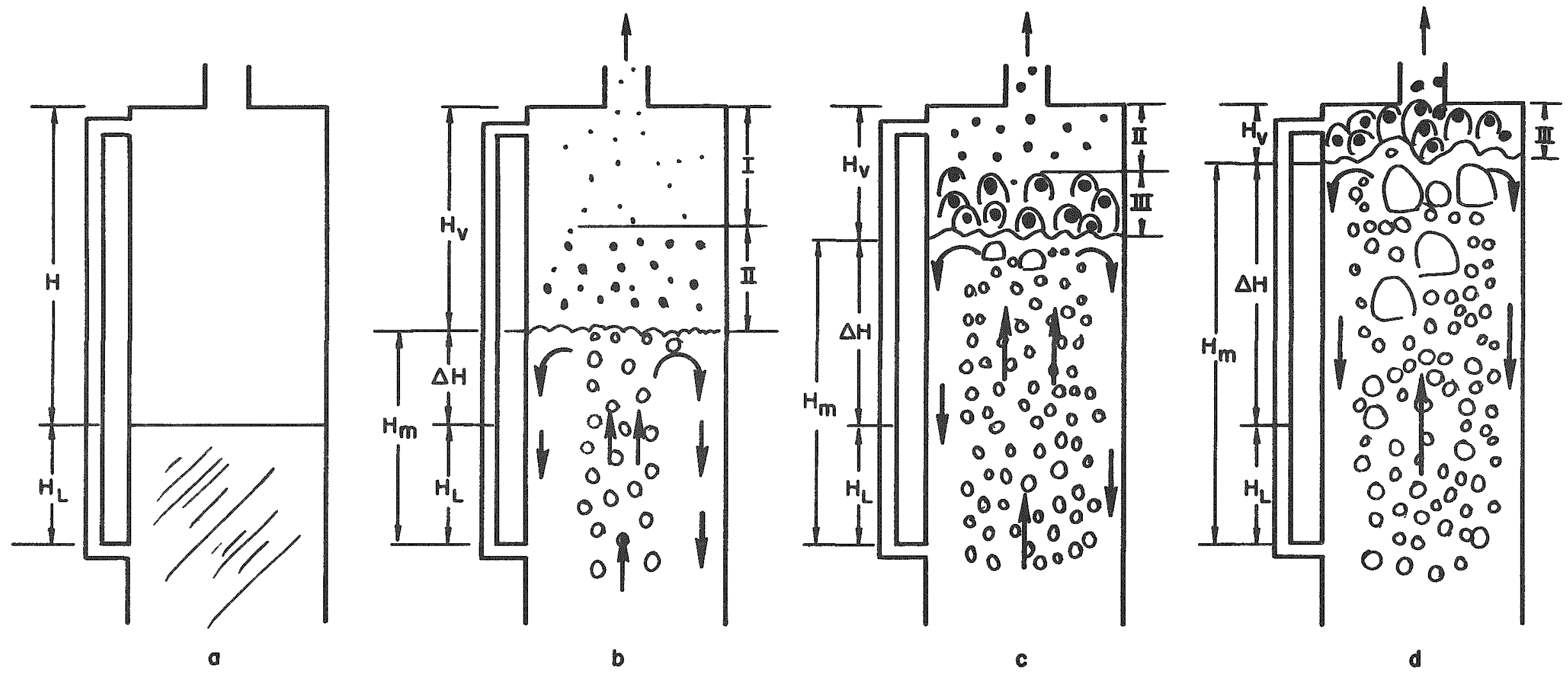

Aw47-246

Figure 2. Mechanisms Governing the Liquid Entrainment. (Ref. 6). 
transported and carried away by the vapor the settling (terminal) velocity of the drop must be equal to or smaller than the reduced velocity $u_{0}$, of the vapor. For low vapor mass flow rates, i.e., for low reduced vapor velocities, only the smallest droplets can be entrained and carried away (see region I on Figure 2-b). The liquic entrainment due to these small drops is low, consequently, in this regime the exponent $n$ in equation (1) has a value of the order of unity (see Figure 1). For larger drops, the settling velocity exceeds the vapor velocity; these drops, which have been ejected from the liquid vapor interface by bursting bubbles, will rise to some maximum height and will return subsequently, to the liquid. The region of the vapor space in which these returning drops are mostly present is denoted by II on Figure 2-b. A further increase in the vapor mass flow rate will result in a decrease of the vapor beight $H_{V}$, (see $\mathbb{F i g u r e ~ 2 - c )}$ ) and in an increase of the reduced vapor velocity. Consequently, some of the larger ejected drops, which for lower vapor flow rates were returning to the liquid, will reach now the exhaust line and will be carried away by the vapor. With increasing vapor flow rates the number of bubbles which burst at the interface increases causing an increase of the number of ejected drops and of the liquid entrainment. As a consequence of these combined effects, the entrainment becomes sensitive to variations of the vapor flow rate; in this region the exponent $n$ in Equation (1) takes a value between 3 and 4. A still further increase of the vapor 10 w rate results in the interaction between single bubbles and in the formation of vapor slugs. These vapor slugs are ejected from local areas of high vapor velocity or liquid 
turbulence (see region III on Figures 2-c and 2-d). The kinetic energy of the vapor is large, the liquid vapor interface is agitated, liquid sheets are splashed in the space above. If the expansion of the two-phase mixture is such that the liquid splashes may reach the exhaust line, the 11quid entrainment will rapidly increase with -increasing vapor velocities. In this region the exponent $n$. in

- Equation (1) assumes values which vary between 7 and 20.

It appears Ixom this brief description of the process that an understanding of the liquid entrainment problem requires an understanding of the processes which affect the bursting of bubbles, the formation and the ballistics of drops, as well as the drop size distribution. Because the rise of bubbles, the agitation of the liquid vapor interface, and the expansion of the two-phase mixture depend upon the hydrodynamic characteristics of the two-phase mixture, an understanding of the problem requires also an understanding of the mechanisms which govern the transportation of vapor through a 1iquid.

This report is a survey of the problem of liquid entrainment by a gas phase. It is written with the purpose of gathering, presenting, and correlating avaliable information which may be useful for predicting the liquid carryover in a boiling water reactor at high pressure. It is hoped also that by correlating available information, this report will prove useful in outlining areas and problems which require further investigation.

The problem of drop formation by bursting bubbles is aiscussed in Chapter I. Because experimental data indicate that the entrainment is primarily due to drops which are ejected by rising 
liquid jets, Chapter II considers some characteristics of these jets. The problem of drop ballistics is taken up in chapter III. A Iormulation of the liquid entrainment problem by considering drop formation, drop trajectories, and drop distribution is outlined in Chapter IV. Because of insuficient information, the analytical methods which are discussed in Chapter IV cannot be used at present for quantitative predictions. Therefore, the semi-theoretical methods, i.e., dimensional analysis and the theory of similarity which were used by various investigators in analyzing and correlating experimental data are discussed in Chapter V. This chapter contains also the heretofore proposed correlations of liquid carryover for water at various pressures. The mount of liquid which is carried away by the vapor depends to a great extent upon the vapor volume fraction $a$, and upon the reduced (supericial) vapor velocity uo", which characterize the hydrodynamic conditions of the two-phase mixture. In order to use the proposed correlations which are discussed in Chapter $V$, it is necessary to relate a to $u_{0} "$. It is necessary also to determine the expansion, i.e., the true height of the two-phase bubbling mixture. Chapter VI considers the semiempirical equations which relate the vapor volume fraction a to the reduced (supericial) vapor velocity uo". This chapter contains also the correlations which bave been claimed to predict the true location of the liquid vapor interface, i.e., the height of the two-phase bubbling mixture. Experimental data on liquid carryover for water at various pressures which were reported in the Russian 1iterature are given in Appendix A and Appendix B of this report. 
In addition to the phenomena which have been just described, the liquid entrainment depends also upon the condensation or evaporation of drops as well as upon the presence of impurities and the foaming propensity of the 1iquid. These aspects of the problem are not discussed in this report. The results of a 12 rge number of Investigations concerned with the effects of impurities and of foaming upon the 1iquid carryover are reported in Reference 7. The bibliography includes number of references, mostly foreign, which may prove useiul as a source of additional information 


\section{DROP FORMATION}

It is generally agreed that drops which are entrained by the rising vapor are formed by three different processes: by the bursting of bubbles at the liquid interface, by splashing the disintegration of liquid slugs, and by foaming. In the range of interest for most systems the formation of drops is due primarily to bursting bubbles. This aspect of the problem has been investigated, therefore, by a number of researchers. We note Garner, Ellis and Lacey (Ref, 4), Newitt, Dombrowski and Rnelman (Refs.8, 9), and Gleim, Shelomov, and Shidlowskii (Refs.10,11) among others. This chapter summarises the results of these investigations.

\section{I.1 THE MECHANISM}

A bubble of moderate size (say $0.5 \mathrm{~cm}$ diameter) rising through a liquid usually assumes a form having an ellipsoidal cross-section, and it rocks in a vertical plane about the long axis. The terminal velocity of ascent is, over a wide range of sizes nearly independent of size. When the bubble reaches the surface of the liquid it usually rebounds back and forth with decreasing amplitude until, just before collapse, it comes to rest with its upper part projecting above the surface in the form of a hemispherical dome. The walls of the dome are extremely thin at the apex but thicken towards the base. The time-lag between the bubble reaching the suriace and collapsing will depend on the state of the interiace. If dirt, salts, or other stabilizing agents are present, the bubble mas remain on the surface for an appreciable time; even in reasonable pure water, the time-lag before collapse is of the order of $1 / 100$ second. 
Wbile the bubble is intact the pressure inside it will be greater than the surrounding pressure by an amount $\Delta p$, depending upon the curvature of the liquid envelope (a thin liquid film having two parallel surfaces) and its surface tension $\sigma$ :

$$
\Delta_{p}=20\left(\frac{1}{R_{1}}+\frac{1}{R_{2}}\right)
$$

where $\mathbb{R}_{1}$ and $\mathbb{R}_{2}$ are the principal radil of curvature. Since the upper dome is nearly hemispherical in shape, $\mathbb{R}_{\mathbf{1}}=\mathbb{R}_{\mathbf{2}}$ and

$$
\Delta \mathrm{p}=4 \sigma / \mathbb{R}_{1}
$$

The liquid level at the base of the bubble is depressed below the surrounding surface by an amount $r$ given by

$$
r=2 \sigma /\left[g\left(p^{p}-p^{n}\right) h+c\right]
$$

where $\mathrm{h}$ is the hydrostatic head of the surrounding liquid, $\rho^{\prime}$ is the liquid density, $p^{p}$ is the vapor density, $g$ is the gravitational acceleration and $c$ is a constant. For small bubbles $r=R_{1} / 2$.

The collapse of the bubble is associated fith a release of energy sufficient to impart a comparatively high velocity to any drops formed and to give rise to a wave disturbance in the surrounding liquid. By using high-speed photographic techniques, Newitt, Dombrowski and Knelman (Refs. 8,9), and Gleim and his associates (Refs. 10,11) were able to show that the mechanism of bubble collapse appears to be as follows (see Fig. I-1 which is taken from Ref. 8).

The bubble coming to rest at the liquid surface forms the hemispherical dome (Fig. I-1 b), its internal pressure producing 


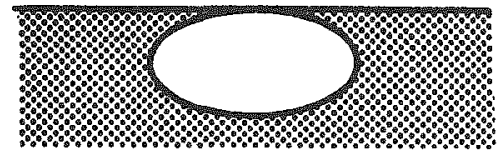

(A)

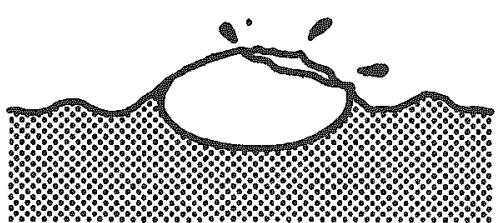

(D)

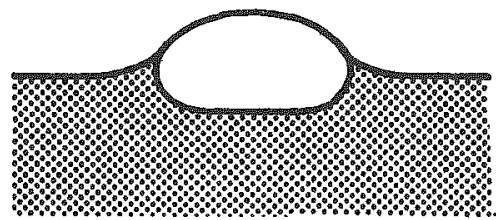

(B)

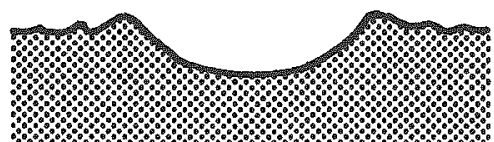

(E)

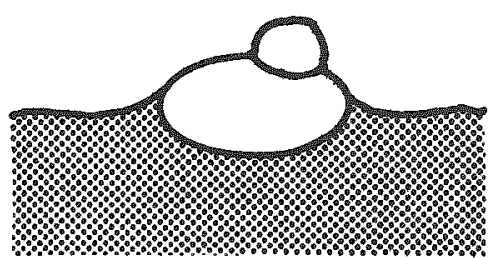

(c)

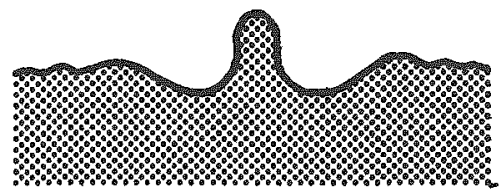

(F)

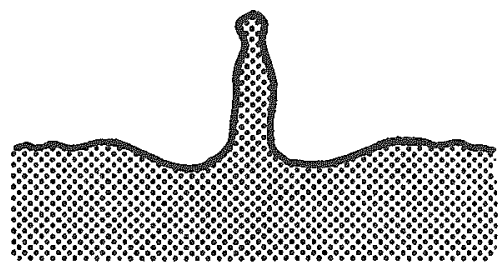

(6)

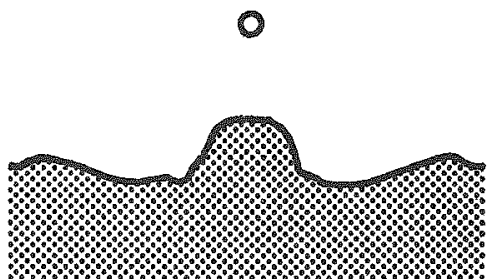

(H)

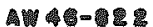

Figure I-1. Mechanism of the Burst of an Air Bubble on the Surface of Water (Ref. 8). 
a depression of the interface. Liquid drains from the dome until the upper part is so weakened that the internal pressure causes the formation of a secondary cap (rig. I-1(c)). This cap then disintegrates by the initial formation of a number of perforations which subsequently expand to give a lace-1ike structure. The liquid ligaments so formed are unstable and breas into small droplets of a few microns in diameter (Fig. I-1(d)). These droplets, which are too small to be seen in the photographs, are carried away by the drag of gas issuing from the periorated dome. The result of these events is to set up a system of standing waves, shown clearly in the Iigures and to leave a well-defined crater (Fig. I-1(e)) in the interface. As the crater ilis in, the momentum of the inflowing liquid produces a jet (rig. I-I(f)), which rises at high velocity and in certain circumstances detaches one or more comparatively large drops (Fig. I-I (g), (h)) from its apex. It is these drops, which may have a diameter of the order of $100 \mu$ or more, that are responsible for the greatest amount of entrained liquid. The jet then retracts and the surface of the liquid returns to rest.

\section{I.2 THE EFFCT OF BUBBLE DIAMITTR ON DROP SIZE DISTRIBUTION}

It is apparent that a quantitaive study of entrainment must take into account two systems of drops, the one derived from a disintegrating dome of liquid and consisting of clouds of minute drops of few microns in diameter and the other of comparatively few large drops derived from the breaking up of rising jets of 1iquid. There will be a size distribution in each system. References 4, 8, 9, 10, and 11 report experimental data which indicate a 
relationship between the bubble diameter and droplet diameter. It was found in these experiments that liquid jets were formed from bubbles which had a diameter below $0.5 \mathrm{~cm}$. The 1iquid jets from bubbles below $0.3 \mathrm{~cm}$ disintegrated into one or more droplets each of which, depending on its size, was projected to a characteristic height. The bubbles above $0.3 \mathrm{~cm}$ diameter formed shorter and thicker jet which broke into a langer droplet. The dimensions of these droplets varied from $100 \mu$ to $1000 \mu$ in diameter. As the bubble diameter approached $0.5 \mathrm{~cm}$, the ratio of the jet length to its diameter became insufficient to form droplets. Bubbles Iarger than $0.5 \mathrm{~cm}$ formed droplets entirely by the collapse of the bubble dome. The majority of these droplets had a dameter below 25 . Figure I-2, which is reproduced from Ref, 8 shows the size distribution of large and small drops, and Figure I-3, which is reproduced from Ref. 4, shows the dependence of the drop size distribution upon the bubble dimension. It can be seen that as bubbles become larger droplets formed by Iiquid jets decrease in number (but increase in size), whereas those formed by the collapse of the bubble dome become more numerous.

The effect of bubble dimensions on the drop size has been estimated by Davies (Ref. 12) for the case of drops generated by rising jets. For small bubbles having nearly hemispherical depression below the free water surface, the hydrostatic head is negligible compared with the surface tension force. If it is assumed that the difference between the surface energy of a hemispherical depression (2mín) and that of a llat surface (Tro) is converted into the potential energy of a drop of mass $\mathrm{m}$, it 


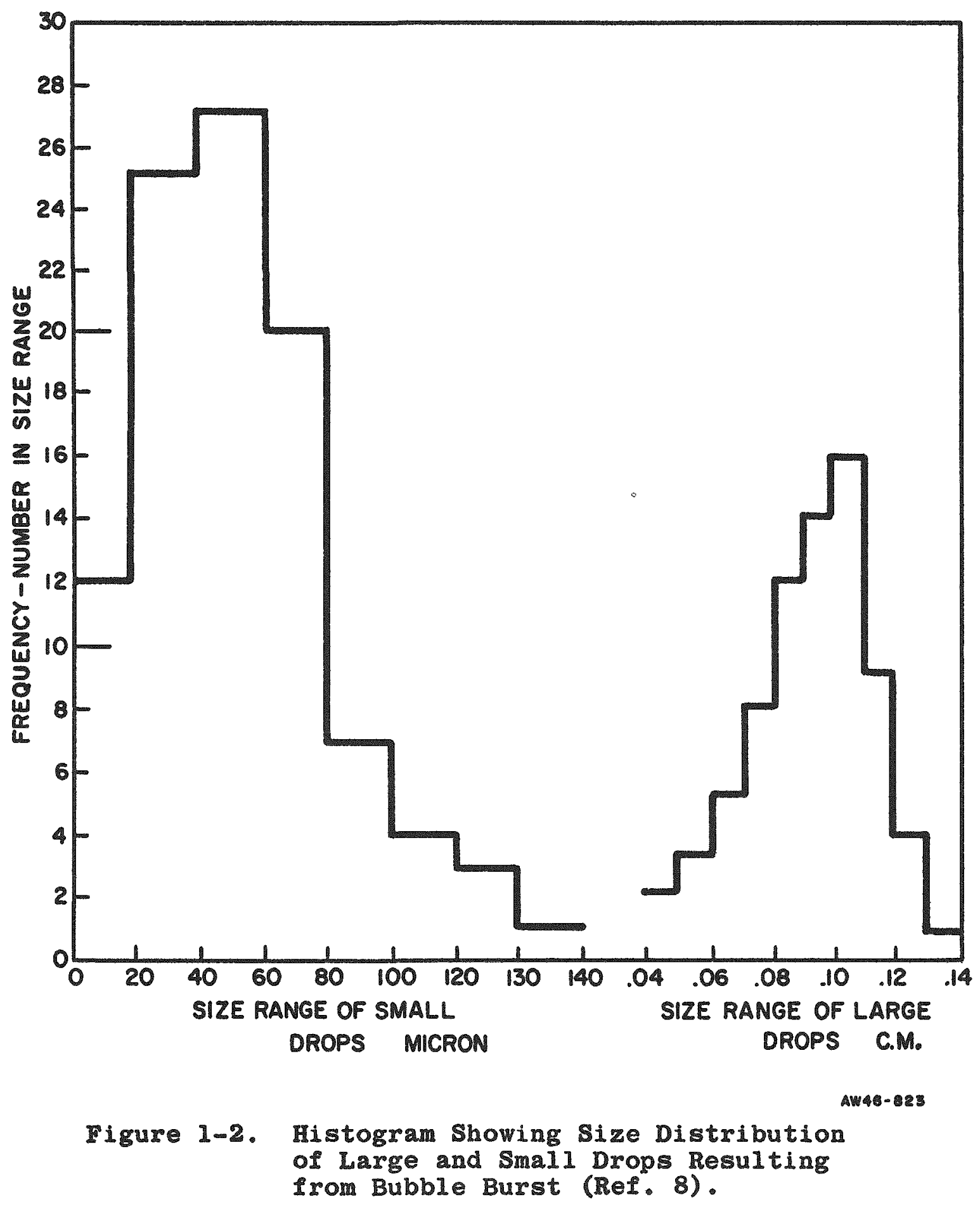



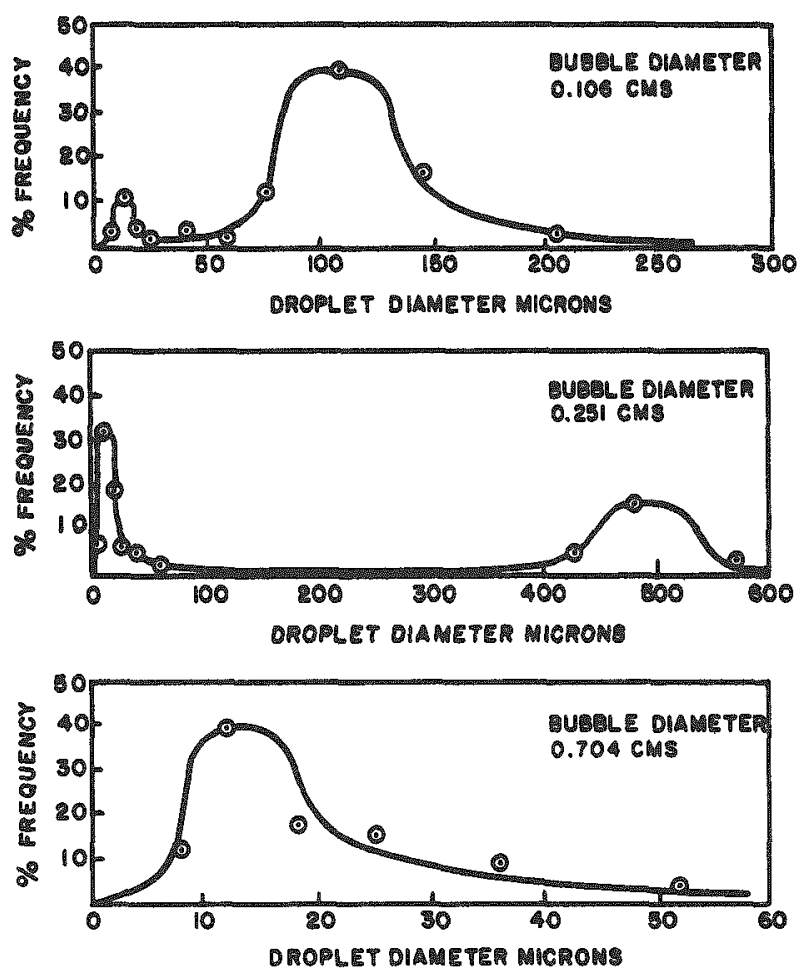

4.

Figure I-3. The Size Distribution of Droplets at a Height of $1 \mathrm{~cm}$ Above the Liquid Surface for Different Sizes of Bursting Bubbles. (Ref. 4). 
follows from an energy balance that

$$
m g h_{m}=\pi r^{2} \sigma
$$

where $h_{m}$ is the maximum height of ascent. From this equation, Davies concluded that il drops rise to approximately the same height, the drop diameter $D_{d}$ should be proportional to $r^{2 / 3}$ or

$$
m=\rho^{\frac{\pi}{6}}-d^{3}=B r^{2}
$$

where $\mathrm{B}$ is a constant. It was recently reported by Gleim and his associates (ReI. 11) that, Ior bubbles with diameter less than $0.7 \mathrm{~cm}$, Iquation (I-5) gives, on the average, the correct relation between $D_{d}$ and $r$ Bubbles larger thar 0.7 cr do not generate drops by the jet mechanism. Thus, for drops formed by rising jets it appears possible to estimate the arop size from bubble dimensions. It can be inferred also that factors which affect the dimensions of a bubble will aflect also the size of the drop.

It can be seen from the foregoing that experiments on Iiquid entrainment indicate that large bubbles are not effective in forming drops from ejecting jets, whereas small bubbles are. It is known from experiments on rising bubbles that large bubbles have an oblate shape whereas small bubbles are relatively spherical. It could be surmised then that the formation of drops by the jet mechanism depends upon the sphericity of a bubble. If this inference is correct, the maximum diameter of a jet ejecting bubble (and, consequently that of the drop) could be estimated by considering the conditions leading to bubble deformation. Such an estimate can be made using the analysis given in References 13, 14, and 15. 
Consider a bubble of radius $r$, rising steadily with velocity u, the balance between the buoyant force and the drag force is given by

$$
\frac{4 \pi}{3} r^{3} g\left(\rho^{\prime}-\rho^{3}\right)=C \frac{\rho^{\prime} u^{2}}{2}-\pi r^{2}
$$

where $C$ is the drag coeficient. The dynamic pressure $\frac{1}{2} \rho^{\prime} u^{2}$ has a tendency to deform a bubble whereas the pressure due to surface tension $20 / 1$ tends to maintain the spherical shape. A buble 11 deform when the effect of the dynamic pressure exceeds the surface tension effect. For a given velocity the maximum bubble radius $r_{m}$ can be estimated by considering the pressure balance at the stagnation point, thus

$$
\frac{1}{2} \rho^{\prime} u^{2}=\text { const. } x \frac{20}{r_{m}}
$$

It follows from Equations $(I-6)$ and $(I-7)$, alter some rearingements, that the maximum radius of a rising spherical bubble is given by

$$
r_{m}=\text { const } x \sqrt{\frac{\sigma}{g\left(\rho^{\prime}-\rho^{\prime \prime}\right)}}
$$

where the value of the constant is of the order of unity. For water, taking $\sigma=70 \mathrm{dyn} . / \mathrm{cm}$, the square root term in Equation (I-8) has a value of 0.267 . Thus, if the formation of drops depends upon the sphericity of a bubble, Equation (I-8) would predict that drops could not be generated from bubbles larger than $0.534 \mathrm{~cm}$ in diameter. This is not in contradiction with the results of Garner et. al. (Ret.4) and of Gleim et.21.(Ref. II) Who observed values of $0.5 \mathrm{~cm}$ and $0.7 \mathrm{~cm}$ respectively.. 
I.3 THE EFFECT OF BUBBLE DIAMETER ON THE MAXIMUM HEIGHT REACHED BY AN EJECTED DROP.

The experimental results of Garner et.al. (Ref. 4) and of Gleim t.al. (Refs. 10,11) provide also information on the effect of bubble diameter upon the ballistics of drops. It was observed in these experiments that droplets formed by the collapse of the bubble dome had a settling velocity (predicted by stokes' law) which was less than the velocity of the rising vapor. Consequently, these minute drops were entrained by the vapor. The dimensions of drops ejected by rising liquid jets were such that they could become entrained only at high vapor flow rates. When not entrained, these drops would rise to a characteristic height (which is a function of the drop diameter) and fall back into the liquid.

The effect of the bubble diameter on the maximum height reached by an ejected drop has been estimated by Gleim et.al. (Ref. 11) using energy considerations similar to those of Davies (Ref. 12). They observed that, since bubbles with a radius larger than a critical value $r_{c r}$, are not effective in forming drops by the jet mechanism, not all of the surface energy is transformed into the potential energy as it is implied by Equation (I-4). According to Gleim et. al. the fraction of the surface which can eject drops is given by

$$
S=\frac{2 \pi r^{2}}{r_{c r}}\left(r_{c r}-r\right)
$$

Then they related the energy of the drop to the energy of the surface $s$ by

$$
m g h_{m}=\mathbb{K} \frac{2 \pi r^{2}}{r_{c r}}\left(r_{c r}-r\right) \sigma
$$


where the coefficient $\mathbb{K}$ is experimentally found to be constant for each 1 iquid( $K=1.23 \times 10^{-2}$ for neutral salts, and water, and $K=0.95 \times 10^{-2}$ for alkaline solutions). It is interesting to note that compared with Eq. (I-10), Eq. (I-4) renders the same result for $r=0.6 r_{\mathrm{cr}}$; overestimates the drop energy for $r>0.6 \mathrm{r}_{\mathrm{cr}} ;$ and underestimates the drop energy for $x<0.6 \mathrm{r}_{\mathrm{cr}}$ (if $\mathrm{K}=1.23 \times 10$ is used). The experimemtal results of Gleim et.al. (Refs. 10,11 ) for water at $25^{\circ} \mathrm{C}$ are shown on Table I and on Figure I-4. From these results they concluded that the maximum height reached by a drop can be linearly

\section{TABLE I.}

Experimental Data of Gleim, et. 21. for Water at $25^{\circ} \mathrm{C}$

\begin{tabular}{ccc} 
Bubble Radius & Mass of the Drop & Maximum Height \\
\cline { 2 - 3 }$r$ & $\mathrm{~m}$ & $\mathrm{~h}_{\mathrm{m}}$ \\
$\mathrm{cm}$ & $\mathrm{gr} \times 10^{6}$ & $\mathrm{~cm}$ \\
0.105 & 2.6 & 17 \\
0.124 & 3.9 & 14.5 \\
0.234 & 9.8 & 9.5 \\
0.340 & 25.0 & 0.8 \\
0.350 & $-\cdots$ & 0
\end{tabular}

related to the bubble radius $x$, thus

$$
h_{m}=A\left(r_{c r}-r\right)
$$

where $\mathbb{A}$ is a constant. These results indicate also that the maximum radius of a bubble which can form a drop by the jet mechanism is approximately $r_{c r}=0.35 \mathrm{~cm}$.

Davies (Ref. 12) estimated also the initial velocity of a drop by considering the initial kinetic energy and the terminal potential energy, thus

$$
u_{i}^{\prime}=\sqrt{2 g h_{n}}
$$

From observations that ejected drops reached a height of $10 \mathrm{~cm}$, 


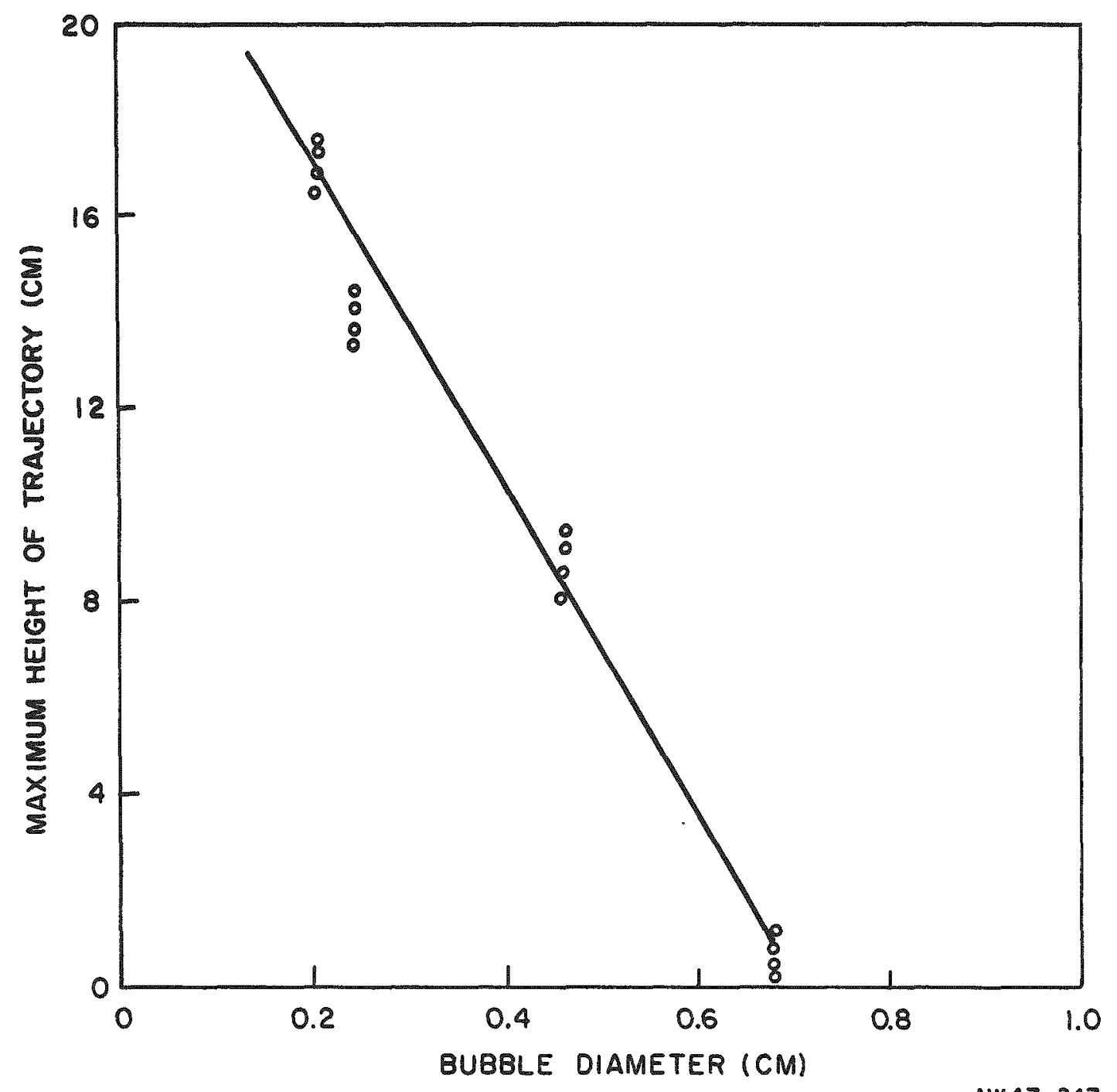

Figure I-4. The Effect of Bubble Diametex on the Maximum Height Reached by an Ejected Drop. (Ref. 11). 
he concluded that the initial drop welocity was approximately $140 \mathrm{~cm} / \mathrm{sec}$.

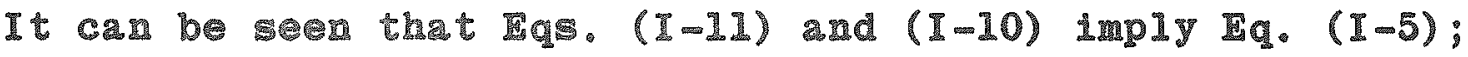
experimental data shown In Table I give support to this relation. Thus, as the bubble radius $x$ is increased, the size of a drop (formed by the jet mechansim) increases but the maximum height reached by the drop decreases. Consequenty, as the droplet size measuring device is raised in the apparatus, the average size of droplets becomes gradualy smallex.

\section{I.4. THE EFFECT OF BUBBLE DIAMETER ON LIQUID ENTRAINMENT \\ Garner, Flis, and Lacey (Ref, 4) calculated the liquid} entrainent from the size and the aumber of droplets which were collected at a given height above the Ilquid interiace. It was found that the entrainent decreased with increasing bubble size. This was due to the decreased formation of droplets from the jet in larger bubbles. Because of their small mass, droplets formed by the collapse of the bubble dome, although large in number, contributed little to the total entraiment.

Garner et.al. (Ref.4) observed that, although the entrainment in all drop sige ranges increases with increasing vapor flow rates, droplets formed by Iiquid jets become more numerous at higher boil-up rates. ConsequentIy, the entrainment increased rapidly with increasigg vapor flow rates. The experimental data of Garner, Ellis, and Lacey which are plotted on Fig. I-5 show this effect. It is noted here that, in this experimental range, 


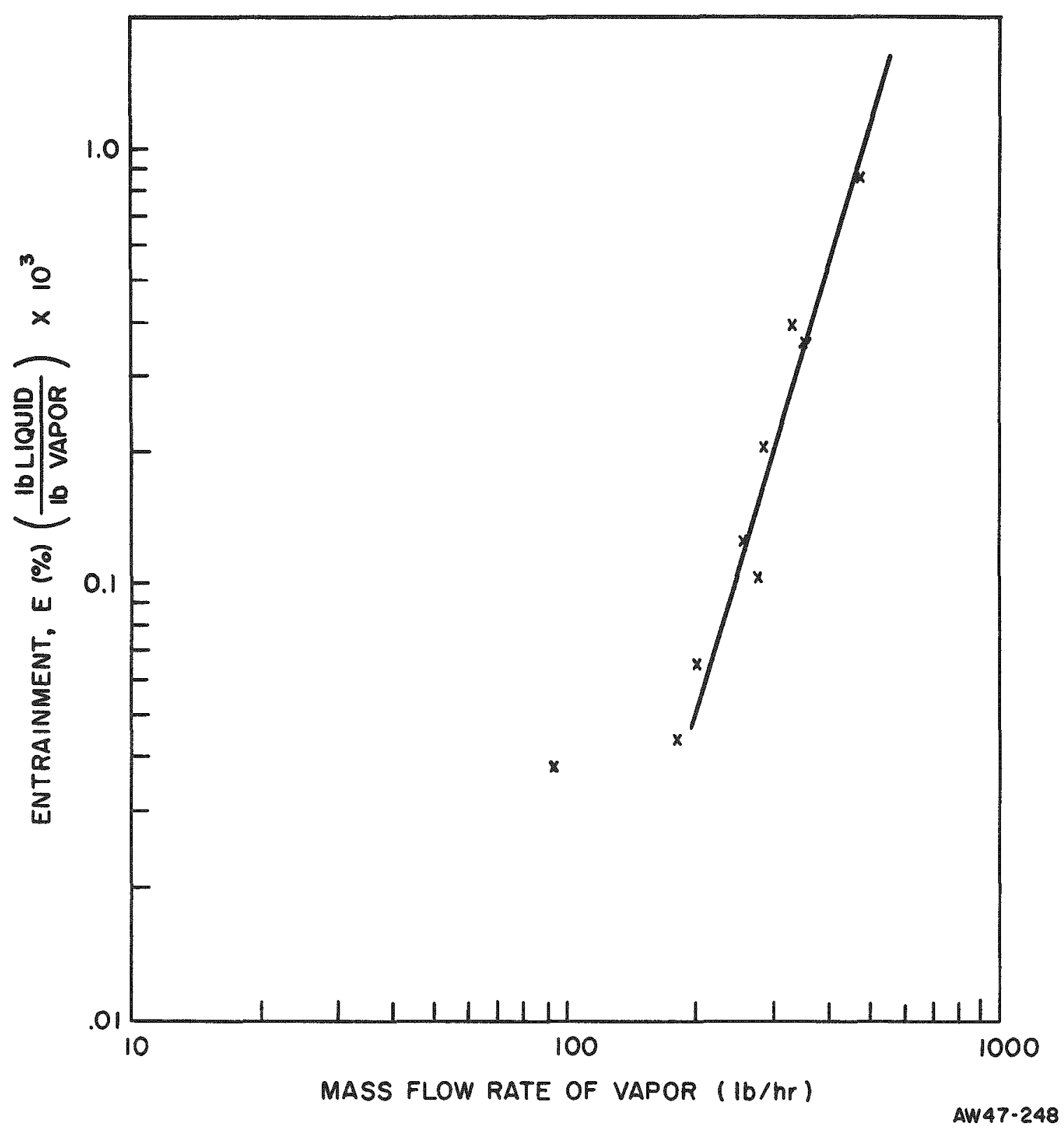

Figure I-5. The Effect of Vapor Mass Flow Rate on the Entrainment of Water at 1 atm. (Data taken from Ref. 4). 
the entraiment can bo approximated by a power low expression of the form of Eq. 1 given in the Introduction. It can be seen that in this range the value of the exponent is $n \approx 4$.

\section{I.5 SUMMARY}

Experimental results indicate that liquid entrainment is primarily due to the drops which are broken up from rising liquid jets. The appearance and the effectiveness of these jets depend upon the dimensions of the bursting bubbles. They will depend also upon the agitation of the Iiquid interface.

Experimental data show that the dimension, the maximum beight of ascent as well as the size distribution of these drops depend upon the dimension of the bursting bubbles. These results indicated also that both the diameters and the maximum heights reached by drops (formed by the jet mechansim) can be related to the diameter of the bursting bubble through simple expressions which are based on energy considerations. 
II. THE CHARACTERISTICS OF RISING LIQUID JETS

Because droplets which are generated by the breaking up of rising I1quid jets contribute most to the ontraimment we shall examine in this chapter some characteristics of these jets. It w11 be seen that it is possible to estimate the velocity and the hoight to which the jet will rise. It will be seen also that if the dimensions of the jet are known, it is possible to estimate the dimensions of the drops which are formed by the instability (break up) of the jet as well as the time of break up.

\section{II.1 THE PROFILE OF A RISING JPT}

Referring to Fig. II-1, the profile of the jet when at rest in its extreme position can be given by

$$
g\left(\rho^{\prime}-\rho^{\prime \prime}\right) y=\sigma\left(\frac{1}{R_{1}}-\frac{1}{R_{2}}\right)
$$

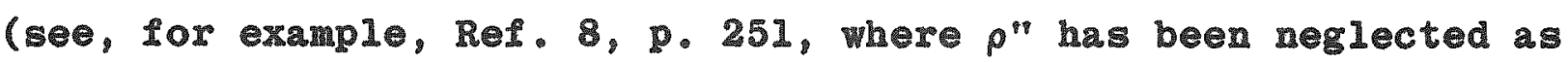
compared with $\rho^{\prime}$ ) where $\mathrm{y}$ is the hydrostatic head and $\mathbb{R}_{1}$ and $\mathbb{R}_{2}$ are the principal radil at any point. The instantaneous values of $1 / \mathbb{R}_{1}$ and $1 / R_{2}$ are $1 / x$ and $(d \theta / d y)$ sin respectively. Hence

$$
g\left(\rho^{\prime}-\rho^{\prime \prime}\right) y=\sigma\left(\frac{1}{\mathrm{X}}-\frac{\mathrm{d} \theta}{\mathrm{dy}} \sin \theta\right)
$$

If $x$ can be expressed as a function of $y$, this equation can be solved. Assuming the curve to be hyperbolic, i.e., $x y=K$. Eq. (II-2) then becomes

$$
g\left(\rho^{\theta}-\rho^{p 7}\right) y=\sigma\left(\frac{y}{K}-\frac{d \theta}{d y} \sin \theta\right)
$$




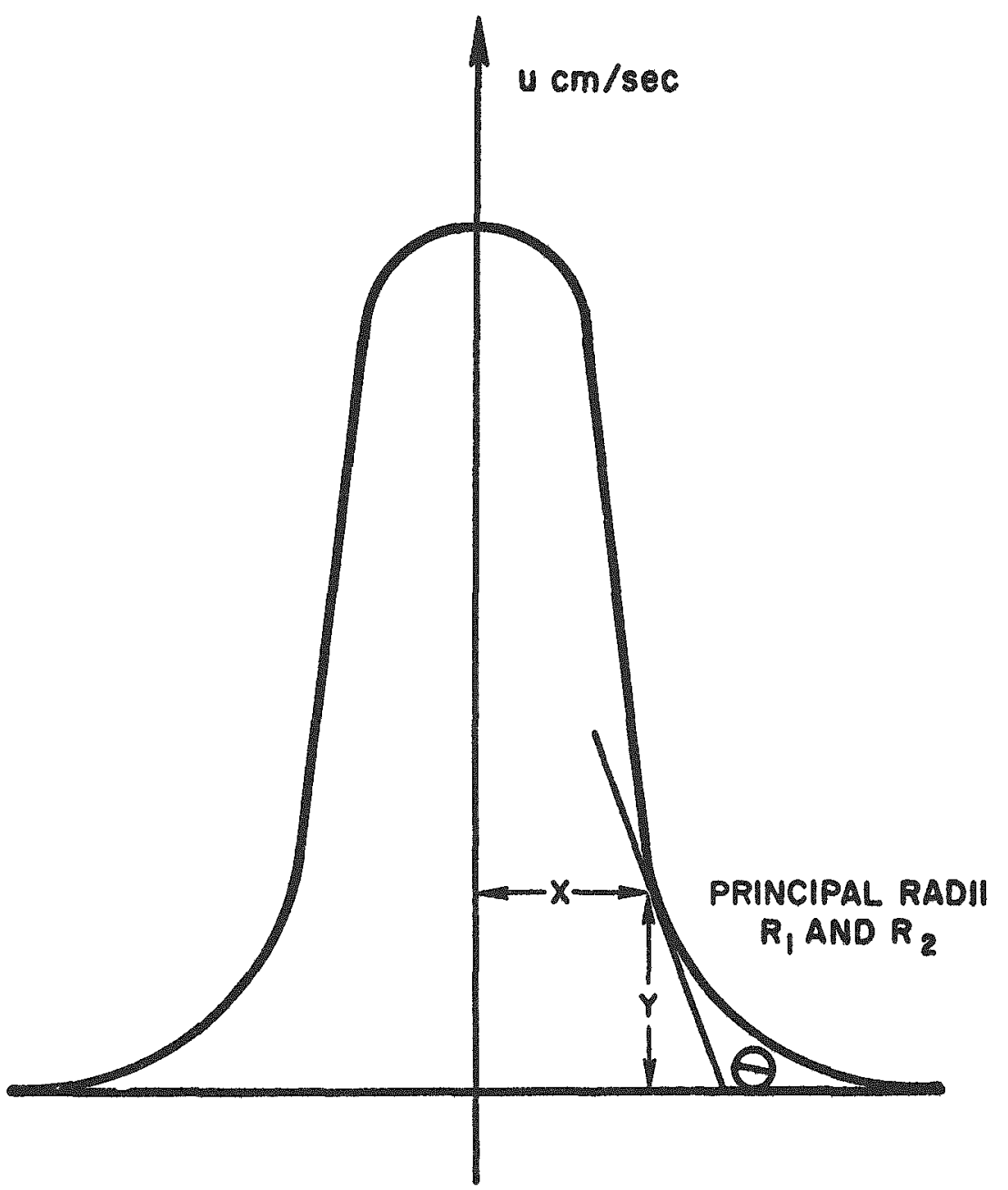

Aพ 48- 24

Figure II-1. Profile of a Rising Jet (ReI.8). 
Integrating

$$
-\int_{0}^{h_{j}} y d y=\frac{1}{\frac{g\left(\rho^{i}-\rho^{n}\right)}{\sigma}-\frac{1}{K}} \int_{\pi}^{\pi / 2} \sin d \theta \text { (II-4) }
$$

whence

$$
h_{j}=\sqrt{\frac{2}{\frac{2\left(\rho^{1}-\rho^{p 9}\right)}{o}-\frac{1}{K}}}
$$

where $h_{j}$ is the maximum height of the jet. Taking actual values of $x$ and $y$ Irom photographic records of jets an average value of $\mathrm{K}=1 \mathrm{~cm}^{2}$ is reported in Ref.8. For values of $0=73 \mathrm{dynes} / \mathrm{cm}$, $\rho^{\prime}=1 \mathrm{gm} / \mathrm{cm}^{3}$ and $\mathrm{g}=980 \mathrm{~cm} / \mathrm{sec}^{2} \mathrm{~h}_{\mathrm{j}}$ is found to bo $0.404 \mathrm{~cm}$ as compared with 0.44 crn as recorded on photographs.

We note that because $\mathbb{K}$ has a value of approximately $\mathrm{K}=1 \mathrm{~cm}^{2}$, it is by one order of manitude smaller than the term $g\left(\rho^{\prime}-\rho^{\prime \prime}\right) / 0$. The maximum height reached by a rising liquid jet can be approximated by the following relation

$$
\mathbf{b}_{j}=\sqrt{\frac{20}{g\left(\rho^{1}-\rho^{p}\right)}}
$$

Comparing Eqs. (II-6) and (I-8) it is; seen that both the maximum bubble radius $x_{m}$ and the maximum jet height $h_{j}$ are proportiona 1 to the same property group given by the square root term. From the definition of the generalized Weber number (Ref. 16):

$$
W_{0} \triangleq \frac{g\left(\rho^{i}-\rho^{m}\right)}{\sigma L^{2}}
$$


where I is a characteristic length, in this case either $\mathbf{r}_{\mathrm{m}}$ or $\mathrm{h}_{\mathrm{j}}$, It appears that for different systems at various pressures the similarity $w_{11}$ be preserved when $W_{e}=$ constant.

\section{II.2 THE VELOCITY OF A RISING JET}

Davies (Ref. 12) derived an expression for the velocity of a rising jet by considering the relationship between the forces on the crater. Consider the vertical force, $P$, roleased at the instant of disruption of a bubble having a nearly hemispherical depression of radius $r$ below the liquid-vapor interface. The hydrostatic head is negligible compared with the surface tension force; therefore, if $p_{i}$ and $p_{0}$ are the internal and external pressures respectively,

$$
P=\pi r^{2}\left(p_{i}-p_{0}\right)=2 \pi 0 r
$$

The mass m of liquid which must be set in motion to fill in the crater is $m=(2 / 3) \pi r^{3} \rho^{\prime}$. Davies assumed that force $p$ decreases linearly with time, so the average force applied to the mass m of the liquid is (1/2)P during the time $t$ wich it is active. No delinite value can be assigned to $t$, but it must be considerably less than the period of disruption of the dome. In a bubble $2 \mathrm{~mm}$ diameter the period of complete disruption of the dome is less than $3.3 \times 10^{-5} \mathrm{sec}$, Davies concluded, therefore, that the application of the force $\mathrm{P}$ is more in the nature of an impulse. If $u^{\circ}$ is the mean velocity acquired by the mass under the application of the mean force $(1 / 2)$ P in time $t$, then

$$
u^{*}=\frac{P t}{2 m}=\frac{3 \sigma t}{2 \rho^{\prime} r^{2}}
$$


Newitt et.21. (Ref. 8) remarked that Davis's Eq. (II-9) gives results which are too low, and this seems to arise from the fact that it is not the excess pressure $\left(p_{i}-p_{0}\right)$ which provides the impulse force, but the absolute pressure. At the instant of burst the gases inside the bubble escape with explosive force leaving a partial vacuum in the crater. Substituting the absolute pressure in Davis's equation, they obtained that

$$
u^{\prime}=\frac{3 t\left(p_{0}+\frac{20}{F^{\prime}}\right)}{4 x p^{\prime}}
$$

Employing this equation and assuming $t$ to be equal to the time for the complete disruption of the dome, 1.e., of the order of $3.3 \times 10^{-5} \mathrm{sec}$, the calculated and observed values of u' are in fair agreement (of the order of $200 \mathrm{~cm} / \mathrm{sec}$ ). Hence, the velocity of the rising jet computed from Eq. (II-10) and the initial velocity of a rising drop computed by Davies for energy considerations (see section I-3) are of the same order of magnitude.

Eq. (II-10) indicates that the velocity of a rising jet is inversely proportional to the bubble radius. Thus, it appears that small bubbles are more effective in projecting drops of liquid than large bubbles.

The authors note, in closing, that a more exact mathematical analysis of the jet profile and of the jet velocity can be made by considering an impulsive pressure applied to the liquid-vapor interface and using the analysis developed by Kelvin (Ref, 17). 


\section{II.3 TIE BREAR-UP OF A IET}

Rayleigh (Ref. 18) has shown tha because of surface tension forces and existing disturbances, a column of liquid will break up il its length is greater than its circumference. Il a rotational symetrical deformation exists on a surface and the wave length of the deformation is $L$, then, if $L$ is greater than $\pi D_{j}$ (where $D_{j}$ is the jet diameter), the surface tension forces will contribute to further increase in the deformation and finally to jet disruption. For nonviscous Iiquids, Weber (Ref. 19) gives the most favorable wave length for break up of a jet as

$$
L_{\text {opt }}=\sqrt{2} \pi D_{j}
$$

and Haenlein's (Ref. 20) experimental value of Lopt $=4.42 D_{j}$ agrees with this.

It is possible to compute the diameter of drop in terms of this critical wave length by equating a cylindrical length of jet, equal to $4.42 \mathrm{D}_{\mathrm{j}}$ with the volume of a drop formed and having a diameter equal to $\mathrm{D}_{\mathrm{d}}$. Thls gives the following relation between $D_{j}$ and $D_{d}$.

$$
D_{j}=0.53 D_{d}
$$

and

$$
D_{d}=1.89 D_{j}
$$

Measurements of a number of jets and main drops indicate that the ratio $\mathrm{D}_{\mathrm{d}} / \mathrm{D}_{\mathrm{j}}$ is usualy less than 1.89 . In one instance the drop diameter as measured from the cine film is about 0.09 cm while the jet diameter just prior to break up is about $0.06 \mathrm{~cm}$, the ratio being 1.5. Ratios as high as 1.7 have been measured. It was 
pointed out by Newitt, et.21, (ReI, 8) that if it is assumed that the entire hemispherical crater left after a bubble burst forms a liquid column, the diameter of the 11quid column for a crater $0.250 \mathrm{~cm}$ diameter will be $0.072 \mathrm{~cm}$ and the drop diameter will be $0.136 \mathrm{~cm}$. This is the size of the very largest drops formed. If the ratio 1.5 is used, the drop diameter would be $0.108 \mathrm{~cm}$.

By considering the stablity of a jet, it is possible to estimate (following the analysis of Castleman and of Weber) the time of break up and the unbroken length of the jet. From this data it is possible to estimate the time required for the formation of a drop.

Castleman (Ref. 21) gave the following expression, based on the work of Rayleigh and Weber, for the time of break up of a IIquid jet or Iigament:

$$
t=\frac{1}{a} \log _{0} \frac{a}{a_{0}}
$$

where

$$
\begin{aligned}
& q= \text { Constant }=0.343 \sqrt{\frac{\sigma}{\rho^{\prime} R_{j}^{3}}} \quad \text { (II-15) } \\
& \alpha=\text { amplitude of the surface disturbance of the } \\
& \\
& j \text { et } \\
&=R_{j}=0.53 R_{d} \\
& \alpha_{0}=\text { initial surface disturbance }=10^{-5} \mathrm{~cm} \text { and } \\
& \rho^{\prime}=\text { density of Iiquid }
\end{aligned}
$$

For water at $20^{\circ} \mathrm{C}, q=2.6 / \mathbb{R}_{j}^{3 / 2}$, whence

$$
t=0.115 \mathrm{D}_{\mathrm{d}}^{3 / 2} \log _{10} 26,500 \mathrm{D}_{\mathrm{d}}
$$


For a drop diameter $0.09 \mathrm{~cm}$, the calculated breals up time Is $0.0098 \mathrm{sec}$. The actua 1 break up time $1 \mathrm{~s}$ about 25 milliseconds. Weber (Ref. 19) has calculated the relationship between the unbroken length of jet and its velocity, and, in the range of velocities met in most practical cases, the relationship is 11near. Haenlein's (Rei, 20) experimental values confrim this. That is, the unbroken length increases directly with the velocity. This distance, $l$, is given by the expression

$$
\ell=U_{0}^{t}
$$

where $V_{0}$ is the initial velocity of the jet. If we comsider the unbroken length of jet as the cylindrical portion which precedes the detached drop, then for a jet velocity of $200 \mathrm{~cm} / \mathrm{sec}$ (see the preceding section) and taking the experimental vajue of $t=0.0025$ sec the unbromen length becomes $l=0.50 \mathrm{~cm}$. ThIs Is of the same order of magnitude as the height of the jet which was computed in the preceding section.

A further point of Interest in the break up of the jets is the formation of satelites. These have been included in the average diameter of the large particles ard most of them have dameters between 0.03 and 0.04 cm. According to straus (Ret. 22) two sets of satellites are formed having diameters $1 / 2.828$ and $1 / 2$ or the main drop respectively.

\section{CONCLUSTONS}

It appears from the preceding discussion that by considering the stability of rising liquid jets, It is possible to estimate the 
average drop size in terms of the jet diameter. It appears possible to estimate also the velocity of a rising jet in terms of the bubble diameter. We note, again, that the more exact mathematical formulation would relate both the jet velocity and the jet radius to the bubble radius. Experimental data indicate that the velocity of a rising jet is of the same order of magnitude as the initial velocity of a rising drop.

Thus, it appears that by considering the stability of rising jets it would be possible to estimate both the average drop size and the initial velocity of a drop in terms of the bubble radius. It will be seen that these two quarities determine to a great extent the trajectory of a drop. 
III. DROP TRAJECTORIES

For qualitative and quantitative entrainment studies the dynamic behavior of drops in various environments must be known; in particular the one- and two-dimensional motions in a gravitational field are of importance.

The behavior of small solid particles entrained in a Iiquid or gas is of interest to engineers in many branches of the profession. The term "micromeritics" has been suggested (Re1.23) for the technology which treats the general dymamics of suspended particles. An unexplored branch of micromeritics is concerned with the behavior of wet saturated vapors. In the field of wet saturated vapors there is an almost complete lack of organized knowledge on the dynamical as distinct from the thermodyamical side, and this arises from the following major difficulties which seriously impede expeximental work.

i. The particles, being liquid globules, have a transitory existence. The statistical size distribution under any given set of conditions, a knowledge of which is basic for any rigorous quantitative treatment, cannot be obtained by any of the standard methods of particle size determination, i.e., direct measurement with sieve or microscope, sedimentation, eluriation or centrifuging.

ii. Size changes can and do occur for both dynamic and thermodynamic reasons and may take place with extreme rapidity, particularly with minute globules.

These difficulties are enhanced by irregular behavior 
which occurs when the thermodynamic state is near the phase boundary. This supersaturation may temporarily inhibit condensation, and Iiquid globules may persist for some time in a superheated atmosphere. With those branches of micromeritics concerned with mixtures of different substances none of these dificulties ocur.

Fortunately the drops encountered in the liquid entrainment studies are in such a size range that, on account of their great structural stability, they more or less assume and preserve a spherical shape and will only abandon it if the relative velocity $u^{\prime}-u^{\prime \prime}$ reaches a considerable value. It is possible, therefore, to regard such a drop as a rigid sphere and thus utilize vast range of data from existing knowledge in gas dynamics. With the above limitations and assumptions in mind, we shall proceed to discuss the drop trajectories.

II. I GENERAL EQUATIONS OF MOTION

Consider the motion of a single drop in an upward moving gas stream. The general two-dimensional equations of motion in the presence of a gravitational field axe (see, for example, (Ref. 24))

$$
\begin{aligned}
& m \frac{d u_{h^{\prime}}}{d t}=-F \cos a \\
& m \frac{d u_{v}^{\prime}}{d t}=-F \sin \alpha-m g\left(\frac{\rho^{\prime}-\rho^{\prime \prime}}{\rho^{\prime}}\right)
\end{aligned}
$$

where $m$ is the drop mass, $u_{h}$ "and $u_{v}$ are the horizontal and 
vertical components of the drop velocity u', is the frictional drag force, $\alpha$ is the angle between $F$ and $u_{h}{ }^{\prime}, g$ is the acceleration of gravity and $\rho^{\prime}$ and $\rho^{\prime \prime}$ are the liquid and gas densities respectively. The last term in Eq. (III-2) represents the effective drop weight.

The initial drop velocity as it is thrown upward from the liquid surface by the violent action of bursting bubbles or rising jets is represented by $u_{i}$ '. However, as soon as it leaves the liquid surface it immediately enters a gas mass flowing at a uniform velocity $u_{0}$ " representing the supericial velocity of the rising gas above the liquid surface.

In Eqs. (III-1) and (III-2) the direction of the horizontal component of $u_{0}$ ' is taken as positive for $u_{h}$ ' and the upward direction is positive for $u_{v}$. The following relations are obvious

$$
\cos \alpha=u_{h} / u^{\prime}, \sin \alpha=u_{v^{\prime}} / u^{\prime}, u^{2}=u_{h}{ }^{2}+u_{v}{ }^{2}
$$

The frictional drag force $F$ can be expressed as

$$
F=C A \frac{\left.p^{\prime \prime} \mid u^{\prime}-u_{0}^{\prime \prime} \sin q\right)^{2}}{2}
$$

where $\mathbb{A}$ is the projected area of the drop and the drag coefficient $C$ is a function of the Reynolds number $\mathbb{R}_{e}$, defined as

$$
R_{e}=\frac{D P^{\prime \prime}}{\mu^{\prime \prime}}\left|u^{\prime}-u_{0} " \sin \alpha\right|
$$

in which $D$ is the drop diameter and $\mu^{\prime \prime}$ is the viscosity of the gas. The $C$ vs. $\mathbb{R}_{e}$ plot, first suggested by Lord Rayleigh, has 
been determined fairly completely for spheres, disks, cylinders, and miscellaneous shapes by numerous experimenters. Fig. (III-1) which is taken from (Ref. 24) presents average curves for various shaped particles. It has been pointed out (Ref. 23) that in the case of a sphere the following algebraic equation gives 2 Iair match for the whole span of the curve:

$$
C=\left[0.63+4.8 / \sqrt{R_{e}}\right]^{2}
$$

Practical evaluation, bowever, is rendered easier by representing the curve by means of three expression corresponding to the three major regions of the Ilow:

a. Iaminar region $(0.001<$ Re $<2.0)$ obeying stokes' law of motion

$$
c=24 / R_{e}
$$

For shapes other than spheres (except cylinders)

$$
C=\mathbb{k} / \mathbb{R}_{e}
$$

where $\mathrm{k}$ is a constant

b. intermediate region $(2.0<\operatorname{Re}<500)$

$$
C=0.4+40 / R_{e}
$$

(See, for example, (Rer. 25)) or

$$
C=18.5 \mathbb{R}_{e}^{-0.6}
$$

(See, for example, (Ref. 8))

c. turbulent region $(500<$ Re $<200,000)$ obeying Newton's law of motion

$$
C=0.44
$$




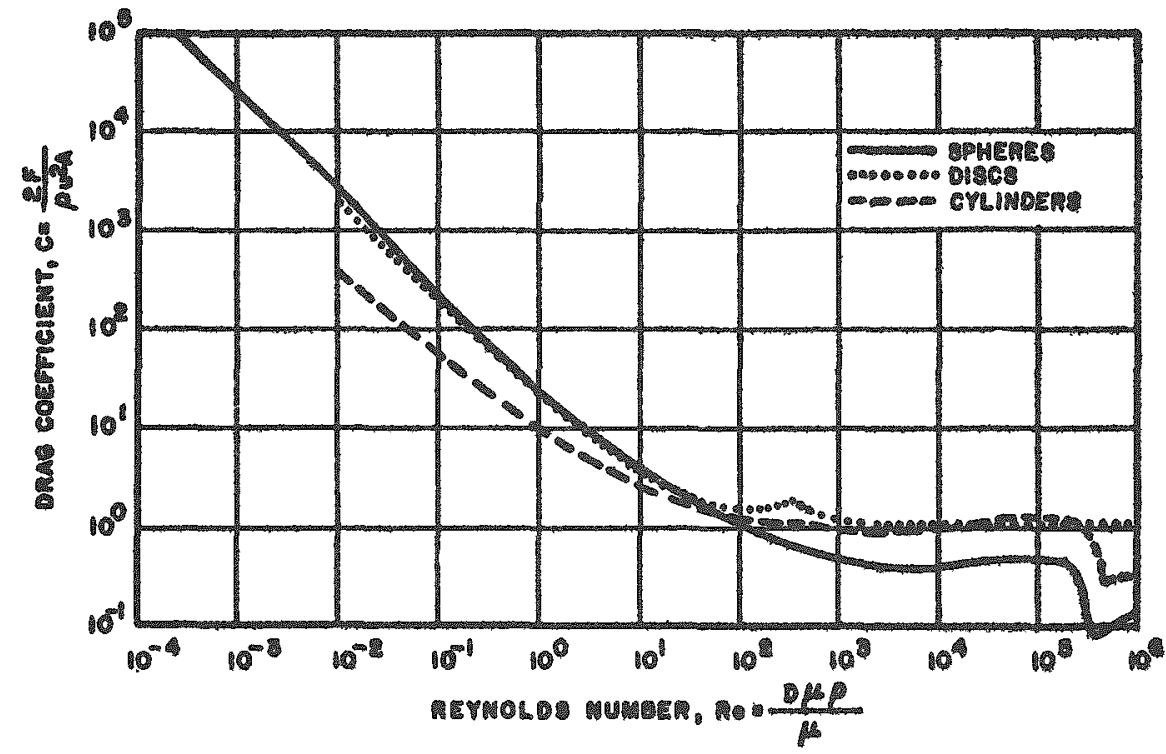

슨

Figure III-1. Drag Coefilcient as Iunction of Reynolds Number (Ref. 24). 
For shapes other than spheres

$$
C=\mathbf{s}^{2}
$$

where $\mathrm{k}^{\prime}$ is a constant.

For a spherical drop

$$
A=\pi D^{2} / A
$$

and

$$
m=\rho^{\prime} \pi D^{3 / 6}
$$

Substituting Eqs. (III-4), (III-5), (III-14), and (III-15) into Eqs. (III-1), and (III-2) we obtain the two-dimensional equations of motion for a spherical drop in the presence of a gravitational field:

$$
\begin{aligned}
& \frac{d u_{h}^{\prime}}{d t}=-\frac{3}{4} \frac{p^{\prime \prime}}{\rho^{\prime}} \frac{C}{D}\left(u^{\prime}-u_{0}^{\prime \prime} \sin \alpha\right)^{2} \frac{u_{h^{\prime}}}{u^{\prime}} \quad \text { (III-I6) } \\
& \frac{d u_{v}^{\prime}}{d t}=-\frac{3}{4} \frac{\rho^{\prime \prime}}{\rho^{\prime}} \frac{C}{D}\left(u^{\prime}-u_{0}^{\prime \prime} \sin \alpha\right)^{2} \frac{u_{v}^{\prime}}{u^{\prime}}-g\left(\frac{\rho^{\prime}-\rho^{\prime \prime}}{\rho^{\prime}}\right)
\end{aligned}
$$

In the following two sections of this chapter we shall apply Eqs. (III-16) and (III-17) to small drop (such as those which originate from the bubble dome) and to large drops (such as those which are ejected by rising liquid jets). It will be shown in Chapter IV how the results from these two sections can be used for an analytical formulation of the liquid entrainment problems. 
III.2 EQUATIONS OF MOTION FOR SMALL DROPS

Due to small sizes and low velocities the motion of the small drops resulting from breaking of bubble films may be considered to be in the laminar flow region. Mence Eq. (III-8) may be used for the drag coefficient, C. Substituting Egs. (III-8) and (III-6) into Eqs. (III-16) and (III-17) we have

$$
\begin{aligned}
& \frac{d u_{h}^{\prime}}{d t}=-\frac{18 \mu^{\prime \prime}}{\rho^{\prime} D^{2}}\left(1-\frac{u_{0}^{\prime \prime}}{u^{\prime}} \sin \alpha\right) u_{h}^{\prime} \\
& \frac{d u_{v}^{\prime}}{d t}=-\frac{18 \mu^{\prime \prime}}{\rho^{\prime} D^{2}}\left(1-\frac{u_{0}^{\prime \prime}}{u^{\prime}} \sin \alpha\right) u_{v}^{\prime}-g\left(\frac{\rho^{\prime}-\rho^{\prime \prime}}{\rho^{\prime}}\right)
\end{aligned}
$$

For the special case of $\frac{u_{0}^{\prime \prime}}{u^{\prime}}$ sin $\alpha \ll 1$ these equations can be further simplified to

$$
\begin{aligned}
& \frac{d u_{h}^{\prime}}{d t}=\frac{-18 \mu^{\prime \prime}}{\rho^{\prime} D^{2}} u_{h}^{\prime \prime} \\
& \frac{d u_{v}^{\prime}}{d t}=\frac{-18 \mu^{\prime \prime}}{\rho^{\prime} D^{2}} u_{v}^{\prime}-g\left(\frac{\rho^{\prime}-\rho^{\prime \prime}}{\rho^{\prime}}\right)
\end{aligned}
$$

which indicate that the motion in a given direction is independent of the motion in a direction perpendicular to the first, and the net trajectory will be that of one superimposed on the other. These equations lend themselves to direct integration. 
The solutions have been given in (Ref, 24). For one-dimensional motion in the presence of a gravitational field Eq. (III-21) renders the time required from initial drop velocity $u_{i}$ iv to drop velocity $u_{v}^{\prime}$ as

$$
t_{v}=\frac{e^{\prime} D^{2}}{18 \mu^{\prime \prime}} \log _{e} \frac{u_{t s^{\prime}}-u^{\prime}{ }_{i v}}{u_{t \xi^{\prime}}-u_{v}{ }^{\prime}}
$$

and the height travelled from $t=0$ to $t=t_{v}$ as

$$
h=u_{t s^{\prime}} t_{v}-\left(u_{t} \dot{s}^{-} u_{i v}^{\prime}\right) \frac{\rho^{\prime} D^{2}}{18 \mu^{\prime \prime}}\left[1-\exp \frac{-18 \mu^{\prime \prime} t v}{\rho^{\prime} D^{2}}\right]
$$

where the "terminal velocity" uts' is by Stokes' law (see, for example, (Ref. 26, p. 599))

$$
u_{t s}^{\prime}=-g \frac{\left(\rho^{\prime}-p^{\prime \prime}\right) D^{2}}{18 \mu^{\prime \prime}}
$$

For another special case of $u^{\prime}=u_{v}$, and $\alpha=\frac{\pi}{2}$

Eqs. (III-18) and (III-14) reduce to one equation

$$
\frac{d u^{\prime}}{d t}=-\frac{18 \mu^{\prime \prime}}{\rho^{\prime} D^{2}}\left(u^{\prime}-u_{0}^{\prime \prime}\right)-g\left(\frac{\rho^{\prime}-\rho^{\prime \prime}}{\rho^{\prime}}\right)
$$

whose solutions are corresponding to Eqs. (III-22) and (III-23) as follows:

time is

$$
t=\frac{\rho^{\prime} D^{2}}{18 \mu^{\prime \prime}} \log _{e} \frac{u_{t}^{\prime}-u_{i}^{\prime}}{u_{t}^{\prime}-u^{\prime}}
$$


and height is

$$
h=u_{t}{ }^{\prime} t-\left|u_{t}{ }^{\prime}-u_{i}\right| \frac{\rho^{\prime} D^{2}}{18 \mu^{\prime \prime}}\left[1-\exp \frac{-18 \mu^{\prime \prime} t}{\rho^{\prime} D^{2}}\right]
$$

where the terminal (i.e., the steady state) velocity is obtained from $\mathrm{Eq}$.. (III-25), thus

$$
u_{t}^{\prime}=u_{0}^{\prime \prime}-g \frac{\left(\rho^{\prime}-\rho^{\prime \prime}\right) D^{2}}{18 \mu^{\prime \prime}}
$$

Eq. (III-26) expresses time $t$ in terms of the drop velocity u'. It can be rewritten as

$$
u^{\prime}=u_{t}^{\prime}\left(1-e^{\left.-\frac{18 \mu^{\prime \prime} t}{\rho^{\prime} D^{2}}\right)+u_{i}^{\prime} e^{-\frac{18 \mu^{\prime \prime} t}{\rho^{\prime} D^{2}}}}\right.
$$

expressing $u$ ' as a function of $t$. The terminal (steady state) velocity as given by $\mathrm{Eg}$. (III-28) corresponds to $u^{\text {' at }} \mathrm{t} \rightarrow \infty$. Eq. (III-28) indicates that a drop w11 be entrained if $u_{t}{ }^{\prime}>0$. The experimental results which were discussed in the preceeding chapter indicate that droplets which are formed by the bubble dome are of the order of $25 \mu$ in diameter. It is of interest to estimate at what reduced (superficial) velocity $u_{0}$ " will these droplets be entrained. For water at 1 atm $\left(\rho^{\prime}=1 \mathrm{gm} / \mathrm{cm}^{3}, \rho^{\prime \prime}=0.598 \times 10^{-3} \mathrm{gm} / \mathrm{cm}^{3} \mu^{2 \prime}=0.12 \times 10^{-3} \mathrm{gm} / \mathrm{cm} / \mathrm{sec}\right)$. Stokes' equation i.e., Eq. (III-24) gives a value of $-2.8 \mathrm{~cm} / \mathrm{sec}$. Thus it appears that if the reduced vapor velocity $u_{0}$ " is larger than $2.8 \mathrm{~cm} / \mathrm{sec}$ then $u_{t}>0$ and 2 drop of $25 \mu$ in diameter will be entrained. 


\section{III.3 EQUATIONS OF MOTION FOR LARGE DROPS}

For large drops resulting from breaking of the jets we encounter larger sizes and higher velocities. Consider an average sized water drop of $0.06 \mathrm{~cm}$. in diameter with velocity of $140 \mathrm{~cm} / \mathrm{sec}$. (as estimated by Davis, (Ref. 12)) traveling vertically in steam $\left(\rho^{n !}=0.598 \times 10^{-3} \mathrm{gm} / \mathrm{cm}^{3}\right.$, $\left.\mu^{\prime \prime}=0.12 \times 10^{-3} \mathrm{gm} / \mathrm{cm} / \mathrm{sec}_{0}\right)$ which has a superficial velocity, $u_{0} " \mathrm{~cm} / \mathrm{sec}$. From Eq, (III-6) the Reynolds number is estimated as:

$$
R_{e}=\frac{0.06 \times 0.59 \times 10^{-3}}{0.12 \times 10^{-3}}\left(140-u_{0} "\right)=41.86-0.3 u_{0} "(\text { III-30) }
$$

Hence depending upon the magnitude of $u_{0} "$, the flow around the drop is either in the intermediate region $\left(2.0<R_{e}<500\right)$ or in the laminar region $\left(0.0001<R_{e}<2.0\right)$. Furthermore, since the jets essentially shoot vertically upwards, it is sufficient to consider the vertical motion of such large drops.

\section{A. Laminar Region}

For trajectories in the Iaminar region Eqs. (III-26), (III-27) and (III-28) directly apply. The maximum height is evaluated by putting $u^{\prime}=0$ in Eqs. (III-26) and (III-27).

$$
\begin{aligned}
& t_{m}=\frac{\rho^{\prime} D^{2}}{18 \mu^{\prime \prime}} \log _{e}\left(1-\frac{u_{i}^{\prime}}{u_{t}^{\prime}}\right) \\
& h_{m}=u_{t}^{\prime} t_{m}-\left(u_{t}^{\prime}-u_{i}^{\prime}\right) \frac{\rho^{\prime} D^{2}}{18 \mu^{\prime \prime}}\left[1-\exp \frac{-18 \mu^{\prime \prime} t_{m}}{\rho^{\prime} D^{2}}\right]
\end{aligned}
$$

where $u_{t}$ is given by Eq. (III-28). 


\section{B. Intermediate Region}

For drops having a Reynolds number in the intermediate region Eq. (III-10) or (III-1I) can be used to express the drag coeficient $C$ in $E q$. (III-17). Since the velocity of the rising drop, and consequently its Reynolds number, varies with time, the drag coefficient will also vary. Because of this the first and second integrals of $\mathrm{Eq}$. (III-17) become more complicated so that the results are most easily obtained by graphical integration and are reported usually in graphical form.

Substituting Eqs. (III-6) and (III-10) into Eq. (III-I7) and setting $u^{\prime}=u_{v}{ }^{\prime}$ and $\alpha=\pi / 2$ it follows after integration that: (see, for example, (Refs. 24 and 25))

$$
\begin{aligned}
\left(\frac{3 \mu^{\prime \prime}}{4 \rho^{\prime} D^{2}}\right) t & =\int_{\mathbb{R}_{e}}^{\mathbb{R}_{e}} \frac{d\left(\mathbb{R}_{e}\right)}{\emptyset+40 R_{e}+0.4 \mathbb{R}_{e}^{2}} \\
\emptyset & =\frac{4}{3} \frac{g \rho^{\prime \prime}\left(\rho^{i}-\rho^{i}\right) D^{3}}{\left(\mu^{\prime \prime}\right)^{2}}
\end{aligned}
$$

where the drop Reynolds' number $\mathbb{R}_{e 1}$ is given by Eq. (III-6) with $u^{\prime}=u_{i}^{\prime} i_{. e}$, in terms of the initial drop velocity $u_{1}{ }^{\prime}$. The value of the integral in $\mathrm{Eq}$. (III-33) can be obtained from standard tables. The distance travelled by the drop is most easily evaluated by plotting $u^{\prime}=u_{i}{ }^{\prime}+\frac{R^{\mu}}{\rho^{\prime \prime}}$ against $t$ 
in Eq. (III-33) and evaluating graphically $h=\int u^{\prime} d t \cdot$ This method has been adopted by Ryley (Ref. 25) who takes also into account the effect of the drop deformation upon the drag coeficient $c$.

Alternatively substituting Egs. (III-1I) and (III-6) Into Eq. (III-17) and setting $u^{\prime}=u_{v}^{\prime}$ and $\alpha=$ T/2 we have

$$
\begin{aligned}
\frac{d u^{\prime}}{d t} & =\frac{-3}{4} \frac{\rho^{\prime \prime}}{\rho^{\prime} D} 18.5 R_{e}^{-0.6}\left(u^{\prime}-u_{0}^{\prime \prime}\right)^{2}=g\left(\frac{\rho^{\prime}-\rho^{\prime \prime}}{\rho^{\prime}}\right) \\
& =-K\left(u^{\prime}-u_{0}^{\prime \prime}\right)^{1.4}-g\left(\frac{\rho^{\prime}-\rho^{\prime \prime}}{\rho^{\prime}}\right)
\end{aligned}
$$

where

$$
K=\frac{13.9 \times\left(p^{11.4}\right)^{1.4}\left(\mu^{0.6}\right)^{0.6}}{\rho^{1} \times D^{1.6}}
$$

For a water drop in steam, at 1 atm we have

$$
\begin{aligned}
K & =\frac{13.9 \times\left(0.598 \times\left. 10^{-3}\right|^{1.4} \times\left|0.12 \times 10^{-3}\right|^{0.6}\right.}{0.958 \times 0^{1.6}} \\
& =\frac{1.967 \times 10^{-6}}{D^{1.6}}
\end{aligned}
$$

Newitt, t, al. (Ref. 8) analysed the rise of drops in still air. For this condition one sets $u_{0}^{\prime \prime}=0$ in Eq. (III-35). The time for a drop to reach its maximum height is then

$$
\int_{0}^{t_{m}} d t=\int_{0}^{u_{j}^{\prime}} \frac{d u^{8}}{m\left(u^{i}\right)^{1.4}+g}
$$


and the maximum height reached in the drop is

$$
\int_{0}^{b_{m}} d h=\int_{0}^{u_{i}^{i}} \frac{u^{\prime} d u^{9}}{K\left(u^{\prime}\right)^{1 \cdot 4}+g}
$$

( In Eqs. (III-38) and (III-39) $\rho^{\prime \prime}$ has been neglected as compared with $\rho^{\prime}$ ). These two equations were graphically integrated by Newit, et, 2. for various drop diameters (i.e., for various values of $\mathrm{K}$ ) and for various initial velocities; figures showing these results can be found in (Ref.8). Newitt, et. 21. reported that the results predicted by Igs. (III-38) and (III-39) are in close agreement with experimental data. As an example they note that these equations predict that a drop $0.009 \mathrm{~cm}$ in diameter having an initial velocity of $113 \mathrm{~cm} / \mathrm{sec}$ would rise to a height of $6 \mathrm{~cm}$ in $0.104 \mathrm{sec}$. The actual values from experiments are $6.4 \mathrm{~cm}$ for the height and 0.106 sec. for the time. The authors note that Eq. (1-12) predicts maximum of $6.5 \mathrm{~cm}$ for an initial velocity of $u_{1}^{i}=113 \mathrm{~cm} / \mathrm{sec}$. indicating that, in still air, the effect of the drag is sma11 and, consequently, that Eq. (I-12) can be used.

When the reduced (supericial) vapor velocity $u_{0}^{\prime \prime}$ is not small compared to the drop velocity, i.e., when the effect of the vapor motion are to be taken into account, Eq. (III-35) must be integrated. Newitt, et.al.(Ref. 8) analyzed this problem by taking a system of comordinates moving upwards with a constant velocity u' relative to the liquid surface. At 
any time, $t$, the origin will bave reached a height u ${ }_{0} t$, upward movement being taken as positive. The drop will rise until at its maximum height its relative velocity is zero. But relative to the moving origin it will have two stages of motion, one upward and one downward.

For upward motion:

$$
\frac{d u^{\prime}}{d t}=-K\left(u^{\prime}\right)^{1.4}-g
$$

and for downward motion:

$-\frac{d u^{\prime}}{d t}=K\left(u^{\prime}\right)^{1.4}-g$

where $\rho^{\prime \prime}$ has been neglected as compared with $\rho^{\prime}$.

$$
\begin{aligned}
& \text { At } t=0, h=0, u^{\prime}=u_{i}^{\prime}-u_{0}^{\prime \prime} \text {. Thus } \\
& \int_{0}^{t} d t=-\int_{u_{i}^{\prime}-u_{0}^{\prime \prime}}^{0} \frac{d u^{\prime}}{K\left(u^{\prime}\right)^{1 \cdot 4}+g}-\int_{u_{0}^{\prime \prime}}^{0} \frac{d u^{\prime}}{K\left(u^{\prime}\right)^{1.4}-g}
\end{aligned}
$$

and

$$
\int_{0}^{h} d h=-\int_{u_{1}^{\prime}-u_{0}^{\prime \prime}}^{0} \frac{u^{\prime} d u^{\prime}}{K_{\left(u^{\prime}\right)^{1 \cdot 4}+g}}-\int_{u_{0}^{\prime \prime}}^{0} \frac{d u^{\prime}}{\pi\left(u^{\prime}\right)^{1.4}-g}
$$


Since the maximum beight

$$
h_{\text {w }}=h+u_{0}^{n t}
$$

we have

$$
\mathbf{h}_{\mathrm{m}}=-\int_{u_{1}^{\prime}-u_{0}^{\prime \prime}}^{0} \frac{u^{\prime} d^{\prime} u^{\prime}}{R\left(u^{\prime}\right)^{1 \cdot 4}+g}+\int_{0}^{u_{0}^{\prime \prime}} \frac{u^{\prime} d^{\prime}}{R\left(u^{\prime}\right)^{1 \cdot 4}-g}
$$

$$
+u_{0}^{\prime \prime}\left[\int_{0}^{u_{0}^{\prime \prime}} \frac{d u^{\prime}}{K\left(u^{\prime}\right)^{1.4}-g}-\int_{u_{i}^{\prime}-u_{0}^{\prime \prime}}^{0} \frac{d u^{\prime}}{K\left(u^{\prime}\right)^{1.4}+g}\right]
$$

When $u_{0} "=0$, these equations reduce to Eqs. (III-38) and (III-39).

\section{III.4 SUMPARY}

It was seen in this chapter that the trajectories of

drops formed by the bubble dome and of drops formed by rising liquid jets can be estimated when the size and the initial velocity of the drop as well as the reduced vapor velocity are known.

The trajectories of drops formed by the bubble dome can be estimated by considering the laminar flow region and can be expressed in terms of simple analytical expressions. 
The trajectories of drops formed by rising liquid jets are analyzed, depending on the value of the Reynolds number, by considering either the laminar region or the intermediate region. In the latter case, the solutions are most easily obtained by graphical integration and reported in graphical forms. It appears that, for these drops, the effect of the vapor drag may be small; however, additional experiments are needed to verify this indication. If this proves to be the case the drop trajectories can be easily estimated by neglecting the vapor drag in the equations of motion. 


\section{ANALYTICAL FORMULATIONS OF ENTRAINMENT}

In this chapter we shall explore what we can learn on the qualitative and quantitive aspects of liquid entrainment from the understanding of the phenomena which govern drop formation and drop trajectories.

The entrainment of solid particles from continuously operating fluidized systems has been investigated both experimentally and theoretically. Theoretical methods have been recently proposed by Zenz and Weil (Ref. 27) and by Andrews (Ref, 28) which provide a basis for estimating solid entrainment by a gas phase. Their techniques can be borrowed for our purpose with certain modifications and extensions.

\section{IV.1 THE FORMULATION OF ZENZ AND WEIL}

Consider the behavior of the liquid drops in a moving gas stream. The vertical motion of any one such drop with any interdrop forces neglected, is described by Eq. (III-25). In what follows the motions of the drops are assumed to be in the laminar region. The case of drop motion in the intermediate region can be formulated by using the corresponding trajectory equations for the intermediate region.

For drops moving in laminar region the solutions of Eq. (III-25) are given by Eqs. (III-26), (III-27), and (III-28) where $u_{i}$ ' is the initial drop velocity as it is thrown upward from the liquid surface by the violent action of bursting bubbles or breaking jets. As soon as it leaves the interface it immediately enters a gas mass flowing at a uniform velocity uo" 
representing the reduced(superficial) velocity of the rising gas above the liquid surface.

Eq. (III-29) expresses $u$ ' as a function of $t$. At the point of maximum vertical rise $u^{\prime}=0$, so the time for reaching the top elevation $t_{m}$ is given by Eq. (III-31). The height of rise $h$ as a function of time $t$ is given by Eq. (III-27) and the maximum height $h_{m}$ is given by Eq. (III-32) which can be simplified to read

$$
b_{m}-\frac{\rho^{\prime} D^{2}}{18 \mu^{\prime \prime}}\left[u_{1}{ }^{\prime}+u_{t^{\prime}} \log e\left(1-\frac{u_{1}^{\prime}}{u_{t}{ }^{\prime}}\right)\right]
$$

If $n$ represents the number of drops of a given drop size of diameter $D$ thrown up by the bubble action over an area of $1 \mathrm{~cm}^{2}$ of the liquid surface/sec., then $N=\sum \mathrm{n}$ represents the average of the total number of 211 drops emerging from the liquid surface per $\mathrm{cm}^{2}$ per second. If the drop velocity is $u^{\prime}$ at an arbitrary height, a drop having crossed a section will have travelled a distance of $u^{\prime} \mathrm{cm}$ upward in one second. n additional drops will have entered the $1 \mathrm{~cm}^{2}$ area. Hence, in a space of $1 \mathrm{~cm}^{3}$ there will be

$$
\epsilon_{1}=n / u^{\prime}
$$

drops of size $D$, where $\epsilon$ denotes the entrained number of drops per unit volume of gas continuously carried up by the gas stream.

In addition to the drops which are carried over by the gas stream, we have to consider also those which are thrust upward from the liquid surface and are falling back. Let $n$ again represent the number of rising drops of a given drop size passing a 
$1 \mathrm{~cm}^{2}$ section/sec, at any arbitrary elevation $\mathrm{h}$. If at this elevation their velocity is $u$, and it takes $i$ sec. for the drops to complete their rise to the maximum height and to fall back to the same elevation, then the number of drops above this elevation will be

$$
\eta=n \bar{t}
$$

However, the difference between the total number of drops existing above two successive elevations separated by a vertical distance dh will express the entrainment volumetrically in a cube of $1 \mathrm{~cm}^{2}$ base and 2 height of $\mathrm{dh}$ :

$$
\epsilon_{2}=\frac{\eta(h)-\eta(h+d h)}{d h}=-\frac{d \eta}{d h}
$$

From Eq. (IV-3)

$$
\frac{d \eta}{d h}=n \frac{d \bar{t}}{d h}
$$

which substituted in Eq. (IV-4) gives

$$
\varepsilon_{2}=-\mathrm{n} \frac{\mathrm{d} \overline{\mathrm{t}}}{\mathrm{dh}}
$$

While Eqs. (IV-2) and (IV-6) appear relatively simple, the real problem is to express $E$ as a function of height above the 1iquid surface or, in other words, $u^{\prime}$ and $d \bar{t} / \mathrm{dh}$ as functions of $\mathrm{h}$. Eqs. (III-29) and (III-27) give $u$ ' and $h$ as functions of $t$; it is also possible to express $h$ solely in terms of $u^{\prime}$ by substituting Eq. (III-26) into Eq. (III-27); thus

$$
h=\frac{\rho^{\prime} D^{2}}{18 \mu^{\prime \prime}}\left[u_{0}^{\prime}-u^{\prime}+u_{t^{\prime}} \log _{e} \frac{u_{o^{\prime}}-u_{t^{\prime}}}{u^{\prime}-u_{t^{\prime}}}\right]
$$


To obtain the $u^{\prime}=u^{\prime}(h)$ function would require inverting Eq. (IV-7). This cannot be done in closed form since this equation is of a general transcendental form. Hence, corresponding values of the $u^{\prime}=u^{\prime}(h)$ function must either be obtained by iteration from Eq. (IV-7) or by a cross plotting of Eqs. (III-29) and (III-27). A similar situation exists with regard to the quantity $\mathrm{dt} / \mathrm{dh}$, which must also be solved by numerical analysis.

In Eqs. $(I V-2)$ and $(I V-6)$ n designates the number of drops of a given size thrust from the liquid surface by bursting bubbles and breaking jets, as averaged out over $1 \mathrm{~cm}^{2}$ of the suriace/sec. In this sense $N=$ En represents the entrainment value immediately at the liquid surface. This is arbitrarily taken as 100 times a constant, and so

$$
N=100 \mathrm{k}=\mathrm{k} \sum \bar{n}
$$

where it is understood that

$$
\sum \bar{n}=100 \quad ; \quad \bar{n}=n / k
$$

with $\bar{n}$ representing the number (or weight) percentage of a given drop size in the total surface spectrum. These considerations are sufficient to establish an entrainment curve over the height of a vessel on the basis of 100 drops liberated on the average/ $\left(\mathrm{cm}^{2}\right.$ of liquid surface)(sec.). This entrainment curve can be converted into the actual curve through multiplication by a factor of $k$. $k$ must be obtained from one or the other of two boundary conditions: the actual entrainment at the liquid surface or at a sufficient height above the liquid surface where entrainment has become relatively constant. 
Finally to convert $\mathcal{E}$ in Eqs. (IV-2) and (IV-6) from the entrained number of drops per unit volume of gas to $e$, the entrained weight of liquid per unit weight of gas we have

$$
e=6 \frac{\pi D^{3} p^{\prime}}{6 p^{\prime \prime}}
$$

The entrainment $e$ is a more relevant quantity for liquid entrainment evaluation.

The numerical calculation procedure proposed by Zenz and Weil is as follow:

1. Subdivide the drop size distribution into a number of representative drop sizes as illustrated in Fig. (IV-I(a)).

2. For a given system the values of $\mu^{\prime \prime}, p^{\prime}$, and $p^{\prime \prime}$ are fixed. Estimate now the initial drop velocity $u_{i}^{\prime}$ leaving the liquid surface. Davis (Ref. 12), for instance, estimated $u_{i}{ }^{\prime}=$ $140 \mathrm{~cm} / \mathrm{sec}$ for large drops (see $\mathrm{Eq} .(I-12)$ ).

3. Calculate the terminal velocity of each of the representative drop sizes by $\mathrm{Eq} .($ III-28) and separate those drops carried by the gas stream $\left(u_{t}{ }^{\prime}>0\right)$ and those returning to the liquid surface $\left(u_{t}{ }^{\prime}<0\right)$.

4. Calculate drop velocities as a function of time from Eq. (III-29) and plot them as shown in Fig. (IV-1(b)). Note that drops $D_{1}, D_{2}, D_{3}$ are carried away $\left(u_{t}^{\prime}>0\right)$ whereas drops $D_{4}, D_{5}, D_{6}$, and $D_{7}$ are falling back.

5. Calculate height of rise in terms of time from $\mathrm{Eq}$. (III-27) and plot as shown in Fig. (IV-I(c)).

6. For drops carried by the gas stream $\left(u_{t}{ }^{\prime}>0\right)$ a cross 

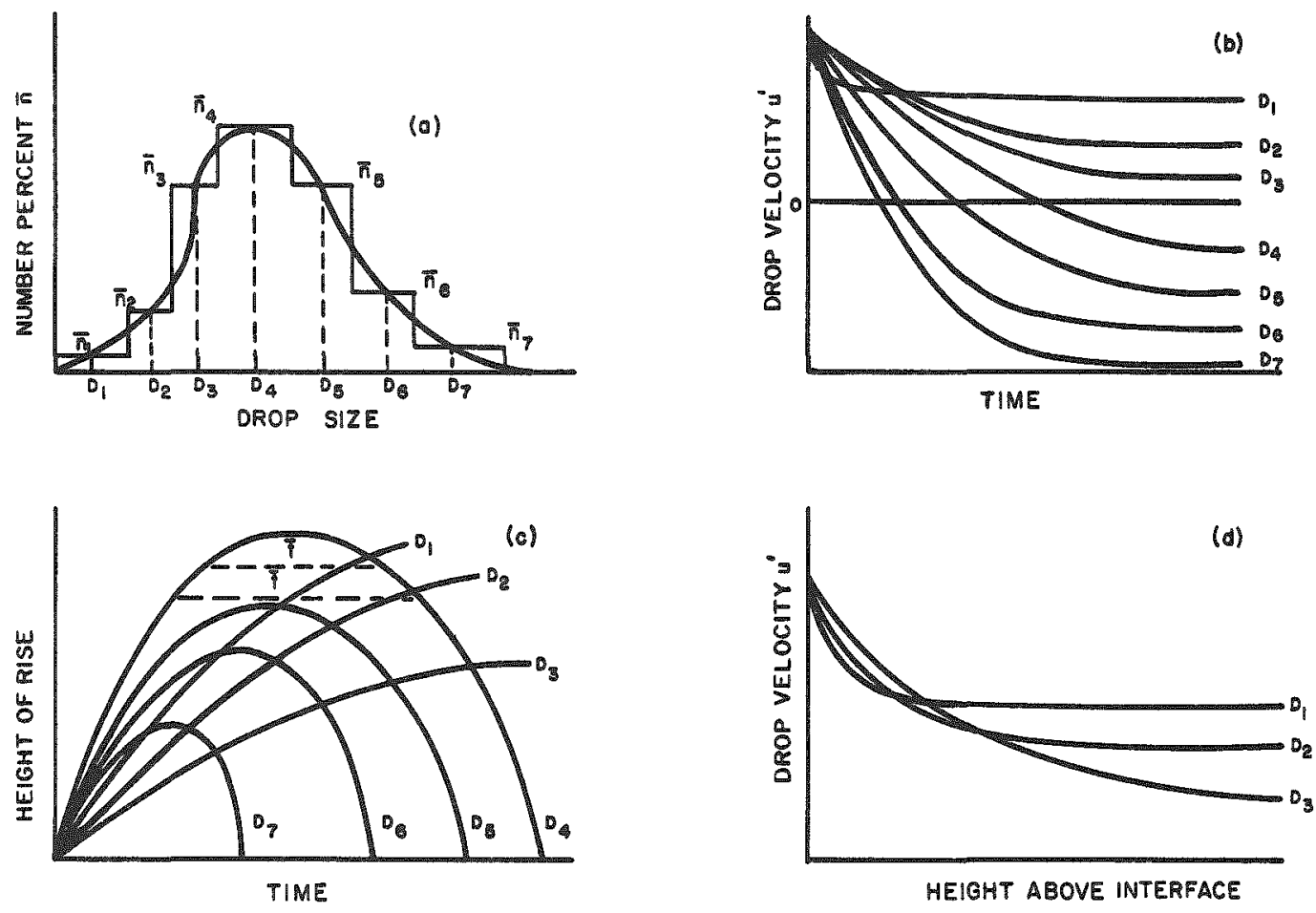

HEIGHT ABOVE INTERFACE
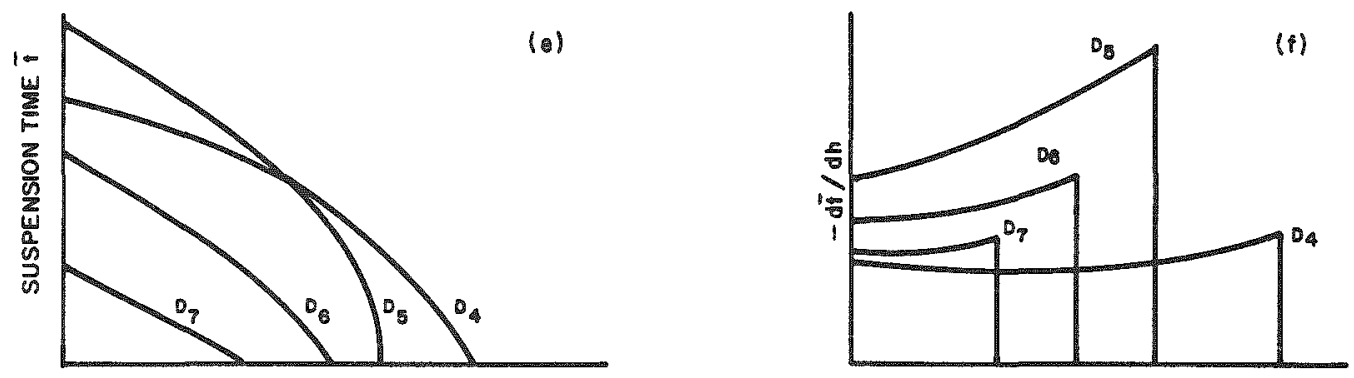

HEIGHT ABOVE INTERFACE

HEIGHT ABOVE INTERFACE

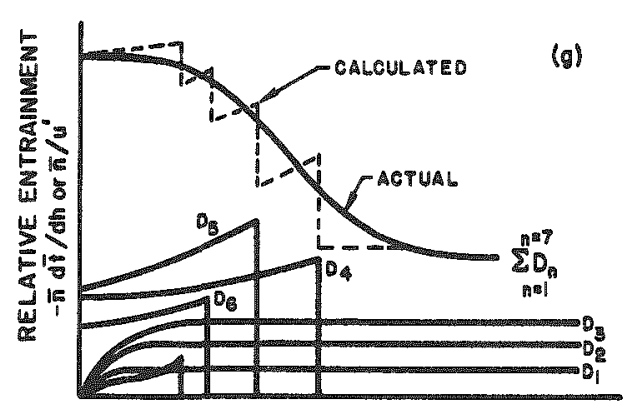

HEIGHT ABOVE INTERFACE

A 4 4- 27

Figure IV-1. Outline of Stepwise procedure for Calculating Entrainment (Froposed by Zenz and Yeil Ref. 27). 
plot of u' vs. $h$ as shown in Fig. (IV-I(d)) permits calculating the relative entrainments from $\epsilon_{1}=\bar{n} / u^{\prime}$ (see Eq. (IV-2)) at various heights above the liquid surface.

7. For drops returning to the liquid surface, the residence times, or chord length $\bar{t}$ pertaining to given $h$ values, permit drawing a plot of $\bar{t}$ vs. $h$ as shown schematically in Fig. $(I V-1(e))$.

8. The tangents drawn at various heights to the curves of Fig. (IV-1(e)) give values of $-\mathrm{d} \bar{t} / \mathrm{dh}$ as a function of $\mathrm{h}$ as shown schematically in Fig. (IV-I(f)). Calculate relative entrainment $\left(\varepsilon_{2}\right)$ through multiplication by 2 factor of $\bar{n}$ corresponding to the various drop sizes (see Eq. (IV-6)).

9. The $\epsilon$ entrainment curves corresponding to each of the various size fractions and to the overall summation are illustrated schematically in Fig. (IV-I (g)).

10. The entrainment curves corresponding to each of the various size fractions and to the overall summation can be constructed by using Eq. (IV-10) and Fig. (IV-I(g)).

It was noted by Zenz and Weil (Ref. 27) that this theoretical approach to entrainment through drop dynamics describes the shape of the entrainment curve with height above the liquid surface as a function of the initial velocity parameter $u_{i}$ 'as well as the physical properties of the operating system. However, it cannot predict entrainment without prior knowledge of $n, u_{i}$ or $u_{0} "$. If sufficient data were available for independent prediction of $n$, this method would serve as a tool for correlating the entire entrainment gradient picture. 
IV.2 THE FORMULATION OF MNDREWS

The formulation of Andrews (Rer. 28) is based on the assumption that, in steady state, the rate of escape from the interface is the limiting step for the entraiment. This assumption was justified by considering that the replacement of an escaped particle from the dense phase requires only a small amount of energy whereas the escape from the surface to the top of the column requires considerably more kinetic energy. Consequently, of 21 particlos which leave the surface only a iraction will bave the necessary energy to escape. The escape energy of a single partcle was determined from energy balance relating kinetic and potential energy of the particle:

$$
-m u^{\prime} d u^{\prime} m g d h
$$

whence

$$
u_{i}=\sqrt{2 g h_{m}}
$$

which relates the maximum height $h_{m}$ reached by the particle to its initial velocity u'

In the contert of this report the model can be rephrased as follow: Or all drops which leave the interface only those which have an initial velocity (initial kinetic energy or escape energy) equal or lager than that given by Eq. (IV-12) (see also Iq. (I-12)) wil be able to reach a height $h$ above the liquid interface. We note that this model can be applied to drops formed by rising liquid jets (note also that the effect of the vapor drag is neglected). Because the escape energy is equivalent to the initial kinetic energy of the drop, it follows 
from the discussion given in Chapter I that the escape energy can be expressed in terms of the bubble surface energy (see Eqs. (I-4, 5, 10, 11, and 12)).

The weight fraction $f_{i}$ of particles (drops) which have the required energy $\epsilon_{i}$ to escape

$$
\epsilon_{i}=\frac{m_{i}{ }^{2}}{2}
$$

was estimated by Andrews assuming that the energy distribution of particles at the interface follows the Maxwell Boltzmann distribution law, thus

$$
\mathbb{f}_{i} \equiv B e^{-B \epsilon_{i}}
$$

where $B$ is the reciprocal of average particle energy. The conditions which must be satisfied for this assumption to be valid were given by Andrews as follows: Steady state must be maintained. The total energy of particles at the surface must remain constant. The movement of particles must be sufficiently unrestricted to follow the laws of probability. The number of particles in the system must remain unchanged. Particles must be identical or indistinguishable from each other.

The entrainment rate of escaping particles is equivalent to their escaping velocity. The decrease of $i^{\text {t th }}$ fraction of particles with initial surface kinetic energy equivalent to or larger than that required to reach 2 height $h$ can be calculated from flow rates by considering the equipartition of energy. Let A be the cross sectional area of the vessel, let $w_{1}$ be the vessel inventory of particles with energy $E_{i}$ it rollows that from Eq. (IV-14) 


$$
d w_{i}=-\frac{A \rho^{\prime} u_{i}^{\prime}}{6} f_{i} d t=-\frac{A \rho^{\prime} u_{i}^{\prime} B e^{-B} \epsilon_{i}}{6} d t
$$

The factor of 1/6 was introduced by Andrews on the assumption that on 1 y $1 / 6$ of the total number of particles present in a cubic volume at the interface will have a positive velocity in the vertical direction. Defining the steady state entrainment rate for the $i^{\prime t h}$ fraction by $w_{i}$ it follows from $\mathrm{Eq}$. (IV-15) that

$$
W_{1}=\frac{d w_{i}}{d t}=-\frac{A \rho^{\prime} u_{i}^{\prime}}{6} B e^{-B} \epsilon_{i}
$$

The total rate of entrainment $w, i . e_{0}$, for all fractions with more than the required energy to reach a height $h$, is obtained by integrating from the minimum to escaping energy to infinite energy:

$$
w=\int_{\epsilon_{i}}^{\infty} w_{i} d \epsilon_{i}=-\frac{A \rho^{\prime}}{6} \int_{\epsilon_{i}}^{\infty} u_{i}^{\prime} B e^{-\beta \epsilon_{i}} d \epsilon_{i}
$$

Substituting Eq. (IV-13) and (IV-12) into Eq. (IV-17) it follows that

$$
W=\frac{A p^{\prime}}{6} \sqrt{2 g} \mathrm{mgB} \int^{\infty} \sqrt{h} e^{-B m g h} d h
$$

Where the integration can be carried out in terms of the error integral $\Phi$ :

$$
\int_{h}^{\infty} \sqrt{h} e^{-B m g h} d h=\frac{1}{2 B m g} \sqrt{\frac{\pi}{B m g}}[1-\Phi(\sqrt{B m g h})]+\frac{\sqrt{h} e^{-B m g h}}{B m g}(I V-19)
$$

If $h$ in the above equation represents the height from the interpace to the outlet of the vessel, the number of particles in the 
outlet line will be affected by the shape of the vessel. Con sequently the right hand side of Eq. (IV-18) should be multiplied by a "conductance coefficient" $\lambda$ to be determined from experiments. If it is assumed that in a mixture of different particle (drop) sizes there is no interaction between different sizes, the rate of entrainment for 211 particle sizes is

$$
W=A \sum_{j}^{\infty}\left[\lambda \frac{(2 g)^{3 / 2} \rho^{\prime}}{12} \beta m\right]_{j}\left(\int_{h}^{\infty} \sqrt{h} e^{-\beta m g h} d h\right)_{j} \mu_{j}
$$

where the summation is over the particle dimeters and $\mu_{j}$ is the mass fraction of particles with diameters equal to $j$.

It has been noted by Andrews that if a weighted mean particle mass is employed, Eq. (IV-20) becomes approximately equal to Eq. (IV-18), provided B is independent of particle mass. In order to make use of $\mathrm{Eq} .(I V-20)$ and to be able to predict, for a given operating condition, the rate of entrainment or Iraction of the height $h$, above the interface it is necessary to evaluate the constant $B$, i.e., the value of the reciprocal of average particle energy. This entrainment rate constant $B$ depends upon the physical and operating characteristics of the system. At present, as discussed by Andrews, it can be only determined from experimental data. This can be done in the following way. Differentiating Eq. (IV-18) and dividing by the negative square root of $\mathrm{h}$ it follows that

$$
-\frac{1}{\sqrt{h}} \frac{\partial W}{\partial h}=\left[\frac{\rho^{\prime} A B m g \sqrt{2 g}}{6}\right] e^{-B m g h}
$$

For a given operating condition (i.e., for steady state conditions 
at the interface) the values of W as function of height $h$ can be used to compute the value of the left hand side of Eq. (IV-21). A plot of $\frac{1}{\sqrt{h}} \frac{\partial W}{\partial h}$ vs $h$ when plotted on semi-log coordinates should be linear and the value of $B$ can be determined from the slope of this Iine. It can be expected that a change of operating conditions, i.e., Increasing the vapor flow rate wil change both the drop size distribution and the entrainment constant.

\section{IV.3 CONCLUSIONS}

It appar from the foregoing discussion that the liquid entrainment problem can be formulated; this in principle provides basis 20 estimating the entralnment as function of operating characteristics and of the height in the vapor space. The information which is needed in order to obtain quantitative estimates are the drop size distribution n, the initial velocity $u_{i}$ of the drop., i.e., the initial kinetic energy of the drop, and the reduced (supericial) velocity $u_{0}$ " of the vapor. of these three quantities only the value of the last one is known from operating conditions; whereas the values of the first two can be, at present, only determined from experiments. Consequently, at present, the problem can be formulated only in terms of constants which have to be evaluated from experimental data. 


\section{SEMI-EMPIRICAL APPROACH TO LIQUID ENTRAINMENT}

It was discussed in Chapter IV that the Iiquid entrainment could be predicted if the information on drop size distribution and on initial drop velocities was available. It was noted that both the size and the initial velocity of a drop can be related to the dimensions of a bursting bubble. Thus, in principle, those quantities could be computed II data on bursting bubbles were available. Such data can be obtained only under very idealized conditions. In practice neither the bubble size distribution and interactions nor the hydrodynamic conditions at the interiace are known. Consequently, at present, a purely analytical approach cannot be used for predicting, quatitativaly, the liquid entrainment. The system of equations which describe the processes leading to drop formation and entrainment can be used, however, for obtaining dimensionless groups which in turn can bo used for correlating experimental data. In this chapter we shall discuss these semiempirical methods of andysis and the proposed correlations for liquid carry over from water bollers.

V. I THE CORRELATION OF RRUZHILIN

One of the proposed correlations for the carry over of water drops from a boliling interface is due to Kruzhilin (Refir. 29, 30). His dexivation is based on two assumptions. It was assumed that drowlets which are transported by the vapor (Iike those which originate from the disintegration of the bubble dome) contribute Iittle to the entrainment; conseguentyy, their effect was neglected. 
According to his second assumption, the entrainment was due to drops which are ejected from the interface by the action of the kinetic energy of the vapor ( $\left(\rho^{n} u_{0} " 2\right)$. In other words, entrainment is due to the dynamic effects of the vapor in disintegrating 11quid Illaments and ejecting droplets from the interface. Postulating that the amount of liquid $\mathrm{G}^{\prime}\left(\mathrm{Kg} / \mathrm{m}^{2} \mathrm{sec}\right)$ leaving the interface and reaching a given height IV, depends upon the following parameters

$$
\rho^{\prime \prime} u_{0} " 2, \rho^{p}, \sigma_{8} \mu^{\prime}
$$

Kruzhilin obtained, using dimensional analysis, the following groups:

$$
\begin{aligned}
& \pi_{1}=\frac{G^{\prime} \sigma g}{\left(\rho^{\prime \prime} u_{0}^{\prime \prime 2}\right)^{2} u_{O} "} \sqrt{\frac{\rho^{\prime}}{\rho^{\prime \prime}}} \\
& \pi_{2}=\frac{\mu^{\prime 2} \rho^{\prime \prime} u_{0}^{\prime \prime 2}}{\sigma^{2} \rho^{\prime}} \\
& \pi_{3}=\frac{\rho^{\prime \prime} u_{0}{ }^{\prime 2}}{g \rho^{\prime} H_{V}} \triangleq \text { Froude Number } \\
& \pi_{4}=\frac{\sigma}{g \rho^{\prime} H_{V}^{2}} \triangleq \text { Weber Number }
\end{aligned}
$$

Because the effects of drop disintegration or coalescence in the vapor space can be considered small Rruzhilin omitted the Weber number from further consideration. From the definition of the entrainment

$$
E=\frac{G^{p}}{\rho^{p p} u_{0}^{p}}=\frac{\rho^{p} u_{0}{ }^{p}}{\rho^{n} u_{0}^{p}}
$$


and $\mathrm{Eq} \cdot(\mathrm{V}-2)$ the entralnuent was expressed 2 a functon of 2 and $\pi 3$ thus

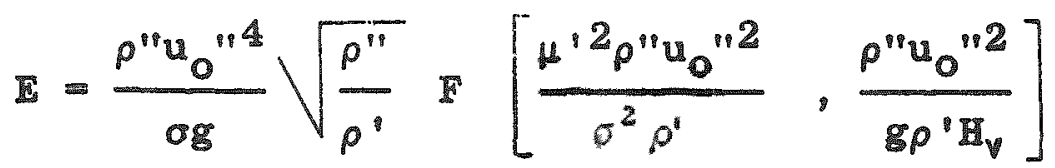

Kruzhilin considered the function as a correction factor which, as a Iirst approximation, was taken as constant, hence

$$
I=C_{1} \frac{\rho^{\prime \prime} u_{0}{ }^{4}}{\sigma g} \sqrt{\frac{\rho^{p}}{\rho^{p}}}
$$

where the value of the constant $C_{1}$ has to be determined from experiments.

It can be seen that the exponent of the reduced vapor velocity is $\mathrm{n}=4$, consequentIy, $\mathrm{Eq},(\mathrm{V}-8)$ should correlate the experimental data in the second region shown on Fig. I in the Introduction (see also Fig. I-5). It must be noted, however, that the height Iy above the Interface does not appeax in the above equation. ConsequentIy. it can bo expected that $\mathrm{g}$. $(\mathrm{V}-8)$ can correlate only data taren at the same height above the interface.

Kruzhilin used IG. $(V-8)$ to evaluate the effect of pressure on the permissible vapor flow rate at a constant entrainment. At a constant entrainment it follows Irom Eq. $(V-8)$ that

$$
\left(\frac{\rho^{\prime \prime} u_{0}^{\prime 4}}{\sigma g} \sqrt{\frac{\rho^{\prime \prime}}{\rho^{p}}}\right)_{1 \text { atm }}=\left(\frac{\rho^{\prime \prime} u_{0}^{\prime 4}}{\sigma g} \sqrt{\frac{\rho^{\prime \prime}}{\rho^{\prime}}}\right)_{p}
$$

which permits a estimate of the reduced vapor velocity for the system operating at a pressure $P$, in terms of the data taken at atmospheric pressure. It was stated in Refs. (29) and (30) that this method of estimating the pressure effect gives satisfactory results. 
Ref. (5) gives a sumnary and conclusions of a series of rather spirited discussions (Refs. 31 through 38 ) on the problem of liquid carry over from wator boilers. These conclusions give support to the analysis of Kruzhilin and to Fq. (V-9). The IImitation of the analysis which is caused by omitting the effect oi the vapor height was noted also.

\section{V - 2 THE CORRELATION OT PANASFMTO AND ANTONOV}

For design purposes it is of interest to determine the value of the entrainment at the second transition point (Point B, Fig. I in the Introduction). It was noted that, In the second region, the entrainment seems to be determined by drops ejected from bursting bubbles whereas the entrainment in the third region is apparenty caused by large splashes of liguld which are thrown out and disintegrated In the vapor space. We note here the similarity of this reglon with the "Ilooding" in bubble bed apparatus.

In the region of "ejected drops", I.e., in the second region the equation of Kruzhilin can bo used to express the dependence of tho entrainment (at a congtant helght) upon the reduced vapor veloc1ty. However, this equation cannot provide any laformation pertalning to the transition Irom reglon II to rogion III. In partcular, it cannot answor the question at what vapor flow rate this change will occur. An investigation and a correlation of liquid entrainment at the transition polnt was reported recently by Panasenko and Antonov (Reis.6 and 39). 
Panasenk and Antonov reasoned that since the second transi tion point (Point B in IIg. 1) means the end of the second region, it should be possible to correlate the data at this point in terms of the dimensionless groups proposed by Kruzhilin for the second region, i.e., for the region of "ejected drops." The ontraiment at the transition point (referred by Russian Investigators as the "Critical point") was expressed therefore in terms of Eq. (V-8) (modified to include $\pi 4$ as well as $\pi 2$ and $\pi 3$ ), where the function F was approximated by a power law relation, thus

$$
E^{*}=C\left[\frac{\rho^{n}}{\sigma g} \sqrt{\frac{\rho^{\prime \prime}}{\rho^{\prime}}} u_{0}^{n 4}\right] \pi_{2^{m}}^{m 3^{m} \pi_{4}^{L}}
$$

where the constant $C$ and the exponent $m, n$, and $L$ were determined from experimental results reported In Refs. (2). (40), (41) and (42)! The values thus determined were: $C=1.96 \mathrm{x}=10^{7}, \mathrm{~m}=0.9, \mathrm{z}=1.92$, $h=1.55$. The correlation of the entrainment at the second transition point can then be expressed as

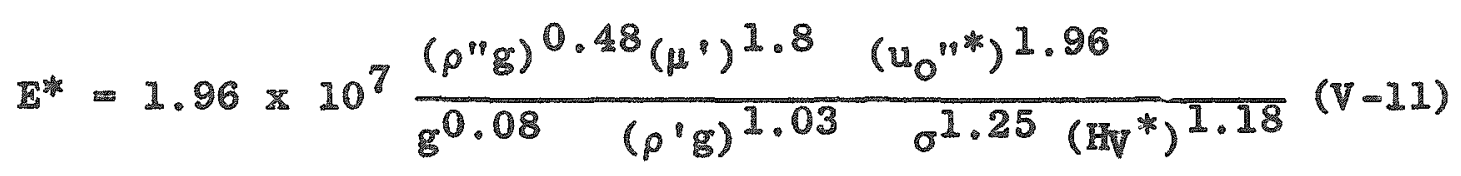

The stars in Egs. $(V-10)$ and $(V-11)$ denote that the data are evaluated at the second transition point. It can be seen that the entrainment $\mathbb{E}^{*}$ given by Eq. (V-11) depends upon the height above the interface, i. . upon the height of the vapor space. It can

F Data on these and other experiments are given in Appendix a ad Appendis $\mathrm{B}$ of this report. 
be seen also that, in order to predict $\mathrm{F}^{*}$, it is necessary to know the values of the reduced vapor velocity $u_{0}{ }^{n *}$, and of the height $\mathrm{HV}^{*}$, at the transition point.

In general, the height of the vapor space (if it is measured from the interface to the top of the vessel, see Fig. 2 in the Introduction) can be estimated if the initial height of the vapor space (in the absence of bubbling) $H$, and the expansion $\Delta H$ of the two-phase bubbling mixture are known, thus

$$
H_{V}=\mathbb{H}-\Delta H=H-H_{L} \frac{a}{1-\alpha}
$$

where $H_{L}$ is the liquid level (in the absence of bubbling) and a is the vapor volume fraction. The corrections which must be introduced in Eq. (V-12) for an estimate of the true height are discussed in Chapter VI. It follow from Eq. $(\mathrm{V}-12)$ that, in order to estimate $H_{y} *$, it is necessary to know the vapor volume fraction at at the transition point. Because a depends upon the reduced vapor velocity uo", this is equivalent to requiring the value of uon* which corresponds to $a^{*}$.

It is important to note here that, in Refs. (2), (40), (4I), and (42), the values of a are not reported. A statement is made in Ref. (42) to the ffect that $\alpha$, and therefore the height of the vapor space $\mathrm{H}_{\mathrm{V}}$, were computed from pressure drop measurements. However, the figure which depicts the apparatus does not show provisions (pressure taps and connections) which would provide pressure measurements for these computations. In Refs. (2), (6), (39) and (41) statements are made to the effect that $\alpha$ can be computed from 
the correlations proposed by Kurbatov (Ref. 43), Margulova (Ref. 44) and by Sterman (Ref. 45) which relate the volumetric vapor fraction a to the reduced vapor velocity $u_{0}{ }^{n \neq}$. Thus, it is not clear whether the values of a were measured in these experiments or if they were computed from the correlations.

In order to relate o to uo" Panasenko and Antonov used the equation proposed by Rurbatov (Ref. 43) which is given by

$$
\alpha=0.67\left(\frac{u_{0}{ }^{10}}{g \sqrt{\frac{\sigma}{g\left(\rho^{\prime}-\rho^{\prime 1}\right)}}}\right)^{1 / 3}\left(\frac{\rho^{\prime}-\rho^{\prime \prime}}{\rho^{\prime}}\right)^{-1 / 3}\left(\frac{\nu^{\prime}}{\nu^{\prime \prime}}\right)^{2 / 9}\left(\frac{d}{\sqrt{\frac{\sigma}{g\left(\rho^{\prime}-\rho^{\prime \prime}\right)}}}\right)^{-1 / 6}(v-13)
$$

The volumetric vapor fraction $\alpha^{*}$ was computed by substituting in the above equation the experimental values of $u_{0}$ "* reported in Ref. (46). (Data on these experiments are tabulated in Table I, Appendix A.) It was found from these computations that in the pressure range from $16.8 \mathrm{~atm}$ to $92.5 \mathrm{~atm}$ the value of $\alpha^{*}$ remained approximately constant $\left(\alpha^{*} \approx 0,43\right)$. Similar results were obtained using the experimental data reported in Refs. (40) and (47). Antonov and Panasenko (Ref. 39) concluded from the experiments that the height $\mathrm{HV}^{*}$ above the interface can be related to $a^{*}$ by the following expression

$$
\mathrm{HV}^{*}=8 \mathrm{a}^{* 3}
$$

where $H_{V}{ }^{*}$ is measured in meters. Since the sharp increase of the liquid entrainment beyond the transition point is attributed to

These equations and their Iimitations are discussed in Chapter VI. 
liquid splashes reaching the vapor exhaust line, according to Panasenko and Antonov, the vapor height HV* corresponds to the height (above the interface) which is reached by the splashes as they are thrown up in the vapor space. It was therefore denoted as the "critical vapor helght" or the "front of liquid splashes."

Eqs. $(V-11),(\nabla-13)$, and $(V-14)$ give a relation between the entrainment $E^{*}$ and the variables $H_{V}^{*}, a^{*}$ and $u_{0}{ }^{* *}$. In the discussion of their paper Panasentro and Antonov (Ref.6) suggest that their analysis can be used to solve two kinds of problems.

a) For a given reduced vapor velocity $\mathrm{u}_{0}$ " $\mathrm{Eq} \cdot(\mathrm{V}-13)$ can be used to determine the value of a whence Eq. (V-14) can be used to compute the "critical vapor height."

b) For a given "critical vapor ineight" $\mathrm{H}_{\mathrm{V}}^{*}$ (i.e., for a given design) Eq. $(\mathbb{V}-14)$ can be used to compute $a^{*}$ and Eq. $(V-13)$ to compute the "critical vapor flow rate" $u_{0} " *$. The corresponding value of the entraiment can be evaluated by means of $\mathbb{E}$. $(V-11)$. When the reduced vapor velocity is lower than the "critical," one, i.e., $u_{0} "<u_{0} " *$, the entrainment $E$ can be evaluated from $\mathrm{Eq} .(\mathrm{V}-8)$, provided that the height above the liquid interface is kept constant. Several remarks and closing comments seem appropriate at this point. It was noted by the editor of the Journal in 2 
footnote of Rar. (39), that the analynin and the method of relating the "critical vapor height" Hy" to the vapor volume fraction $\alpha$ is both novel and controversial. The question as to how was determined in these experiments (was it measured or was it computed) is still left open. This and the scatter of the experimental data on Iiquid entraineat make the validity of Eq. (V-14) questionable.

Panasento and Aronov found that for the experiments of Blinov and Sterman (Rer. 46) the value of $a^{*}$ was $a^{*}=0.43$. When this value is inserted into $\mathbb{E}$. $(V-14)$ the computed value of $\mathrm{HV}^{*}$ becomes $\mathrm{HV}^{*}=0.64$ 通 which is identical with the initial height (in the absence of bubbling) of the vapor space (see Appendix A). Consequenty, instead of representing a "critical height" in the vapor space, Ho may actually represent the maximum expansion of

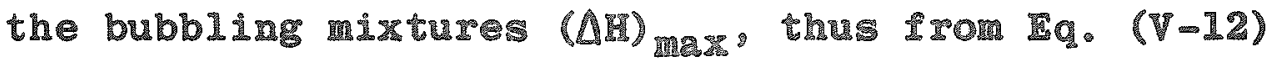

$$
(\Delta \mathrm{F})_{\text {mas }}=\mathrm{H}_{\mathrm{L}}\left(\frac{a}{1-\alpha}\right)=\mathrm{H}
$$

as $H_{y}=0$. Because all of the recessary information was not reported and because of the scatter of the data which are reported in Ref. (39), the authors were not able to prove or dism prove this inference. If this inference proves to be correct, it would be possible to make an estimate of $a^{*}=a_{\text {max }}$ by using Eq. V-15 and knowing and If. This walue of a could be then

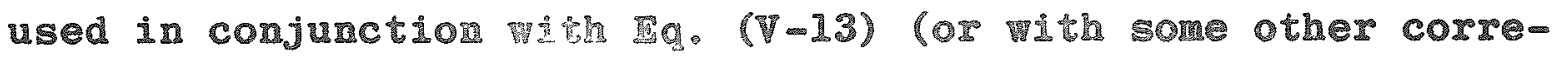

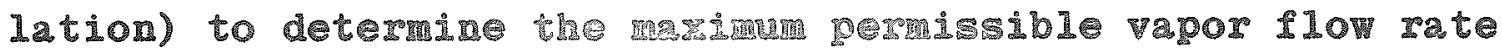

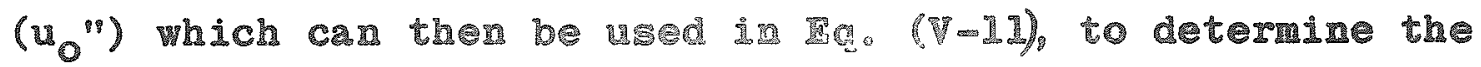
entrainment. 
Although in the work of Panasenko and Antonov manyestions are left open, this work points to some aspects of the problem worthy of further investigation. The reader will recall that in region II (region of "Ojected drops") the entrainment is primarlly caused by drops which are ejected from bursting bubbles. The entrainment depends, therefore, upon the conditions which affect the bubbling process in a two-phase mixture. It is known that, under certain conditions which depend upon the vapor volume fraction and upon the reduced vapor velocity uon $^{\prime \prime}$, the flow pattern in a bubbling mixture will change due to the interaction and the coalescence of smaller bubbles and the formation of larger vapor slugs. The rising and bursting slugs of vapor cause an oscillation of the liquid interface; the amplitude of these oscillations increase with increasing slug size and increasing vapor flow rates. The agitation of the interface and the rising vapor slugs generate liquid splashes that are thrown up and disintegrate in the vapor space. This phenomenon is often referred to as "looding." Because region II is characterized by ejected drops, whereas region III by liquid splashes, the transition point could be regarded as a "flooding point" which will be determined by a hydrodynamic instability. Since instabilities occur at some critical flow conditions, this inference would imply that, at the transition point, there exists a limiting functional relation between $\alpha$ and $u_{0} "$. In other words, it could be surmised that if the transition point is regarded as a "flooding point" the chamge from region II to region III wiIl occur when $\alpha$ and $u_{0}$ " attain some characteristic values. 
The results of Panasento and Antonov are not contradictory with this point of view. Their results, if correct, imply that the transition from region II to regiun III occurs at charasteristic values of $\alpha^{*}$ and $u_{0}{ }^{\prime *}$. If it is assumed that the initial velocity of the splashes is approximately equal to the reduced vapor velocity $\mathrm{u}_{0}$, then, upon eliminating $\alpha^{*}$ between Eqs. (V-14) and $(V-13)$, it can be seen that the "critical vapor height" is proportional to the initial kinetic energy of the Iiquid.

$$
\mathbb{H}^{*} \sim \rho^{8}\left(u_{0} \| *\right)^{2}
$$

The above relation can be interpreted by saying that liquid splashes reach a characteristic height under the action of an initial sharacteristic velocity $u_{0}{ }^{n *}$. By considering the effect of Taylor instability upon disintegrating liquid sheets a relatively uniform drop distribution could be expected and computed. In conclusion, the validity and the implications of the work of Panasenko and Antonov still remain to be verified. An 2nalysis of the transition from the "region of ejected drops" to the "region of liquid splashes" can be conducted by considering the hydrodynamic effects and instabilities. To conduct such an investigation and to evaluate the proposed correlations good experimental data are needed.

$\mathrm{V}-3$ THE CORRELATION OF STERMAN, ANTONOV AND SURUVV

The results of a large number of experiments performed with the purpose of investigating the effects of pressure and of the initial height in the vapor dome upon the liquid entrainment is reported in Refs. (2), (40), (41), (42), and (44), In these 
experiments with water the pressure was varied from 17 atm to 185 atm and the initial height $H, i . e .$, the helght in absence of bubbling from $0.4 \mathrm{~m}$ to $0.8 \mathrm{~m}$.

Fig. $(V-1)$ which is reproduced from Ref. (42) shows the effect of different initial heights upon the entrainment at a pressure of $36 \mathrm{2tm}$. In terms of the nomenclature of this report, the ordinate on this figure is the entrainment, i.e., $\omega \triangleq \mathbb{E}$, whereas the abscissa is the reduced (superficial) velocity uo" divided by the initial height $H, i .0 ., D \triangleq u_{0} " / H\left(\mathrm{~m}^{3} / \mathrm{m}^{3} \mathrm{hr}\right)$. The values of fl for the indicated lines on this figure are, 1: $H=0.852-0.860 \mathrm{~m}, 2: H=0.470-0.478 \mathrm{~m}, 3:$ H $=0.657-0.665 \mathrm{~m}$ 。 It can be seen from $\mathbb{F i g} .(V-1)$ that as the value of 1 increases higher reduced vapor velocities are required to produce the same entrainment.

It is reported in Refs. (2), (41), and (42) that at a constant pressure the effect of various initial heights upon the entrainment can be correlated by plotting the entrainment $\mathbb{E}$ versus the following dimensionless group.

$$
N=\frac{4 o^{n 2}}{a H_{V}}
$$

where $\mathrm{HV}$ is the height from the interface to the vapor exhaust line (or to the measuring device) and is given by Eq. $(V-12)$. Fig. (V-2) which is reproduced Irom Ref. (41) shows the experimental data plotted in this fashion; the lines indicate various pressures, 1.e., 1: $P=17 \mathrm{~atm}, 2: P=36 \mathrm{~atm}, 3: P=91 \mathrm{~atm}$, 


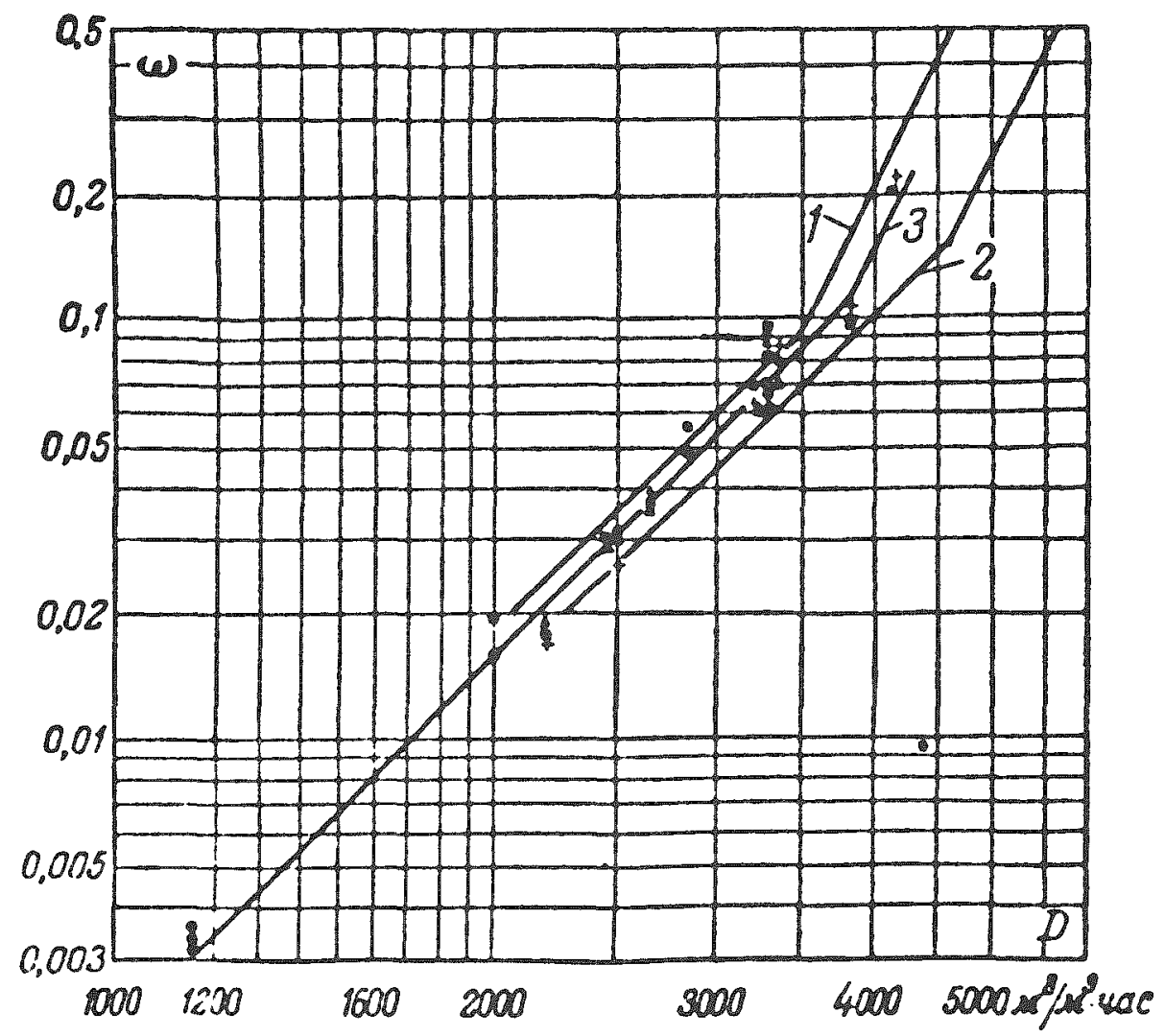

Figure V-I The Effect of the Reduced (Superficial) Vapor Velocity $U_{0}$ " and of the Initial Height in the Vapor Space $H$ on the Entrainment of Water at 36 atm. (Ref. 42)

$1: H=0.852 m-0.860 m ; 2: H=0.470 m-0.478 m ;$

$3: H=0.657 \mathrm{~m}-0.665 \mathrm{~m} ; \omega=\mathrm{E}(\%) ; \mathrm{D}=\frac{\mathrm{U}_{0} "}{\mathrm{H}}\left(\mathrm{m}^{3} / \mathrm{m}^{3} \mathrm{hr}\right)$ 


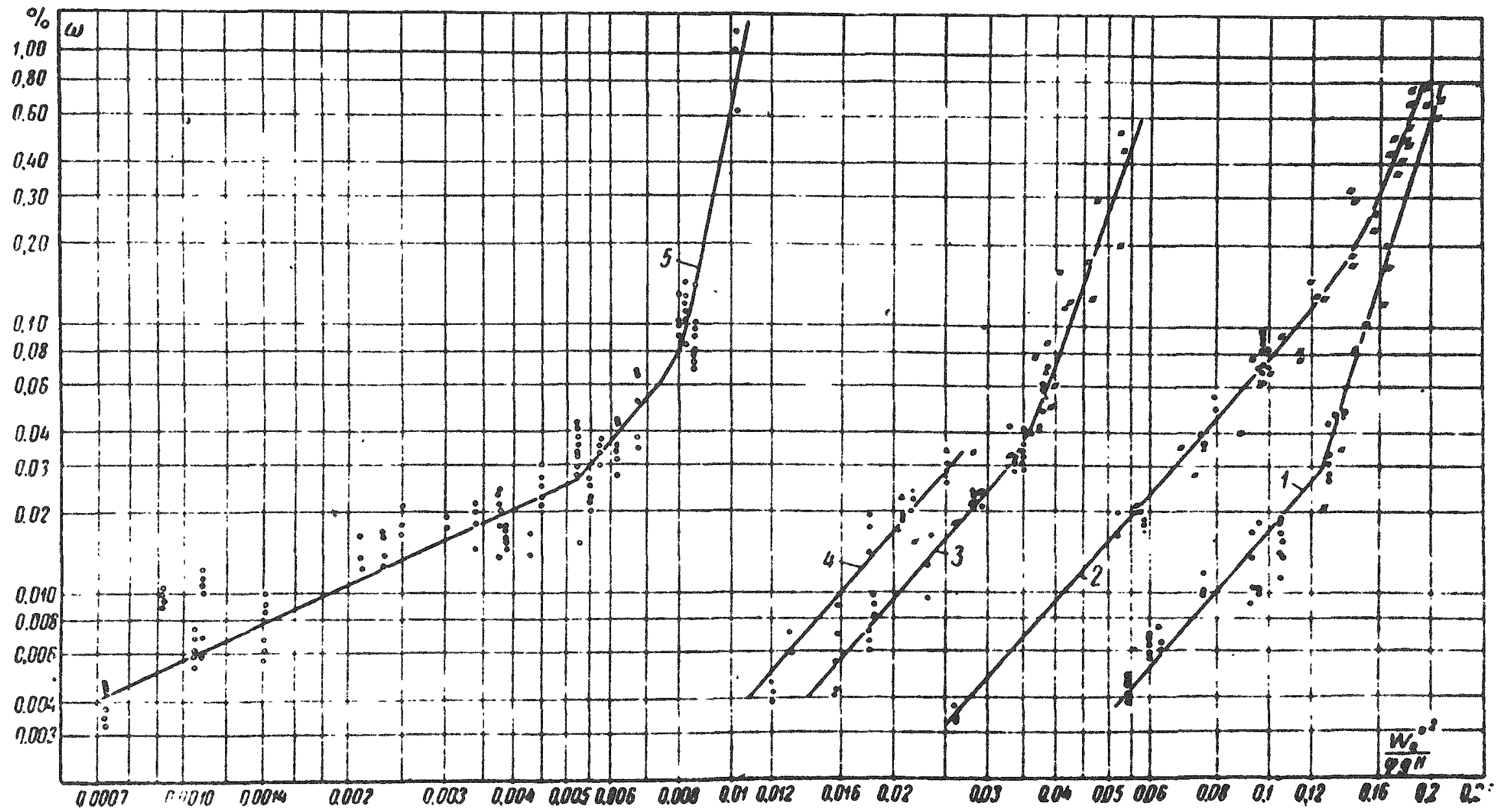

Figure V-2 The Entrainment $\mathrm{E}(\%)$ as Function of Pressure and of the Dimensionless Group $\mathrm{N}=\frac{\mathrm{U}_{0}{ }^{\prime \prime 2}}{\alpha \mathrm{gHv}}$. (Ref. 41) $1: P=17$ atm; $2: P=36$ atm; $3: P=91$ atm; $4: P=110$ atm; $5: P=185 \mathrm{~atm}$. 
4: $P=110 \mathrm{~atm}, 5: P=185$ atm. It is important to note here again that in these references it is not made clear whether the values of a were measured in these experiments or computed from calculations. Additional data on these experiments are given in Appendix A.

It is stated in Refs. (2) and (41) that, for a given entrainment $E$ and a constant height $H$, their results permit one to determine the corresponding values of the reduced vapor velocity as a function of pressure. The procedure is as follows. Solving Eq. (V-16) for uo", the reduced vapor velocity can be expressed as a function of a and of N. Thus

$$
u_{0} "=\sqrt{\operatorname{agH} H_{V}^{N}}
$$

To relate a to uo" sterman et.al. (Refs. 2 and 41) used the empirical equation of Margulova (Ref. 44) which is given by

$$
\alpha=(0.576+0.00414 P)\left(u_{0} 11\right)^{0.75}
$$

where the pressure $P$ is measured in atmospheres and $u_{0}$ in meters per second. This equation and a possible inaccuracy are discussed in Chapter VI.

Defining

$$
K_{0}=0.576+0.00414 P
$$

it follows (rom Eqs. $(V-19),(V-18)$, and $(V-17)$ that

$$
u_{0} "=\left(K_{0} g V_{V}\right)^{0.8}
$$

whence, for a given $\mathrm{H}_{\mathrm{V}}$, the reduced vapor velocity uo" becomes a function of pressure $\left(\mathbb{K}_{0}\right)$ and of $N$. For a chosen value of the 
entrainment $\mathbb{E}$ the corresponding values of $\mathbb{N}$ as a fumction of pressure can be read from $F i g .(V-2)$. Substituting these values of $\mathrm{K}_{0}$ into Eq. $(\mathrm{V}-20)$ permits ane to compute the zeduced vapor velocity as a function of pressure for the chosen values of and of $\mathrm{HV}$. Table V-1, which is reproduced from Refs. (2) and (41), shows the results of such computations for the chosen values of $E=0.05 \%$ and $\mathrm{Hy}=0.60 \mathrm{~m}$.

\section{Table $\mathrm{V}-1$}

The Computed Values of $u_{0} "$ as a Function of Pressure for

$$
E=0.05 \% \text { and } H_{V}=0.60 \mathrm{~m}
$$

\begin{tabular}{|c|c|c|c|c|}
\hline P & $\mathbf{K}_{\mathbf{0}}$ & $\mathbf{N}$ & $u_{0} "$ & \\
\hline $\operatorname{atm}$ & computed from & from & $\mathrm{m} / \mathrm{sec}$ & (computed from \\
\hline & Eq. $(V-19)$ & Fig. $(V-2)$ & & $\mathbb{E q} \cdot(-20)$ \\
\hline 17 & 0.640 & 0.137 & 0.588 & \\
\hline 36 & 0.725 & 0.0835 & 0.436 & \\
\hline 91 & 0.953 & 0.038 & 0.290 & \\
\hline 110 & 1.031 & 0.029 & 0.251 & \\
\hline 185 & 1.342 & 0.0068 & 0.0978 & \\
\hline
\end{tabular}

Fig. (V-3) which is reproduced from Refs. (2) and (41) shows the computed reduced vapor velocity and vapor mass flow rate as a function of pressure. The ordinates are normalized with respect to the data at $17 \mathrm{~atm}$. Thus 


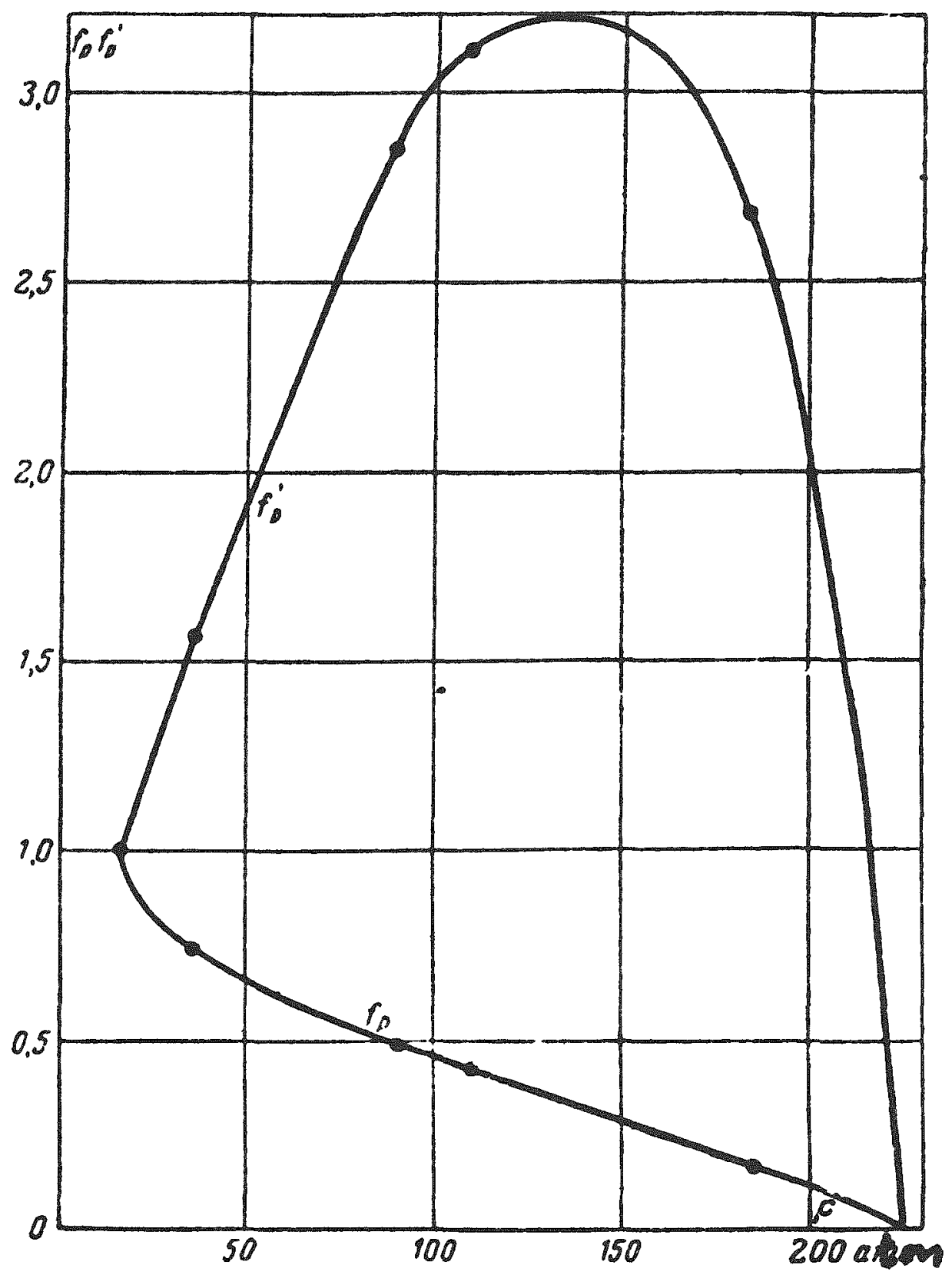

Figure V-3 The Effect of Pressure on the Reduced Vapor Velocity and on the Vapor Mass Flow Rate at a Constant Entrainment $(E=0.05 \%)$ and for a Constant Height in the Vapor Space $\left(\mathrm{H}_{\mathrm{v}}=0.600 \mathrm{~m}\right)$. (Ref. 41$)$
$\mathrm{f}_{\mathrm{p}} \triangleq \frac{\left(\mathrm{U}_{0}^{\prime \prime}\right)_{\mathrm{p}}}{\left(\mathrm{U}_{0}^{\prime \prime}\right)_{17 \mathrm{~atm} .}}$
$\left.f_{\mathrm{p}}^{\prime} \triangleq \frac{\left(\rho^{\prime \prime} \mathrm{U}_{0}^{\prime \prime}\right)}{\left(\rho^{\prime \prime} \mathrm{U}_{0}^{\prime \prime}\right)}\right] \mathrm{p}$ atm. 


$$
\begin{aligned}
& f=\frac{\left(u_{0}{ }^{\prime \prime}\right)_{P}}{\left(u_{0} "\right)_{17} \text { atrm }}
\end{aligned}
$$

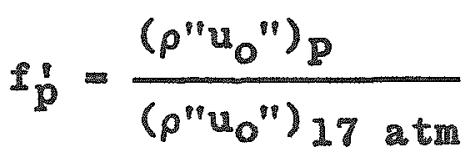

It can be seen from this figure that, for a given height of the vapor space, as the pressure increases lower vapor velocities are required to induce the same entrainment. For a given entrainment and vapor height as the pressure increases the reduced vapor velocity decreases whereas the vapor mass flow rate $\mathrm{G}^{\prime \prime}\left(\mathrm{Kg} / \mathrm{m}^{2} \mathrm{sec}\right)$ goes through a maximum at about 130 atms.

It can be seen from the foregoing that this method appears potentially useful for estimating the effects of pressure, dome height and of the reduced vapor velocity upon the liquid entrainment. However, two cautionary remarks should be made. The first is concerned with the values of which were used in correlating and plotting the data shown on $\mathbb{F}$ ig. $(V-2)$. It is not clear how these values were obtained, from experiments or from some correlation. The second remaxk is concerned with the accuracy of Eq. $(V-19)$, which will be taken up in Chaptex VI.

$V-4$ THE CORRELATIONS OF STERMAN

It was stated in Refs. (2), (41), and (42) that the effects of different initial heights in the vapor space upon the entrainment can be correlated by plotting the entrainment $\mathrm{E}$ versus the dimensionless group $\mathrm{N}$ given by $\mathrm{Eq} \cdot(\mathrm{V}-16)$. It can be seen from $\mathbb{F}$ ig. $(\mathbb{V}-2)$ that a plot of this kind does not 
correlate the effect of pressure. A correlation which takes this effect into account was recently proposed by sterman (Ref. 48). Sterman reasoned that since the dimensionless group $\mathrm{N}$ given by Eq. (V-16) correlates the effect of height it should be corrected by other dimensionless groups to take into account the effect of pressure. By considering the equations of motion and of energy discussed in Chapter IV, he derived several dimensionless groups: the Reynolds, Froude, Weber group, etc.; for the correlation, all but three groups were neglected. The entrainment was approximated by a power law relation, thus

$$
\mathrm{E}=\mathrm{C}_{1}\left(G_{\mathrm{a}}\right)^{l}(\mathrm{~N})^{\mathrm{m}}\left(\frac{\rho^{\prime \prime}}{\rho^{p}-\rho^{p 1}}\right)^{n}
$$

where

$$
G_{a}=\frac{g\left(\frac{\sigma}{g\left(\rho^{\prime}-\rho^{\prime \prime}\right)}\right)^{3 / 2}}{\left(V^{\prime}\right)^{2}}
$$

$\mathrm{N}$ and $\mathrm{HV}$ are given by $\mathrm{EqS.}(\mathrm{V}-16)$ and $(\mathrm{V}-12)$, respectively, $1 . e .$, by

$$
\begin{aligned}
& \mathrm{N}=\frac{u_{0}{ }^{2}}{a H_{V}} \\
& H_{V}=H-H_{L} \frac{\alpha}{1-\alpha}
\end{aligned}
$$

The values of the constant $C_{1}$ and of the exponents $l$, m and $n$ were determined from the data shown on Fig. $(V-2)$. For region II, i.e., for the region of "ejected drops" the values thus determined were: $c_{1}=2.75 \times 10^{8}, h=-1.1, m=2.3, n=0.25$. Thus, for region II the correlation of liquid entrainment becomes 


$$
E=2.75 \times 10^{8} \frac{N^{2} .3}{G_{a}^{1.1}\left(\frac{\rho^{\prime \prime}}{\rho^{\prime}-\rho^{\prime \prime}}\right)^{0.25}}
$$

On Iig. $(V-4)$, which is reproduced from Ref. (48), Eq. $(V-23)$ is compared with the experimental data shown on Fig. $(\mathrm{V}-2)$. In terms of the notation of this report the symbols on this figure are $\omega=\mathrm{E}$ and $\gamma^{\prime}=g \rho^{\prime \prime}, \gamma^{\prime \prime}=g \rho^{\prime \prime}$.

Sterman proposed also a correlation of the entrainment at the transition from the region of "ejected dropg" (reglon II) to the "region of splashes" (region III). From the data reported in Refs. (2), (40), (41), (42), and (47) he obtained a correlation giving the value of $\mathbb{N}$ (at the transition point) in terms of the density group and of $\mathrm{G}_{2}$, thus

$$
N^{*}=\left(\frac{u_{0}^{\prime \prime}}{a g H V}\right)^{*}=4.2 \times 10^{-6} G_{2}^{0.55}\left(\frac{\rho^{p 1}}{\rho^{\prime \prime}-\rho^{\prime \prime}}\right)^{0.35}
$$

As in Sec. V-2, the star in the above equation means that the value of $N$ corresponds to the transition point i.e. to the "critical conditions." The entrainment E* at this point can be computed by substituting Eq. $(\mathrm{V}-24)$ into $\mathrm{Eq} \cdot(\mathrm{V}-23)$, hence

$$
\mathbb{E}^{*}=1.16 \times 10^{-4} \mathrm{G}_{\mathrm{a}}^{0.165}\left(\frac{\rho^{\prime \prime}}{\rho^{\prime}-\rho^{\prime \prime}}\right)^{0.555}
$$

Fig. (V-5) which is reproduced from Ref. (48) shows a plot of the data in region II and region III together with the transition (critical) point in terms of the normalized coordinates $\mathbb{E} / \mathbb{E}^{*}$ versus $\mathbb{N} / \mathbb{N}^{*}$ 


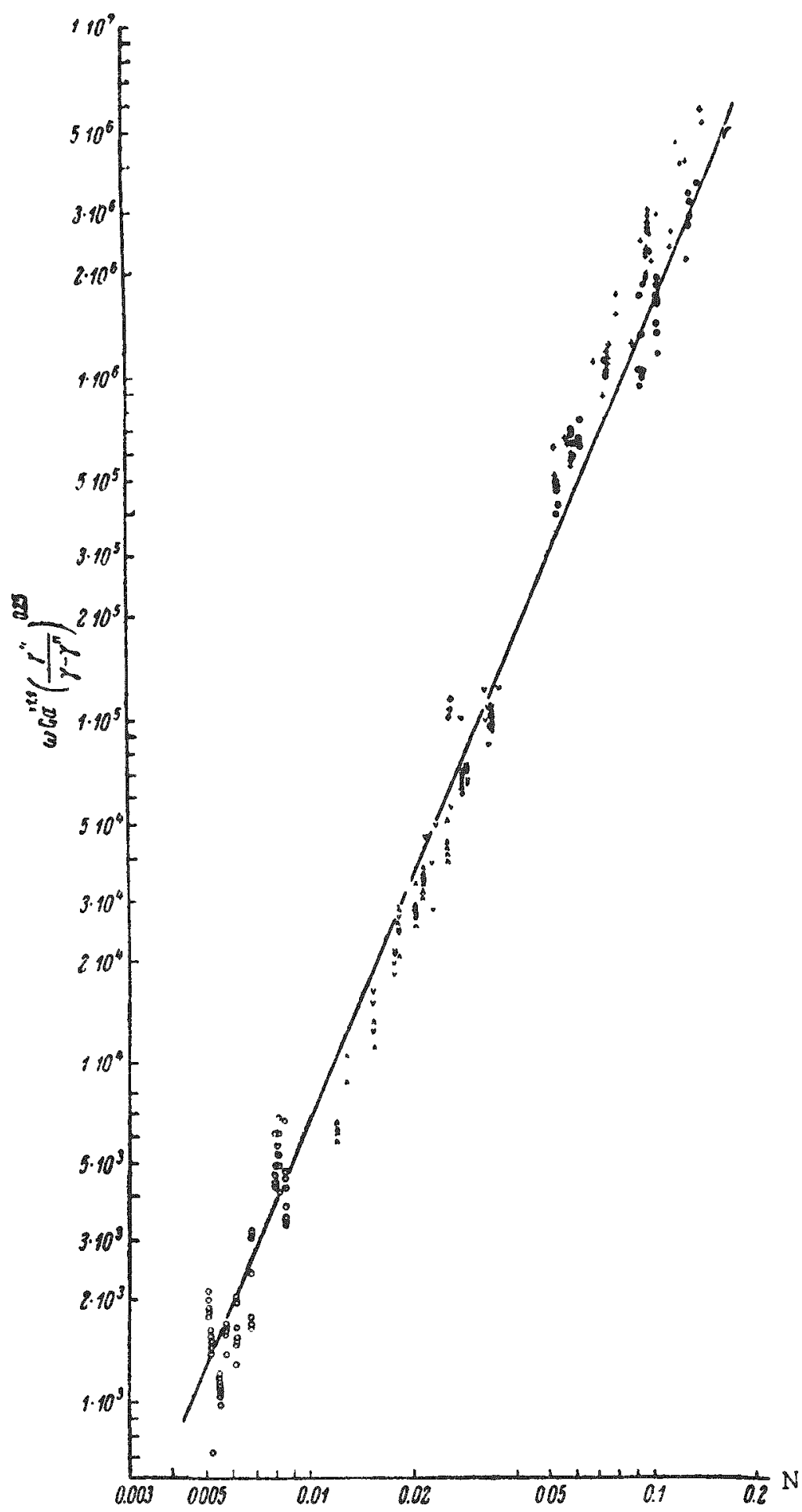

Figure V-4 Comparison of Eq. V-23 with Experimental Data Shown on Figure V-2. (Ref. 48) 


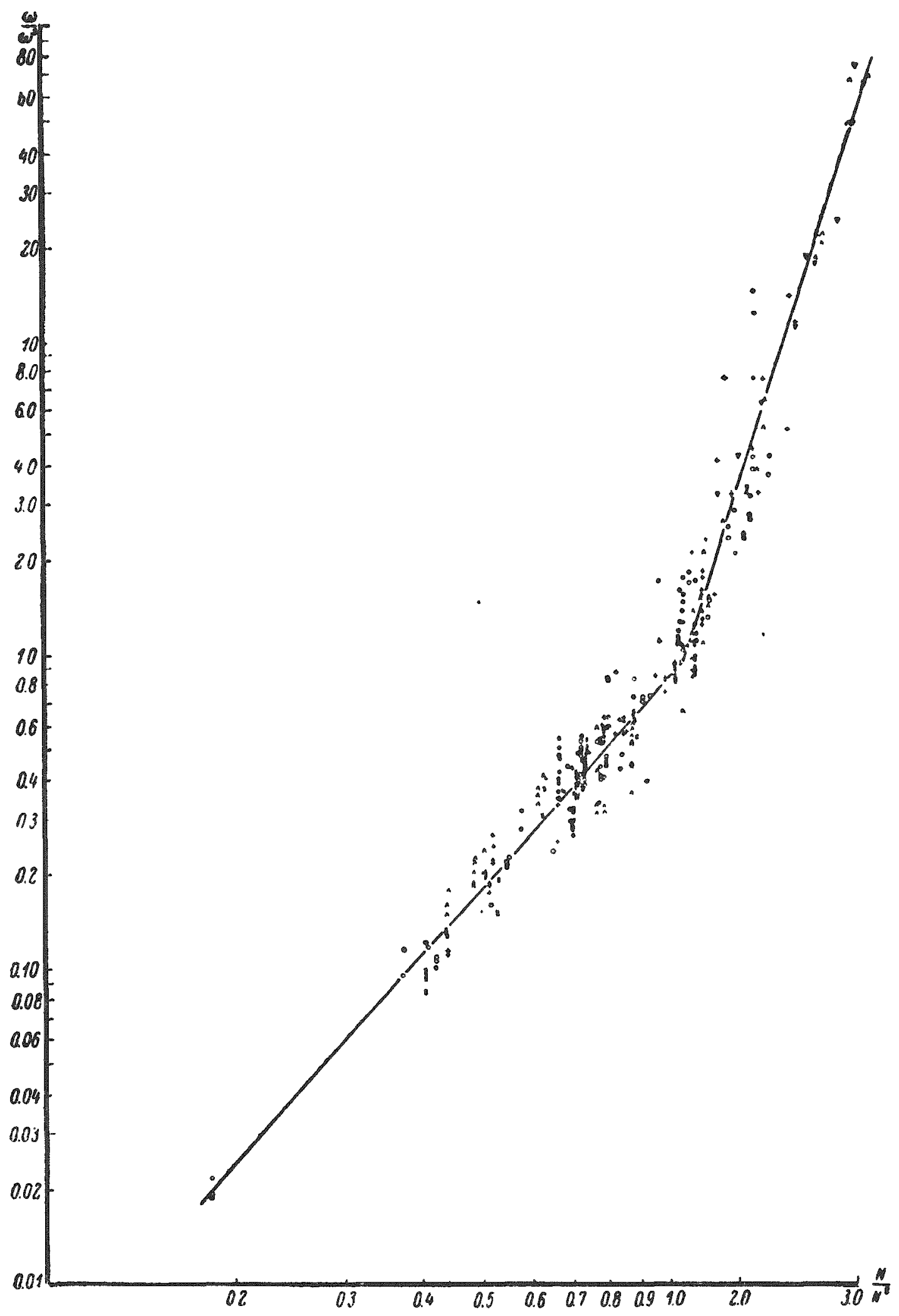

Figure V-5 Sterman's Correlation of Water Carry Over

$$
\frac{w}{w^{*}}=\frac{E}{E^{*}}=\frac{E q \cdot V-23}{E q \cdot V-25} \quad ; \quad \frac{N}{N^{*}}=\frac{E q \cdot V-22-b}{E q \cdot V-24}
$$


It can be seentrom ad. $(\mathrm{V}-23)$ and irom $\mathrm{sqs} \cdot(\mathrm{V}-22-\mathrm{b}, \mathrm{c})$ that in order to evaluate the entrainment it is necossary to have a relation between and $u_{0} "$. It will be recalled that in order to express this relation Panasenko and Antonov (Ref.6) used Eq. (V-I3), whereas Sterman et.21. (Refs. 2, 41, and 42) used Iq. (V-18). In Ref. (48) Sterman uses still another equation; It was derived in Ref. (45), and is of the form

$$
a=0.26\left(\frac{u_{0}{ }^{102}}{\sqrt{\frac{\sigma}{g\left(\rho^{\prime}-\rho^{\prime \prime}\right)}}}\right)^{0.4}\left(\frac{\rho^{\prime \prime}}{\rho^{\prime}-\rho^{\prime \prime}}\right)^{0.12}
$$

This equation is valid provided that

$$
\sqrt{\frac{d}{\sigma\left(\rho^{\prime}-\rho^{\prime \prime}\right)}}\left(\frac{\rho^{\prime \prime}}{\rho^{\prime}-\rho^{\prime \prime}}\right)^{-0.2}>260
$$

where d is the diameter of the container. The accuracy of this equation is discussed in Chapter VI. Substituting Fq. $(V-22)$ and (V-26) into Eq. (V-23), the entraimment can be expressed as

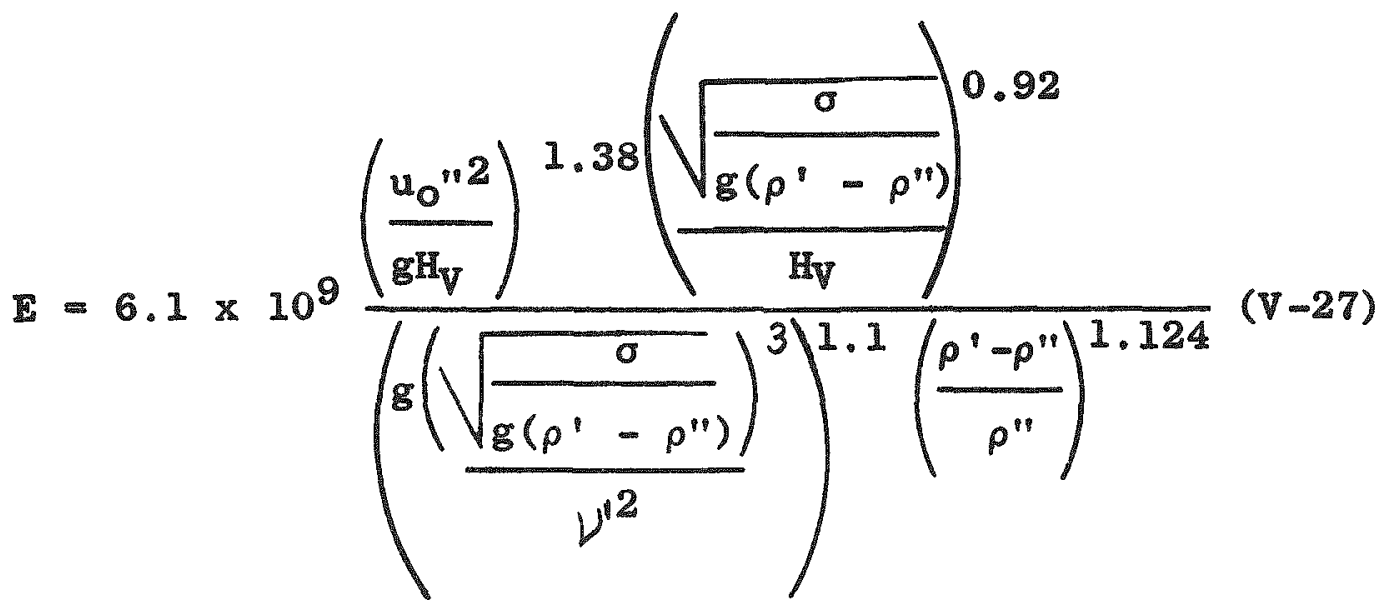


or with approximation

$$
I=6.1 \times 10^{9} \frac{F_{I}^{1.38}}{A_{x^{1.1}}}\left(\frac{\sqrt{\frac{\sigma}{g\left(p^{\prime}-p^{\prime \prime}\right)}}}{H_{V}}\right)^{0.92}
$$

where

$$
\begin{gathered}
F_{I}=\frac{u_{0}{ }^{\prime 2}}{g H_{V}}=\text { Froude Number } \\
A_{I}=\frac{\left(\frac{\sigma}{g\left(\rho^{i}-\rho^{\prime \prime}\right)}\right)^{3 / 2}}{\nu^{\prime 2}}\left(\frac{\rho^{\prime}-\rho^{\prime \prime}}{\rho^{\prime \prime}}\right) \\
H_{V}=H-H_{L} \frac{a}{I-a}
\end{gathered}
$$

It appears from the foregoing that the correlations of Sterman may be useful for estimating the effects of pressure, dome height and of the vapor load upon the liquid entrainment. However, the same cautionary remarks which were made at the end of the preceding section are appropriate here. Because sterman used for his correlation the experimental data shown on $F i g .(V-2)$ the uncer tainty concerning the values of applies to this case also. The second remark is concerned with the accuracy of $\mathrm{Eq} \cdot(\mathrm{V}-26)$; this question is taken up in Chapter VI.

\section{$\mathrm{V}-5$ CONCLUSIONS}

The correlations which have been discussed in this chapter permit one to evaluate the effects of pressure, of the vapor dome height and of the vapor load upon the water carry over. The 
validity and the limitations of these correlations still must be determined. The questions which arise in evaluating their accuracy stems from the fact the experimental procedure, the accuracy of the data and other information on the experiments are not reported in more detail in the published literature. Additional experimental results are needed to evaluate the proposed correlations. 
VI. THE TRANSPORTATION OS STEAM IN

A BUBBLING TWO PHASE MIXTURE

Liquid entrainment depends upon the hydrodynamic conditions of a two phase bubbling mixture not only because these affect the formation of drops or of liquid splashes but also because the expansion of the mixture and, therefore, the true height of the interface depends upon the hydrodynamic process. In bubbling, the two phase flow process depends upon the volumetric vapor fraction and upon the reduced vapor velocity uo". Consequently, the liquid entrainment will depend also upon these two parameters; this dependence is reflected in the correlations which have been discussed in the chapter.

The hydrodynamics of a bubbling mixture will be analyzed and discussed in more detail in a separate report. In this chapter we shall discuss this problem only in relation to the equations which have been used for correlating the data on liquid entrainment, 1,e., in relation to Eqs. $(\mathbb{V}-13),(V-18)$, and $(\mathbb{V}-26)$. We shall do this only to the extent of pointing out some inaccuracies and inconsistancies which must be considered when the correlations of liquid entrainment discussed in the precedIng chapter are used.

The equations of Kurbatov (Eq. $(\mathrm{V}-13))$, of Margulova (Eq. (V-18)), and of sterman (Eq. $(V-26)$ ) give relations between the volumetric vapor fraction and the reduced vapor velocity $u_{0} "$. It is noted that these three equations show three different functional relations between and $u_{0}{ }^{p}, i_{0} e_{0}$, the exponent of $u_{0} "$ 
has three different values. Since these correlations were derived by using the same experimental data, it is this point which we wish to discuss in this chapter.

\section{VI.1 THE CORRELATION OF IUURATOV}

From dimensional analysis Kurbatov (Ref. 43) derived the following relation between and uo"

$$
c=c\left(\frac{u_{0}^{\prime \prime 2}}{g \sqrt{\frac{\sigma}{g\left(\rho^{\prime}-\rho^{\prime \prime}\right)}}}\right)^{k}\left(\frac{\rho^{\prime}-\rho^{\prime \prime}}{\rho^{\prime}}\right)^{l}\left(\frac{\nu^{\prime}}{\nu^{\prime \prime}}\right)^{m}\left(\frac{d}{\sqrt{\frac{\sigma}{g\left(\rho^{\prime}-\rho^{\prime \prime}\right)}}}\right)^{n}
$$

The coeficient $c$ and the exponents $k, l, m$, and $n$, were determined from the experimental data of Behringer (Ref.49) and of Margulova (Ref. 44). The values thus determined were $c=0.67$, $\mathrm{k}=1 / 3, \ell=-1 / 3, \mathrm{~m}=2 / 9$, and $\mathrm{n}=-1 / 6$. The correlation then becomes

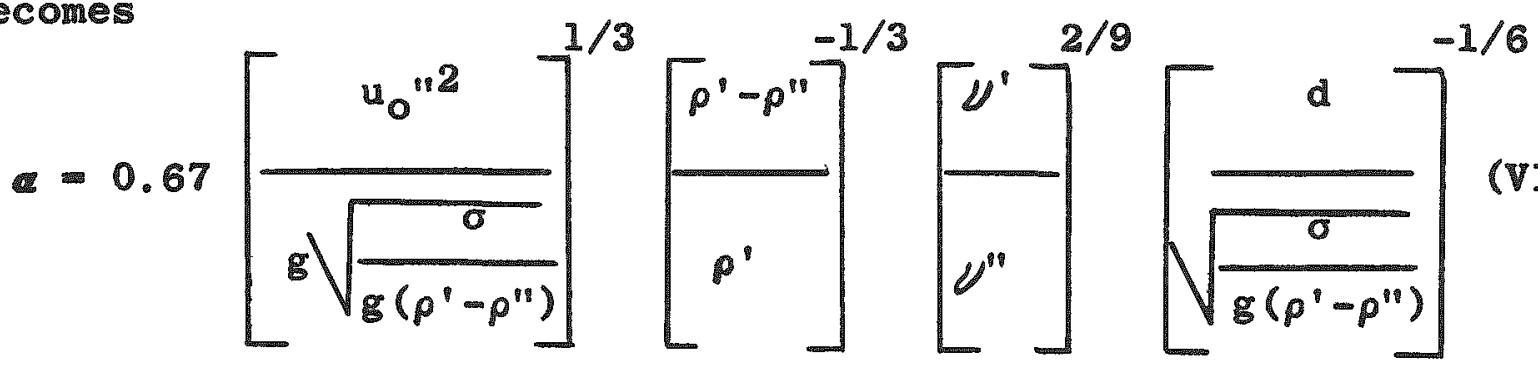

Behringer's experiments were performed with water in a pressure range from $1.07 \mathrm{~atm}$ to $40 \mathrm{~atm}$. The effect of geometry was tested by using three different pipe diameters, i.e., $d=5.7 \mathrm{~cm}, 6.9 \mathrm{~cm}$, and $8.25 \mathrm{~cm}$. Vapor was generated from an electric heater which was located at the bottom of the $6.1 \mathrm{c}$ long test section. Pressure measurements were taken from six pressure taps located along the test section. The vapor volume fraction was computed from these pressure measurements. The 
reduced vapor velocity was detemined from an energy balance.

On Figure VI-1 the authors have plotted as a function of $u_{0}$; the values were computed from the data shown on Fig. II (pipe diameter d $6.9 \mathrm{~cm}$ ) in Behringer's paper. Behringer's data are reported as a plot of $4_{0} " /$ a versus $p_{m}=(1-a) p^{\prime}+a p^{\prime \prime}$. Therefore it is possible that on Igure VI-1 some scatter has been introduced during the process of the reproductions, $i . e$. first by Behringer in reducing and plotting his data and then by athors in reading and recomputing the data from Behringer's ilgure.

The reader will note from Fig. VI-1 that, at a constant pressure, can be related to $u_{0} "$ by a power low expression. Although there is a qustion which exponent $n$ gives the best approximation to the data, it appears that $n=2 / 3$ gives 2 satisfactory relation. This is also the relation given by the equation of Iurbatov, i.e., by Iq. $(\mathrm{VI}-2)$. In addition to the experimental data of Behringer, Kurbatov, in deriving Eq. (VI-2), used also the data of Margulova. Her experinents are discussed in the next section.

\section{VI.2 THE CORRELATION OF MARGULOVA}

Margulova (Ref. 44) performed her experiments with water at three different pressures, $1.0 .$, at $P=91$ atm, $P=150$ atm, and $P=190$ tm. Vapor was introduced through a perforated plate located $21 \mathrm{~cm}$. below the Iiquid surface in the absence of bubbling. The test section was a circular tube $23.8 \mathrm{~cm}$. in diameter. The vapor volume fraction was computed Ixom 


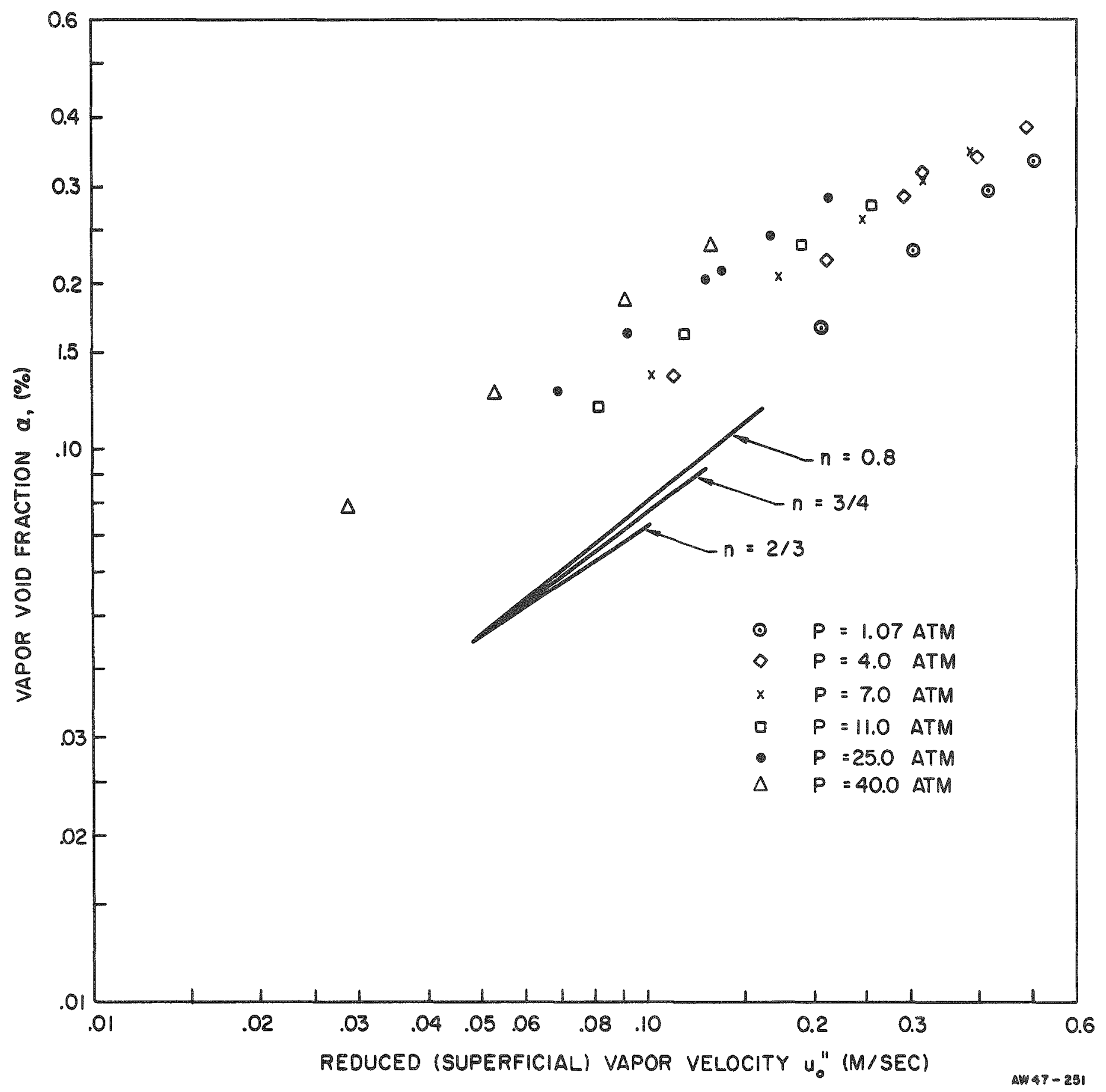

Fig. VI-1 Volumetric Vapor Fraction a as Function of the Reduced Vapor Velocity uo" for the Experimental Data of Behringer (Ref. 49) (Pipe Diameter $d=6.9 \mathrm{~cm}$ ). 
the pressure drop between two taps located $25 \mathrm{~cm}$. apart.

Margulova's data are tabulated in Appendix $B$ and are plotted on Figure VI-2. From these data she proposed the following relation between and uo"

$$
c=(0.576 \div 0.00414 \mathrm{P}) \mathrm{u}_{0}{ }^{10} 0.75
$$

where the pressure $\mathrm{P}$ is measured In atmospheres and the velocity uo" in meters per second.

It is not clear why she proposed the exponent $n=0.75$ because, as indicated by Fig. VI-2, her data can be approximated more closely by an exponent $n=2 / 3$, wich is in agreenent with the correlation of Iurbatov.

\section{VI.3 THE CORRELATION OF STERMAN}

Applying the theory of similarity to the equations which describe a two phase flow process (Ref. 50), Sterman (Ref.48) dexived several dimensionless groups which appear significant in describing the bubbling process. The vapor volume fraction a was aproximated by a power law relation and expressed as a function of three groups gus

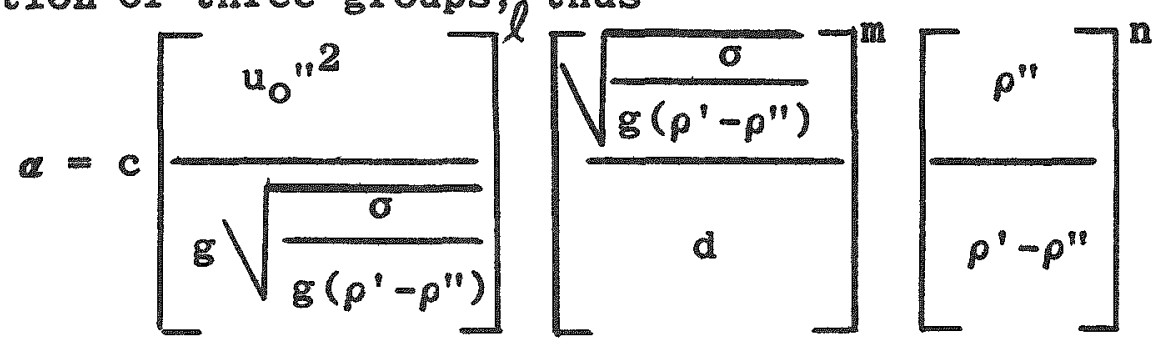

In evaluating the coefficient $c$, and the exponents $l, m$, and $n$, Sterman used the experimental data of Behringer, and of Margulova, in adition to his data taken at 17 atm and 91 tm. The values 


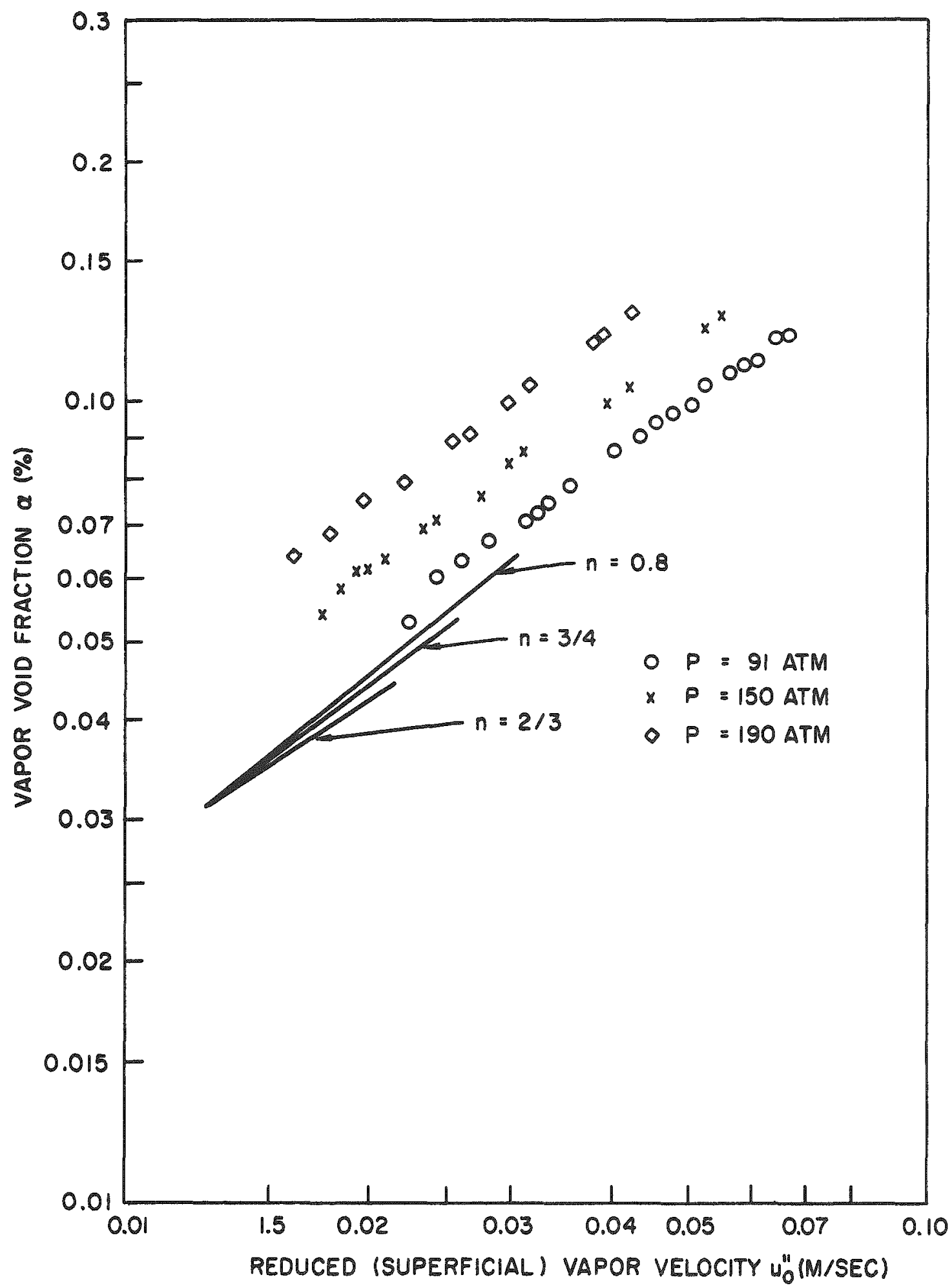

Fig. VI-2 Volumetric Vapor Fraction a as Function of the Reduced Vapor Velocity uo" for the Experimental Data of Margulova (Ref.44) (Pipe Diameter $d=20.0 \mathrm{~cm}$ ). 
thus determined were $c=1.07, l=0.4, \mathrm{~m}=0.25, \mathrm{n}=0.17$, hence the correlation is given by

$$
=1.07\left[\frac{u_{0}^{\prime \prime 2}}{g \sqrt{\frac{\sigma}{g\left(\rho^{\prime}-\beta^{\prime \prime}\right)}}}\left[\frac{\sqrt{\frac{\sigma}{g\left(\rho^{\prime}-\rho^{\prime \prime}\right)}}}{d}\right]^{0.25}\left[\frac{\rho^{\prime \prime}}{\rho^{\prime}-\rho^{\prime \prime}}\right]^{0.17}\right.
$$

It is important to note that the majority of data used in deriving this equation were those of Behringer and of Margulova, i.e., the same data which Kurbatov used in deriving Eq. (VI-2). The reader will note that, whereas Kurbatov proposed $n=2 / 3$ for the exponent of $u_{0} "$, Eq. (VI-5) gives a value of $\mathrm{n}=0.8$. By examining the original data plotted on Figs. $V I-1$ and $V I-2$, it would appear that the value of $n=2 / 3$ approximates somewhat better the data. However, it was reported recently by Dementiev, et. al. (Ref. 51) that Eq. (VI-5) correlates their experimental results. Since their original data are not reported, it is not possible to evaluate this statement, their experiments are discussed in the next section.

\section{VI.4 THE EXPERIMENTS AND THE CORRELATION OF DEMENTIEV, LEPILIN, AND LOGINOV}

The experiments of Dementiev, et.21. (Ref.51) were performed with water at $33 \mathrm{~atm}$. The test vessel was $7.9 \mathrm{~m}$. 1ong, $37.7 \mathrm{~cm}$. in diameter. Vapor was introduced through a perforated plate (45\% open area, $0.6 \mathrm{~cm}$. hole diameter). The volumetric vapor fraction was determined from the attenuation of $\gamma$ rays. The reduced velocity of the vapor was varied from $0.20 \mathrm{~m} / \mathrm{sec}$ to $1.5 \mathrm{~m} / \mathrm{sec}$. 
Dementiev, et, al. (Ref, 51) plotted their data on Fig. VI-3, which is reproduced from their report. The coordinates on this figure are those which are obtained from Sterman's correlation 1.e.:
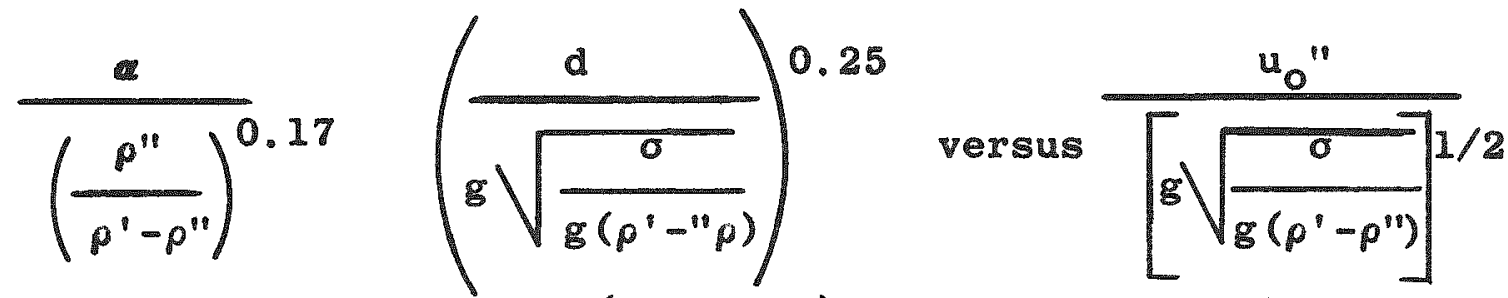

In addition to their data (symbol $\bullet$ ), Dementiev, et, al, plotted on Fig. VI-3 also the data of Behringer ( 0 ), of Margulova $(\Delta)$, of Sterman ( ), and of Dementiev $(\nabla)$. It can be seen that on this figure the data can be approximated by two lines. From these results Dementiev, et, 2I. (Ref, 51) concluded that Eq. (VI-5) correlates the experimental data when

$$
\left.\frac{u_{0}^{\prime \prime}}{\left[\sqrt{\frac{\sigma}{g\left(p^{\prime}-p^{\prime \prime}\right)}}\right]}\right]<3.7
$$

and

$$
=1.9\left[\frac{u_{0}^{\prime 2}}{g \sqrt{\frac{\sigma}{g\left(p^{\prime}-\rho^{\prime \prime}\right)}}}\right]\left[\begin{array}{l}
0.17 \\
d
\end{array}\right]
$$

correlates the data when

$$
\frac{u_{0}^{\prime \prime}}{\left[\sqrt{\frac{\sigma}{g\left(p^{\prime}-p^{\prime \prime}\right)}}\right]^{1 / 2}} \geq 3.7
$$




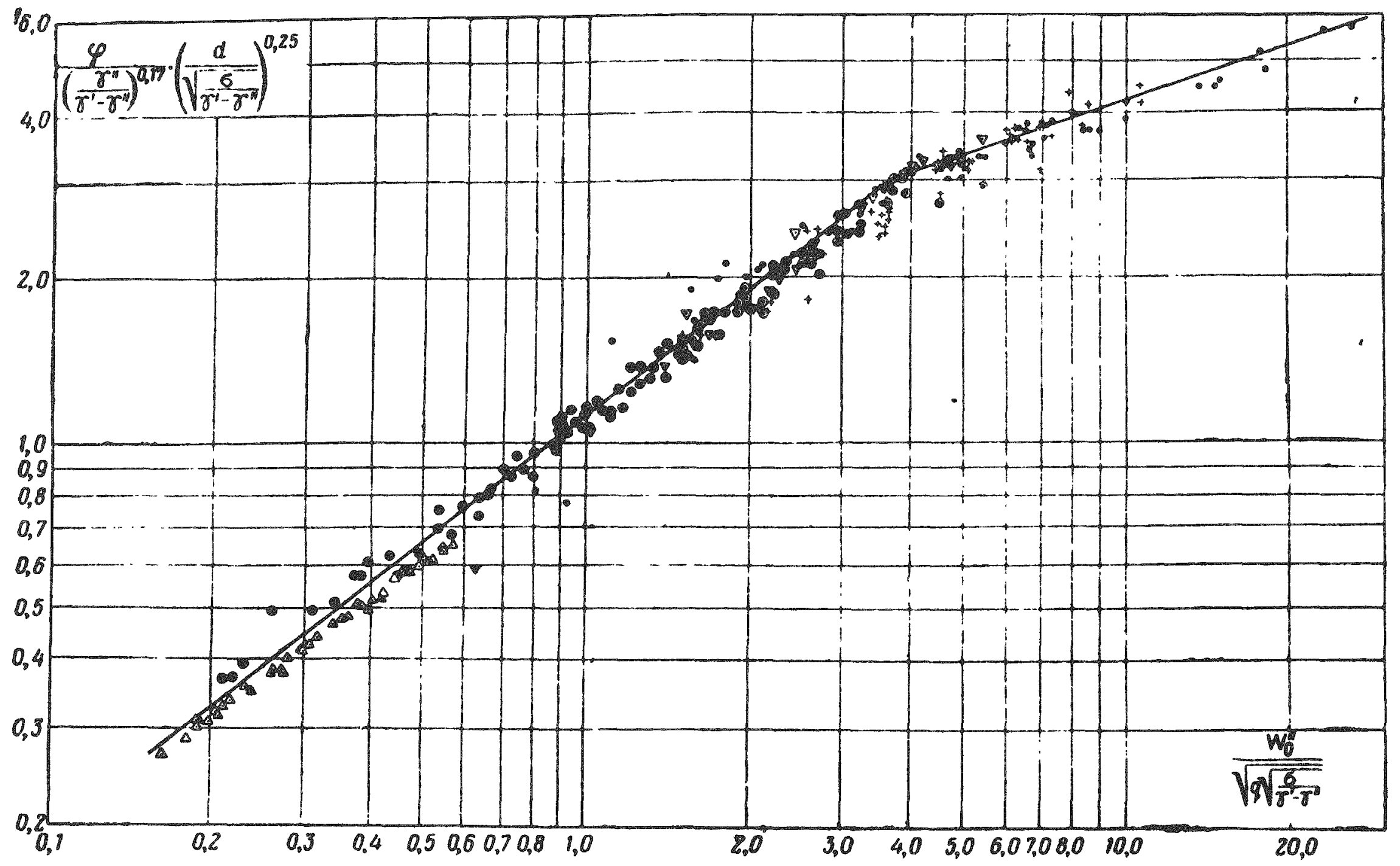

Figure VI-3 The Correlation of Sterman (Ref. 46) and of Dementiev, et. al. (Ref. 51). [This Figure was Reproduced from Ref. (51).] Experimental Data; + of Dementiev, et. al; $\odot$ of Behringer; $\triangle$ of Margulova; of
Sterman; $\nabla$ of Dementiev. 
The reader wil note that, at a particular reduced vapor velocity $u_{0} "$, the data plotted on Fig. VI-3 show a sharp change of slope. In two phase llow such break points, i.e., discontinuities mark a change of the flow regime. It was surmised in Sect. V.2 that the change of liquid entrainment from the "region of ejected drops" to the "region of liquid splashes" could be related to a change of 1 low regime in the bubbling two phase mixture. It would be of considerable interest to investigate whether the transition point in the liquid entrainment actually corresponds to the discontinuity shown on Fig. VI-3. To conduct such an investigation experimental data, taken simultaneously, on liquid entrainment and on the hydrodynamic conditions of a bubbling mixture are needed.

\section{VI.5 THE EXPANSION OF A BUBBLING MIXTURE AND THE TRUE LOCATION OF THE LIQUTD INTERFACE}

The amount of Iiquid entrained depends upon the distance between the interface (where drops or splashes are generated) and the vapor exhaust 1ine. For a given design, because of the expansion of the bubbling mixture, this height will decrease as the vapor flow rate is increased (See Fig. 2 in the Introduction). It was stated in section V.2 that, when the initial height of the liquid HL (initial meaning in the absence of bubbling) and the expansion $\triangle$ I axe known, the location of the interface of the mixture $\mathrm{H}_{\mathrm{m}}$ can be estimated from $\mathrm{Eq} \cdot(\mathrm{V}-12)$, i.e., from

$$
H_{m}=H_{L}=\Delta H \equiv \frac{H_{L}}{1-a}
$$


This equation can be used if does not vary along the axis of the vessel. In general, in a bubbling mixture, will vary in the radial direction as well as in the axial dixection. The results of a series of experiments designed to investigate the radial and the axial distribution of are reported in Ref. 52. It was found in these experiments that the radial distribution of the vapor volume fraction as aximum at the axis of the vessel, and it can be approximated by power law expression. This radial effect is similar in nature to the radial distribution of in a forced, two phase flow system which has been analyzed by Bankof (Ref. 53) and discussed in Ref. 54 .

In the axial direction it is possible to consider two regions, one in which remains constant and the second in which aries. Figure VI-4, which is reproduced from Ref.52, shows the variation of along the axis. The region of constant was refered by these investigators as the "stable region" whereas the second was referred to as the "transition region". The experimental apparatus used in the experiments reported in Ref. 52 was described in the preceding section. It was stated in Refs. 52 and 55 that. in the region where - remains constant, the value of can be computed from the correlations which have been discussed in the preceding sections. When the reduced vapor velocity $u_{0} "$ is below $0.2 \mathrm{~m} / \mathrm{sec}$, the effect of the "transition region" can be neglected and the location of the interface can be estimated from Eq. (VI-5). As the reduced vapor velocity $u_{0}$ " is increased, the height HTR of 


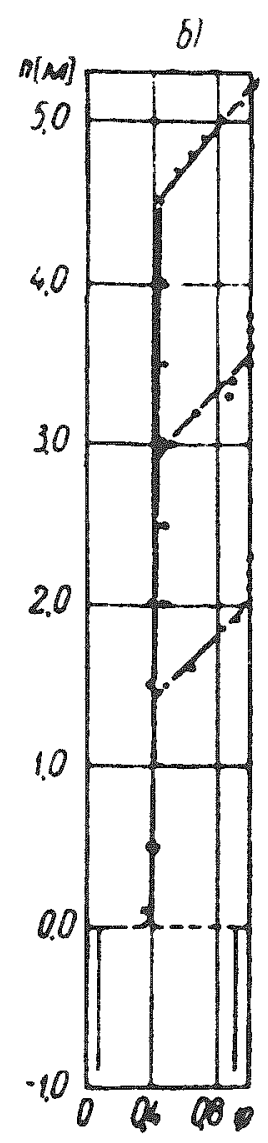

Figure VI-4 The Axial Variation of the Volumetric Vapor Fraction in a Two-Phase Bubbling Mixture. (This Figure is Reproduced from Ref. 52.)

$x: H=99.8 \mathrm{~cm} ; 0: H=186.9 \mathrm{~cm} ; t: H=250.8 \mathrm{~cm} ; \mathrm{P}=41 \mathrm{~atm} ;$ Vapor Mass Flow Rate $=3000 \mathrm{~kg} / \mathrm{hr}$.

Coordinates: $h=\mathrm{H}_{\mathrm{m}}$ (in meters); $\phi=\alpha(\% / 0)$. 
the "transition region" increases; this effect is shown on Figs. VI-5 and VI-6, which are reproduced from Rel. 52. The coordinates on these I1gures are $\mathrm{I}_{\mathrm{TR}}$ (In meterg) varsus uo" (1n meters per second). For the data shown of F1g. VI-5, the dimeter of the test vessel was $d=0.353 \mathrm{~cm}$, whereas for the data rhown of Fig. VI-6, It was d $0.238 \mathrm{~cm}$. As Indicated on these I1gures, the experiments were periormed in the pressure range from 4 atm to $92.2 \mathrm{tm}$.

From these data Dementiov, et,al. (Ref. 52), derived the following correlation for the height of the transition region

$$
\mathrm{H}_{\mathrm{TR}}=0.15 \mathrm{p}^{0.52} \mathrm{u}_{0} \mathrm{n}
$$

where $\mathrm{p}$ is measured in atmosphere and $u_{0}$ " in meter/second. For estimating the total height of the bubbling mixture (the scable plus the transition region), Dementiev, et,al.(Ref. 52), recommended the following expression

$$
\mathrm{H}_{m}=\frac{\mathrm{HL}_{L}}{1-\alpha}+\frac{\mathrm{HTR}_{\mathrm{T}}}{2}=\frac{\mathrm{H}_{\mathrm{L}}}{1-a}+0.075 \mathrm{p}^{0.52} \mathrm{u}_{0}
$$

where is computed from the correlations which were discussed in the preceding sections.

Sterman and Lepilin (Ref. 55) using the same experimental data, 1.e., the data shown on Igs. VI-5 and VI-6, proposed the following correlation
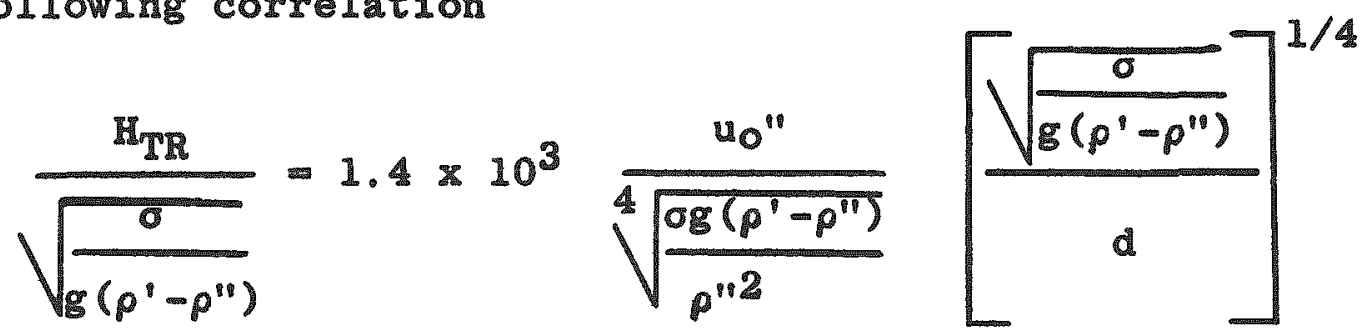


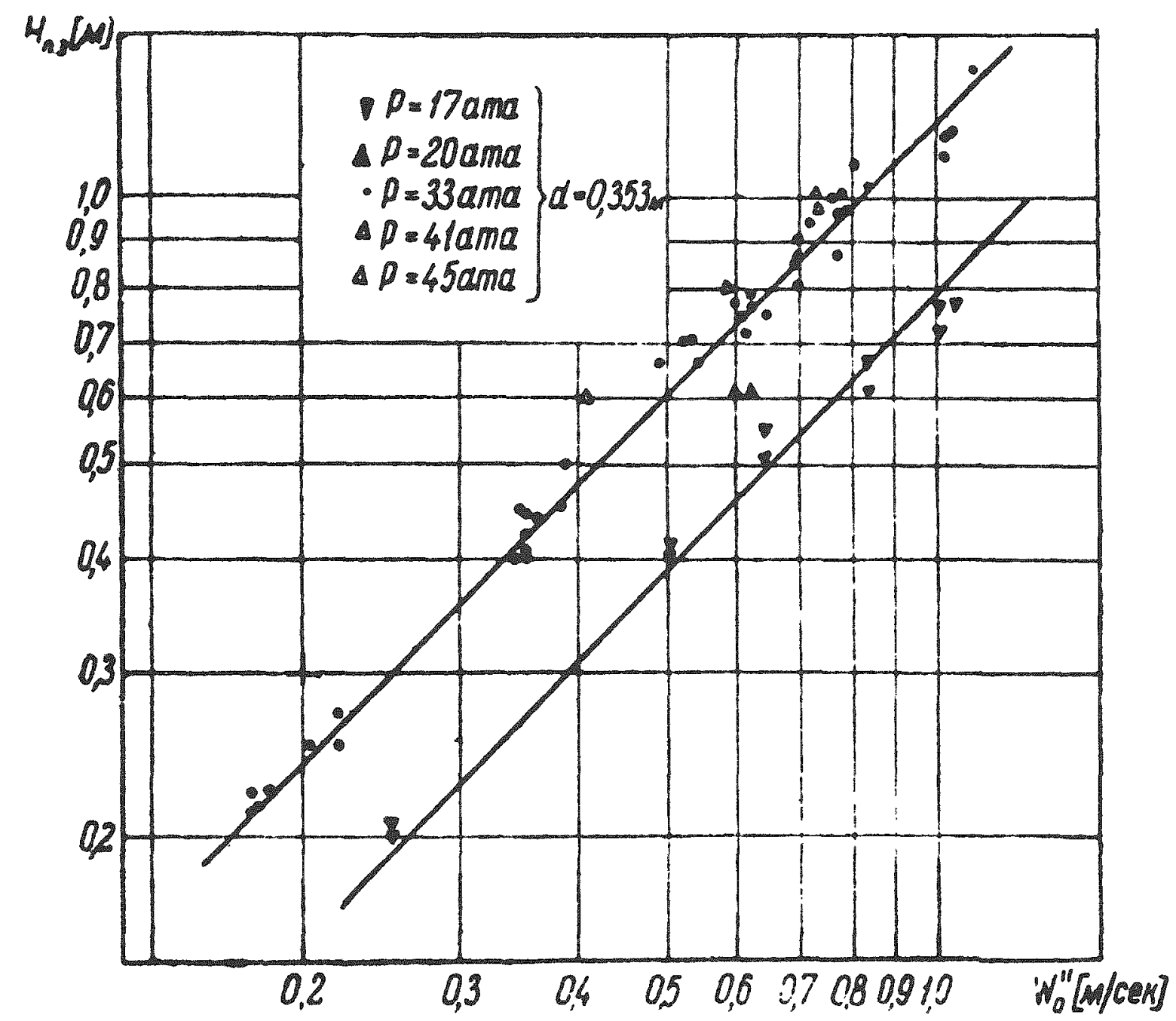

Figure VI-5 The Height of the Transition Region HTR as Function of the Reduced Vapor Velocity $u_{0}$ " at Various Pressures. $\mathrm{H}_{\mathrm{TR}}(\mathrm{m})$; $\mathrm{W}_{0} "=\mathrm{u}_{0} "(\mathrm{met} / \mathrm{sec})$. (Vessel Diameter $\mathrm{d}=0.353 \mathrm{~m}$.) This Figure was Reproduced from Ref. (52). 


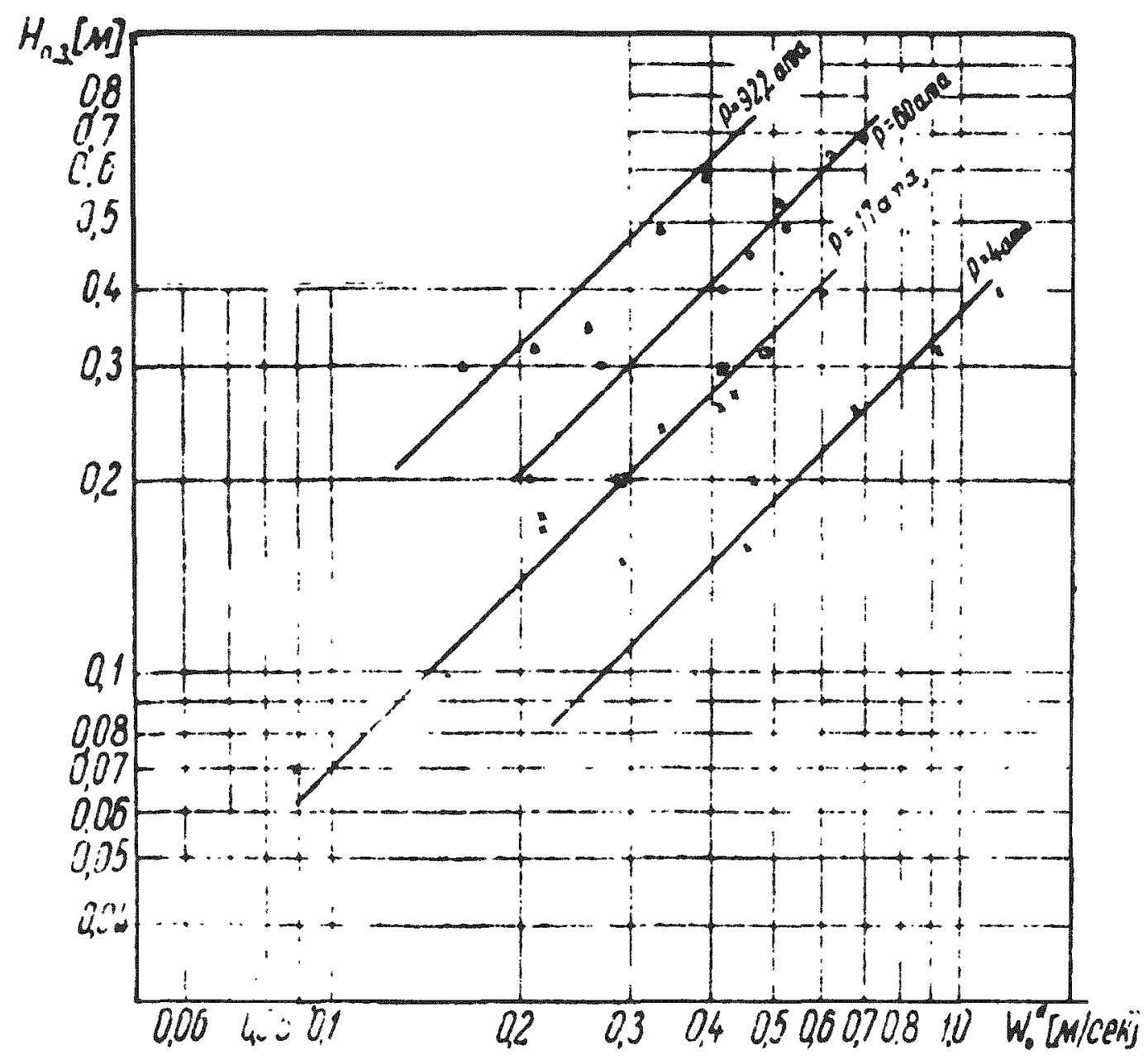

Figure VI-6 The Height of the Transition Region $\mathrm{H}_{\mathrm{TR}}$ as Function of the Reduced Vapor Velocity $u_{0}$ " at Various Pressures. $\mathrm{H}_{\mathrm{TR}}(\mathrm{m})$ $\mathrm{W}_{0} "=\mathrm{u}_{0} "(\mathrm{met} / \mathrm{sec})$. (Vessel Diameter $\mathrm{d}=0.238 \mathrm{~m}$.) [This Figure was Reproduced from Ref. (52)]. 
(where is the diameter of the vessel measured in meters) if

$$
d \leqslant d_{r}=260\left(\frac{p^{p 1}}{p^{1}-p^{p 1}}\right)^{-0.2} \sqrt{\frac{\sigma}{g\left(p^{1}-p^{18}\right)}}
$$

If, however, $d>d_{r}$ then $d_{r}$, given by Eq. $(V I-13)$ is substituted in place of $d$ in $\mathrm{Eq} .(\mathrm{VI}-12)$. For estimating the maximum height of the bubbling mixture Sterman and Lepilin recomended

$$
\mathrm{H}_{\mathrm{m}}=\frac{\mathrm{H}_{\mathrm{L}}+\Delta \mathrm{H}_{\mathrm{L}}}{1-a}+\frac{1}{2} \mathrm{H}_{\mathrm{TR}}
$$

where $\mathrm{H}_{\mathrm{L}}$ is the height indicated by a manometer and $\Delta \mathrm{H}_{\mathrm{L}}$ is the maximum amplitude of oscillation of the meniscus in the manometer. The value of is computed from the correlations which were discussed in the preceding sections.

\section{VI.6 SUMMARY}

The correlations which have been briefly discussed in this chapter permit one to estimate the volumetric vapor fraction a in a bubbling mixture in terms of the reduced vapor velocity $u_{0} "$. It is noted, however, that these correlations are in disagreement with each other in regard to the functional relation between and $u_{0} "$. Additional experimental data are needed to establish the validity and the limitations of these equations. Experimental data on bubbling mixtures indicate that the volumetric vapor fraction varles in the radial as well as in the axial direction. The expansion of the mixture (and therefore the 11quid entranment) is affected by the axial distribution of c. Two available correlations have been cited which, 
as claimed, permit one to estimate both the expansion of the mixture and the true location of the interface in a bubling mixture. Additional experimental data are required to establish the validity and the limitations of these correlations. 


\section{REFERENCES}

1. Shor, A. J., Ward, H. T., Miller, D., and W. A. Rodger, "Radioactive Carry-Over from Borax III and Test Systems", Nuclear Science and Engineering, vol. 2, 126, 1957.

2. Sterman, L. S., Antonov, A. I., and A. V. Surnov, "An Investigation of the Steam Quality at $185 \mathrm{~atm}^{\mathrm{n}}$, Teploenergetika, vol. 4, 1957, no, 3, pg. 17 .

3. Place, P. B., "Carryover Problems and Identification of Carryover Types" Combustion, March 1957, pg. 29.

4. Garner, F. H., Ellis, S. R. M., and J. A. Lacey, "The Size Distribution and Entrainment of Droplets", Trans. Inst. Chem. Engr., vol. 32, pg. 223, 1954.

5. Kirpichev, V. M., "The Conclusions of the Commission Concerned with the Summary of the Discussion on the Mechanism of Moisture Entrainment from Vapor Boilers" Izvestia Akad, Nauk, Otd. Tech. Nauk, no. $12, \mathrm{pg}, 1863,1953$.

6. Panasenko, M. D., and A. I. Antonov, "Correlation of Mechanical Carryover by Steam", Teploenergetika, vol. 6, no. 10, pg. 49, 1959.

7. Chernaev, I. I. and M. A. Styrikovich, "Physical and Chemical Processes Inside Boilers" Akad, Nauk SSSR, Moscow, 1957. This monograph contains 40 research papers on the purity of steam, the purity of water, and on corrosion.

8. Newitt, D. M., Dombrowski, N., and $\mathbb{F}$. H. Knelman, "Liquid Entrainment, 1. The Mechanism of Drop Formation from Gas or Vapor Bubbles", Trans. Inst. Chem. Engr., vol. 32, p. 224, 1954.

9. Knelman, F. H., Dombrowski, No, and D. Mo Newitt, Nature, Lond. vol. $173, \mathrm{pg} .261,1954$.

10. Gleim, V. G., "On the Problem for a General Theory on Moisture Entrainment from Boiling Mixtures", Zhur. Prikl. Khim., v.28, no. 1, pg. 12, 1955.

11. Gleim, V. G., Shelomov, I. K., and B. R. Shidlowskil, "processes Leading to Generation of Droplet by the Rupture of Bubbles at the Liquid-Gas Interface", English Translation: Journ, Appl. Chem. of the USSR, vol. 32, no. 1, pg. 222, 1959.

12. Davis, R. F., "The Physical Aspect of Steam Generation at High Pressures and the Problem of Steam Contamination", Proc. of the Inst. of Mech. Engineers, vol. 144 (1940) pp. 198-216. An abstract appears in the Figineer, Dec, 1940, pp. 399-401, $412-414$. 
13. Prandt1, L., Essentials of Fluid Dynamics, Hafner Pub. Co,, New York.

14. Levitch, V. G., Physicochemical Hydrodynamics, 2nd Ed., Gos. Izd. Fiz. Mat. Lit, Moscow, 1959.

15. Birkhof , G. and E. H. Zarantonello, Jets, Wakes and Cavities, Acad. Press, New York, 1957.

16. Hinze, J. O., "Fundamentals of the Hydrodynamic Mechanism of Splitting in Dispersion Processes", A.I.Ch.E. Journal, $\nabla .1$, p. $289,1955$.

17. Thompson, W., "On the Waves Produced by Single Impulses in Water of Any Depth or in a Dispersed Medium", Proc. Roy. Soc., vol. 42, D. 80,1887 .

18. Lord Rayleigh, "On the Instability of Jets", Proc. Lond, Math. Soc., vol. 10 (1878), pp. 4-13.

19. C. Weber, Z. Angew. Math. Mech., vol. 11 (1931), p. 136.

20. A. Haenlein, Forsch. Ing, Wes., vol, 2 (1931), p. 139.

21. R. A. Castleman, Jr., "The Mechanism of the Atomization of Liquids", Bur. Stand.J. Res. Wash., Vol, 6 (1931), pp.369-376.

22. R. Straus, Ph.D. Thesis, London University (1950).

23. J. H. Dallavalle, Ricromerities; The Technology of Fine Particles, Second Edition (1948), Pitman, New York.

24. C. I. Lapple, and C. B. Shepherd, Calculation of Particle Trajectories" ${ }^{0}$, Industrial and Engineering Chemistry (Industrial Edition), Vol. 32, No. 5 (May, 1940), pp. 605-617.

25. D. J. Ryley, "Behaviour of Water Globules in Steam", The Engineer (July 16, 1954), pp. 74-78.

26. Sir Horace Lamb, Hydrodynamics, Sizth Edition, Dover Pub., New York (1932).

27. F. A. Zenz and N. A. Weil, A Theoretical-Empirical Approach to the Mechanism of Particle Engrainment from Fluidized Beds", A. I. Ch. E. Journal, Vol. 4, No. 4 (December, 1958), pp. $492-279$.

28. Andrews, J. M., "Minetic Study of Fluidized Solids Entrainment" Ind. and Ingr. Chem., vol. 57, pg. 85, 1960.

29. Kruzhilin, G. N., "The Dependence of the Permissible Vapor Load upon the Pressure" Izv, Ak, Nauk, SSSR, Otd, Tekh, Nauk, no 7, pg, 1106, 1951. 
30. Kruzhilin, G. N. "Some Remarks on the Article by M. D. Styrikovich, I. S, Sterman, and T, I, Margulova", Izv, Arad. Nauk, SSSR, 0.T.N., no. 10, pg. 1560, 1951.

31. Styrikovich, M. A., Sterman, L.S., Margulova, T. M., "On the Laws Concerned with the Entrainment of Drops by Vapor from a Boiler", Izv. Akad. Nauk., SSSR, 0.T.N., no. 8, p. 1250, 1951.

32. Guhman, A. A., On the Formula of Kruzhilin Concerned with the Dependence of Steam Molsture Upon the Vapor Load", Izv. Akad. Nauk., SSSR, 0.T.N., no. 2, p. 280, 1952.

33. Sterman, L. S., "Stil1 More on the Discussion Concerned with the Theory of Drop Entrainment from a Boiler" Izv. Akad, Nauk, SSSR, 0.T.N., no. 3, p. 459, 1952.

34. Stoishin, N. G. "On Some Relations Concerned with the Carryover of Moisture from 2 Vapor Boiler", Izv. Akad. Nauk, SSSR, O.T.N., no. $3, \mathrm{p}, 464,1952$.

35. Tatarinov, B. P., On Some Relations Concerned with the Carry over of Moisture and of Salt from Vapor Boilers", Izv. Akad. Nauk, SSSR, O.T.N., no. 4, p. 620, 1952.

36. Blinov, K. A., MOn the Model Proposed by G. N. Rruzhilin for the Process of Carry-Over of Moisture", IzV. Akad. Nauk, SSSR, O.T.N., no. $3, p .467,1952$.

37. Panasenko, M. D., Timofeev, V. N., and A. I. Filimonov, On the Interpretation of Experimental Data for Analyzing the Carry Over of Moisture", Izv. Akad. Nauk, SSSR, O.T.N., no. 5, p. 615,1952 .

38. Styrikovich, M. A., "On the Problem Concerned with a Theory of Carry Over of Moisture", IZv. Akad. Nauk, SSSR, 0.T.N., no. 2, p. 281, 1952.

39. Antonov, A. I. and M. D. Panasenko, "The Influence of the Vapor Volume Faction Upon the Critical Height of the Vapor Space in a Boiler", Teploenergetika, vol, 4, no. 8, pg. 39, 1957.

40. Sterman, I. S., Motloturbostroenie, no. 5, 1952.

41. Sterman, I. S., Antonov, A. I., and A. V. Surnov, An Investigation of the Steam Quaity at 185 atm Using Radioactive Isotopes", paper in the monograph entitled "Teplotehnika i Gidrodynamika" edited by Styrikovich, M. A. G. E. Kholocovski, and $\mathrm{h}$. S. Fomitchev, Gozenergoizdat, Moscow, 1958.

42. Styrikovich, M. A. Sterman, L, S. and A. V. Surnov, "An Investigation of the Cary Over of Salt by Stear Using Radioactive Isotopes", Teploenergeting, vol, 2, no. 2, pg. 43, 1955. 
43. Rurbatov, A. V., "The Bubbling and the Problem of Critical Loads in Steam separation". Trans. of the Power Inst.

"M. Molotov", Vol. II, Moscom, 1953.

44. Margulova, T.H., "An Experimental Investigation of the Relative Velocity of Vapor in Bubbling Through a Layer of Water at High Pressures", Trans. of the Power Inst., M.V.Molotov", vol. 1I, Moscow, 1953.

45. Sterman, L. S., "The Correlation of Fxperimental Data for Vapor Bubbling through a Liquid", Zh, Tech, Fiz, vol. 26, p. 1519, 1956, translated in the Soviet Physics - Technical Physics, p. $1479,1957$.

46. Blinov K. A, and L. S. Sterman, Kotloturbostroenie, No. 5, 1949.

47. Kolokoltzev, $V$. A., "An Investigation of the Conditions in the Steam Space of ISV Evaporators", Dissertation, Translations of the Power Institute, "Y. M. Molotov", vol. 10, 1952.

48. Sterman, L. S. "The Theory of Stean Separation", zhur. Tech. Fiz., Vol, 28, no. 7, p. 9, 1958, translated in the soviet Physics - Technical Bhysics, p. 1440, 1959.

49. Behringer, P., "Steiggeschwindigkeit von Dampiblasen in Kesselrohren", V.D.I. Forschungs Heft 365, 1934.

50. Kutaleladze, S. S. Heat Transer In Condensation and Boiling, Gozenergiozdat Moscow, I952, ACC IransI2tion AEC-tr-3770.

51. Dementiev, B. A. Lepilin, R. S. and A. A. Loginov, "An Investigation of the Hydrodymamic Process of Bubbling through a Vapor-Liquid Mixture of Considerable Height", Nauch. Dok. Vish. Shko1. - Tuergetiga, no. 2, p. 251, 1959.

52. Dementiov, B. A., Lepilin, R. S. and A. A. Loginov, "An Investigation of the Hydrodynamics in the Volume occupied by Water for a Bubbing Mixture of Considerable Height", Nauch. Dok. Vish. Shko1. = Energetika, no. 2, p. $263,1959$.

53. Bankoff, S. G. "A Variable Density Singlo-Fluid Model for Two Phase $\mathrm{F}$ low with Particular Reference to Steammater Flow". ASME Paper 59-HT-7, 1959, to be published in the ASUE Transactions - Journal of Heat Transfer, vol. 82, Ser. C, no. 4, p. 205, 1960.

54. Zuber, N., "On the Variable Density single-Fiuld Model for Two Phase Flow", ASME Txans", Journal of Heat Transter, ASIL Trans., vol. 82, Ser, C no. 3, p. 255, 1960.

55. Sterman, L. S. and R. S. Lepliln, "On the Problem of Determining of the True Interface during Bubbling of steam through Liquids", Teploenergetika, V.7, no. 1, p. 45, 1960. 
56. Margulova, T. H., "Application of Radioactive Isotopes in an Investigation of Steam Purity in Industrial Boilers at High Pressures" ${ }^{\text {br }}$ Izv. Akad. Naun. SSSR, 0.T.N., no. 8 p. 29,1959 .

57. Manowitz, B., Brelton, R. H. and R. V. Horrigan, "Entrainment in Evaporators", Chem. Engr. Prog., v. 57, p. 313, 1955.

58. Wilson, Jo and M. Me Dermont, "Moisture De-Entrainment Tests in Two and Four Inch Diameter Test Sections", Rep. ACNP-5921, All is Chalmers Mfg. Co., Milwaukee 1, Wisc., Nov 15, 1959.

59. Mitsuishi, N. Sakata, S., Matsuda, Y. and Y. Yamamoto, "Liquid Entrainment and Its Removal of Large Scale Evaporation Unit", Jour. of the Atomic Energy of Japan, vol. 1, p. 363, 1959.

60. Garner, F. H., Ellis, R. M. and D. B. Shearn, "Entrainment in Evaporators", Trans. Inst. Chem. Engr., vo1. 37, p. 246, 1959.

61. Gaston, E. C., "Eliminating Carry Over and Blade Deposits at Pensacola Stean Plant", Southern Power and Industry, p. 42, Dec. 1946.

62. Seniff, R. W., "Steam Contamination by Aquaglobejection", Amex, Railway Engr. Asst., v. 46, p. 446, 1944.

63. Mumford, A. R., "A Theory of Carry Over", Combustion, p. 39, February 1947 .

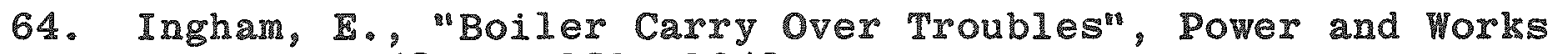
Engr, v. 43, p. 121, 1948.

65. Walker, V., "Problem of Carry Over from High Pressure Boilers", Elect. Times, v. 10, n. 2635, Apr. 1942.

66. Straub, F.G., "Steam Turbines Blade Depositg", Bul1, 364, Univ。 of Illin. Eng. Exp. St., Urbana, Il1., 1946.

67. Seniff, R. W., "Foaming and Carry Over in Boilers", Am. Water Works Ass. Jour., v. 40, no. 9, p. 961, 1948.

68. O'Connel, A. E. and E. S. Pettyjohn, "Liquid Carry Over in a Horizontal Tube", AIChE Trans., v. 42, p. 295, 1946.

69. Nicholson, P.J., "An Investigation of Droplet Size at High Quality in a Boiling Column of Water", M. S. Thesis, M.I.T., 1957.

70. Kitchenev, J. and G. F. Cooper, "Current Concepts in the Theory of Foaming", Quart. Rev, v. 13, p. 71, 1959. 
71. Coulter, E. and T. Campbe11, "Steam Purity Determination by Tracers Techniques", Combustion, v. 28, p. 63, 1956.

72. Gelperin, N. I. and V. B. Kogan, "Mechanical Carry over by Vapor Irom an Evaporator", Khim. Prom,s p. 96, 1958.

73. Sterman, L. S. "Foaming in Water Boilers", Elektricheskie Stantzie, no. 9, 1949 .

74. Gleim, V. G., "The Boiling Regime of Mixtures and the Factors which Influence It", Zhur. Prikl. Khim., v. 26, no. 1, p. 1157 , 1953.

75. Gleim, V. G. and A. I. K. Shelomov, on the Phenomena at the Interface between Two phases in Boiling Mixtures", Zhur. Prinkl. Khim., v. 30, no. 1, p. 32, 1957.

76. Braude, I. E. and I. I. Zhirnov, Modern Boiler Units; Essential Components and Devices, Gozenergoizdat Moscow, 1959.

77. Styrikovich, M. A. and I. G. Vinokur, "The Application of Radioaktive Isotopes for an Investigation of the Carry Over of Salt by Vapor", Doklady Acad. Nauk., v. 40, no. 2, p. 179, 1953.

78. Andreevski, A. A. and U. Zenkievich, "Investigation of the Salt Entrainment by Vapor Utilizing Radioaktive Isotopes", Teploenergetika, v. 4, no, 9, p. 37, 1955.

79. Margulova, T. H. Katovskaia, $\mathrm{K}$, and L. Borodulina, "Nomograms for Computation of Steam Purity", Teploenergetika, v. 5, no. 1, p. 6,1956 .

80. Nikolenko, I., "Expansion of Boiler Feed Water of Different Composition", Teploenergetika, v. 7, no, 8, p. 71, 1960.

81. Panasenko, M. D., "The Role of the Volume of Water in the Boiler on the Formation of Splashes", Izv. Vses. Tep. Inst. (V.T.I.), no. 5, 1947 .

82. Styrikovich, M. A., Khaibulin, I. Kh., and L. K. KholhIov, "The Influence of Solutility upon the Performance of a Vater Boiler", Problemi Energetiki Anad. Nauk. SSSR, 1959, p. 483.

83. Styrikovich, H. A. E. Serov, D. K. Smirnov, mivestigation of the Steam Quality of a Uniflow Boiler at Supercritical Pressures and for Different reed Vater Compositions", Teploenergetika, v. 7 , no. 1, 1960.

84. Styrikovich, M. A. Katkovskaia, K. I. and E. P. Serov, Boiler Plants, Gozenergoizdat, Moscow, 1958. 
85. Krol, L. B., Characteristics of High Pressure Boilers, Gozenergoizdat, Moscow, 1957.

86. Zenkievich, U. V. and A. P. Turnovski, "On Some Basic Factors which Influence the Effective Scribing of Vapor", Energomashinostroenie, no. 10, p. 18, 1956.

87. Zenkievich, U. V., "About the Formation of Salt Deposits on Turbines", Teploenergetika, v, 7, no. 4, p. 62, 1960. 
110

•

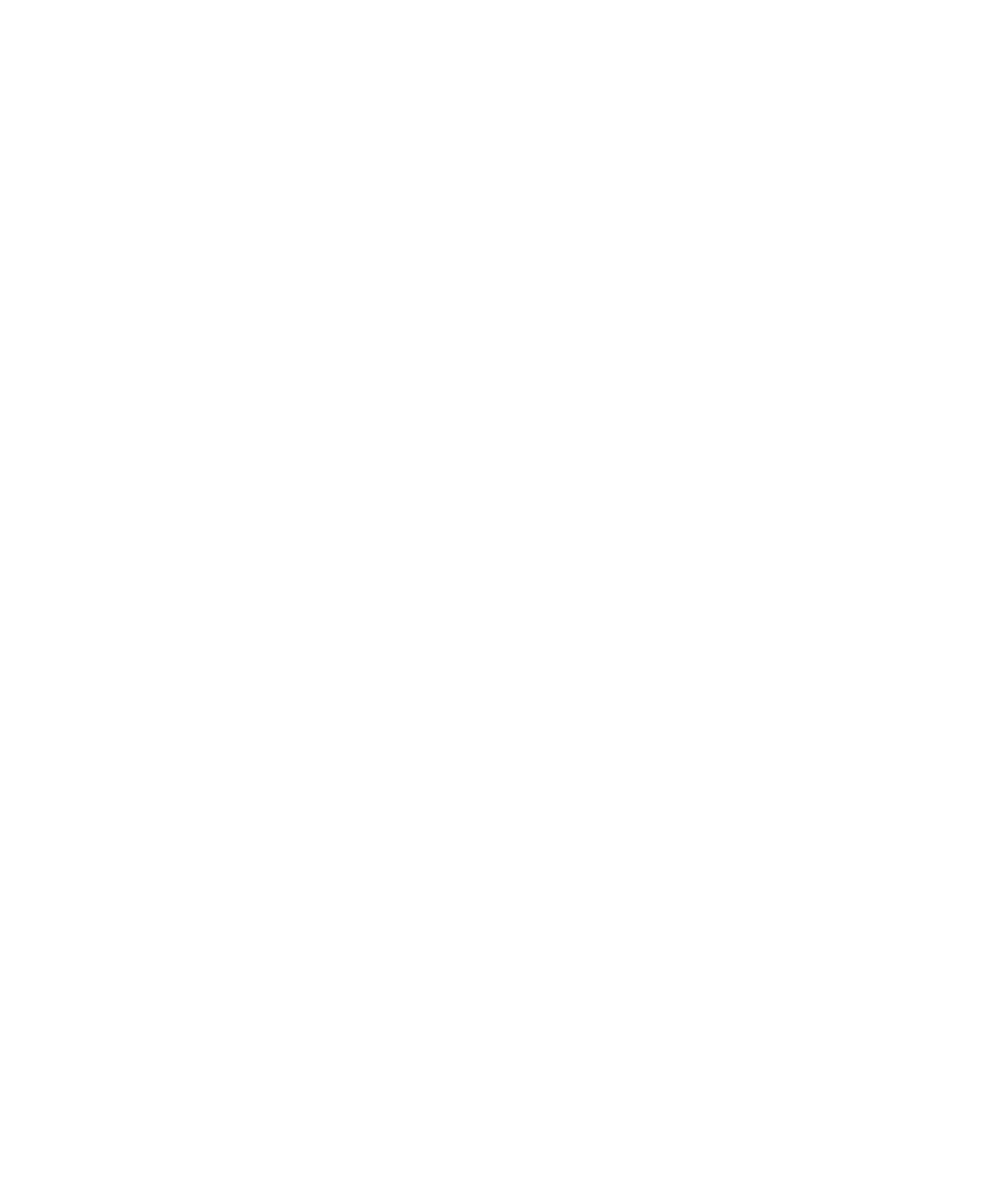


APPIMDIX A

EXPMRIMENTAL DATA ON WATER CARRY-OVER

FROM BOLLERS AT RIGH PRESSURES

A large number of experimental investigations concerned With water carry-over were conducted in Russia. The results of these experiments, which were performed over a wide pressure range, are reported and summarized in Refs. $2,40,41,42,46$, 47, and 56. In the experiments reported in Rer. 46, the 1iquid entrainment was determined from calorimetric measurements; whereas for the experiments reported in Refs. $2,41,42$, and 56 the entrainent was determined from the decay of isotope $\mathrm{s}^{32}$. The experimental apparatus consisted of a circular vessel; steam was introduced through a perforated plate which, in the absence of bubbling, was immersed to a depth $\mathrm{H}_{\mathrm{L}}$ below the liquid interface. The dimensions of the equipment together with the experimental conditions, i.e., pressure, initial liquid level I above the perforated plate and the initial beight $H$ of the vapor space (vapor dome) are tabulated on Table I, which is based on the data reported in Refs, $2,6,39,41,42$, and 56. On the same table are shown the values of the entrainment $\mathbf{E}$ of the reduced vapor velocity $u_{0} "$, and of the vapor mass 1 low rate G", which correspond to the transition from the region of "ejected drops" to the "region of 1iquid splashes", i.e., to the transition point $B$ shown on Fig. 1 of the Introduction. The values of the exponent $\mathrm{I}$ II $\mathrm{Eg}$. 1 of the Introduction, which correspond to these two regions, are shown also. 
Figure A-1, which is reproduced Prom Ref. 56, shows the entrainment $E$ at two pressures $(P=110 \mathrm{~atm}$ and $\mathrm{P}=185 \mathrm{~atm})$ for three different initial heights In the vapor space. In terms of the nomenclature in this report, the coordinates on Fig. A-1 are

$$
\begin{gathered}
W=E(\%) \\
R_{V}=\frac{u_{o} "}{H}\left(\frac{m^{3}}{m^{3} h r}\right)
\end{gathered}
$$

where the values of $H(H=650 \mathrm{~mm}, H=890 \mathrm{~mm}$, and $H=1220 \mathrm{~mm})$ are indicated on the figure. 
Table I

\begin{tabular}{|c|c|c|c|c|c|c|c|c|c|}
\hline Investigator & 两 & ${ }_{\mathrm{L}}$ & I & $\mathrm{g}$ & $\begin{array}{l}\mathbf{E} \\
\%\end{array}$ & $\begin{array}{c}\mathrm{u}^{\prime \prime} \\
\mathrm{mec}\end{array}$ & $\mathrm{Kg} / \mathrm{m}^{2} \mathrm{sec}$ & $\mathbf{n}_{2}$ & $n_{3}$ \\
\hline $\begin{array}{l}\text { V. A. Ko lokoltzov } \\
\text { (ReP. A7) }\end{array}$ & $\begin{array}{l}0.3 \\
0.3 \\
0.3 \\
0.3 \\
0.3\end{array}$ & $\begin{array}{l}0.25 \\
0.25 \\
0.15 \\
0.15 \\
0.25\end{array}$ & $\begin{array}{l}0.4 \\
0.6 \\
0.6 \\
0.3 \\
0.57\end{array}$ & $\begin{array}{l}1.25 \\
1.25 \\
1.25 \\
1.25 \\
1.25\end{array}$ & $\begin{array}{l}0.158 \\
0.132 \\
0.166 \\
0.150 \\
0.125\end{array}$ & $\begin{array}{l}0.763 \\
0.95 \\
1.015 \\
0.615 \\
0.784\end{array}$ & $\begin{array}{l}0.545 \\
0.680 \\
0.728 \\
0.440 \\
0.560\end{array}$ & $\begin{array}{l}5 \\
5 \\
5 \\
5 \\
5 \\
5\end{array}$ & $\begin{array}{l}13.3 \\
15 \\
15 \\
15.45 \\
14.5\end{array}$ \\
\hline $\begin{array}{l}\text { L. S. Sterman } \\
\text { and } \\
\text { I. A. BIlnov } \\
\text { (Re1. 46) }\end{array}$ & & & $\begin{array}{l}0.64 \\
0.64 \\
0.64 \\
0.64 \\
0.64 \\
0.64 \\
0.64 \\
0.64\end{array}$ & $\begin{array}{l}16.8 \\
31 \\
36 \\
40 \\
46 \\
61 \\
74.5 \\
92.5\end{array}$ & & $\begin{array}{l}0.555 \\
0.467 \\
0.464 \\
0.450 \\
0.458 \\
0.395 \\
0.333 \\
0.292\end{array}$ & & & \\
\hline $\begin{array}{l}\text { L. S. Sterman } \\
\text { (Rei. 40) }\end{array}$ & $\begin{array}{l}0.238 \\
0.238 \\
0.238 \\
0.238\end{array}$ & $\begin{array}{l}0.13 \\
0.13 \\
0.13 \\
0.13\end{array}$ & $\begin{array}{l}0.67 \\
0.67 \\
0.442 \\
0.82\end{array}$ & $\begin{array}{l}17 \\
36 \\
36 \\
91\end{array}$ & $\begin{array}{l}0.035 \\
0.12 \\
0.25 \\
0.08\end{array}$ & $\begin{array}{l}0.56 \\
0.56 \\
0.45 \\
0.35\end{array}$ & $\begin{array}{c}4.7 \\
9.88 \\
7.95 \\
16.85\end{array}$ & $\begin{array}{l}3.64 \\
3.44 \\
4 \\
4\end{array}$ & $\begin{array}{l}12 \\
12 \\
7 \\
12.5\end{array}$ \\
\hline
\end{tabular}


Table I (continued)

\begin{tabular}{|c|c|c|c|c|c|c|c|c|c|}
\hline Inveatigator & a & 䟠 & 垌 & 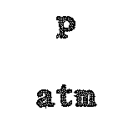 & $\begin{array}{l}\text { 漹 } \\
\%\end{array}$ & ${ }_{0}^{18}$ & $G^{24} \sec$ & $\mathbf{n}_{2}$ & $\mathbf{n}_{3}$ \\
\hline $\begin{array}{l}\text { L. S. Sterman } \\
\text { (Rer. 40)(Cont.) }\end{array}$ & $\begin{array}{l}0.238 \\
0.238\end{array}$ & $\begin{array}{l}0.13 \\
0.13\end{array}$ & $\begin{array}{l}0.67 \\
0.442\end{array}$ & $\begin{array}{l}91 \\
91\end{array}$ & $\begin{array}{l}0.045 \\
0.10\end{array}$ & $\begin{array}{l}0.27 \\
0.215\end{array}$ & $\begin{array}{l}13.05 \\
10.4\end{array}$ & $\begin{array}{l}4.3 \\
4.16\end{array}$ & $\begin{array}{l}12 \\
10\end{array}$ \\
\hline $\begin{array}{l}\text { 4. S. Sterman, } \\
\text { A. Antonov and } \\
\text { A. V. Surnov } \\
\text { (ReIs.2, 41) }\end{array}$ & $\begin{array}{l}0.255 \\
0.255\end{array}$ & $\begin{array}{l}0.17-0.2 \\
0.14-0.175\end{array}$ & $\begin{array}{l}0.45 \\
0.61-0.645\end{array}$ & $\begin{array}{l}185 \\
151\end{array}$ & $\begin{array}{l}0.06 \\
0.12\end{array}$ & $\begin{array}{l}0.075 \\
0.160\end{array}$ & $\begin{array}{l}10.95 \\
15.72\end{array}$ & $\begin{array}{l}3.8 \\
4\end{array}$ & $\begin{array}{l}15.2 \\
15\end{array}$ \\
\hline $\begin{array}{l}\text { M. A. Styrinovich, } \\
\text { L. S. Steruan } \\
\text { A. V. Surnov } \\
\text { (Re. 42) }\end{array}$ & $\begin{array}{l}0.238 \\
0.238 \\
0.238\end{array}$ & $\begin{array}{l}0.165-0.18 \\
0.165-0.18 \\
0.165-0.18\end{array}$ & $\begin{array}{l}0.650-0.665 \\
0.650-0.665 \\
0.650-0.665\end{array}$ & $\begin{array}{r}36 \\
91 \\
110\end{array}$ & $\begin{array}{l}0.1 \\
0.04\end{array}$ & $\begin{array}{l}0.524-0.535 \\
0.260-0.266\end{array}$ & $\begin{array}{c}9.24-9.45 \\
12.55-12.65\end{array}$ & $\begin{array}{l}3.7 \\
3.5 \\
3.3\end{array}$ & $\begin{array}{r}29 \\
-10\end{array}$ \\
\hline
\end{tabular}




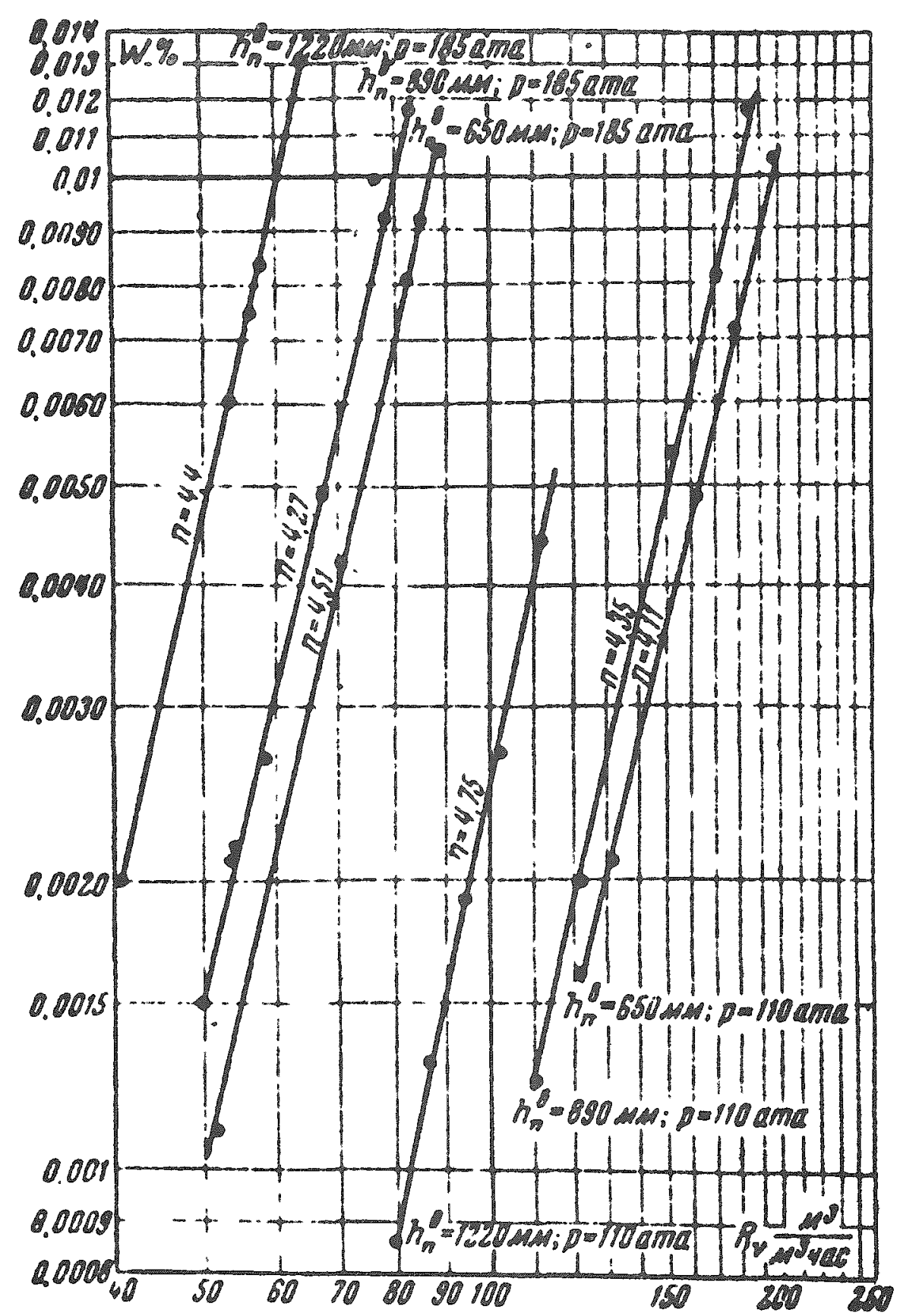

Figure A-1 The Entrainment $E(\%)$ as Function of the Reduced Vapor Velocity at High Pressures $(P=110$ atm and $P=185$ atm $)$ and for Different Heights of the Vapor Dome. (Ref. 56)

$$
a-E(0) ; \quad R_{V}=\frac{u_{0}{ }^{\prime \prime}}{H} \cdot\left(\frac{m^{3}}{m^{3} h r}\right)
$$

(where the values of $\mathrm{H}$ are indicated on the Figure; $H=650 \mathrm{~mm}, H-890 \mathrm{~mm}, H=1120 \mathrm{~mm}$ ) 
APPENDIX $B$

VOLUMETRIC VAPOR FRACTION A AS FUNCTION OF THE REDUCED VAPOR VELOCITY UO" AT HIGH PRESSURES

Experimental data of Margulova (Ref. 44) (Diameter of the vessel $d=20.0 \mathrm{~cm}$ ).

Pressure $91 \mathrm{~atm}$

uo"
$\mathrm{m} / \mathrm{sec}$

0.0672

0.0644

0.0611

0.0586

0.0564

0.0527

0.0501

0.0480

0.0458

uo"

m/Sec

0.0550

0.0527

0.0422

0.0397

0.0311

0.030

0.0276

0.0243

$4_{0}^{\prime \prime}$

$\mathrm{m} / \mathrm{Sec}$

0.0424

0.0391

0.0383

0.0316

0.0297

0.0268

0.0255

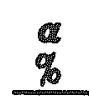

0.121

0.120

0.113

0.111

0.108

0.105

0.099

0.0965

0.0940 uo"

$\mathrm{m} / \mathrm{sec}$

0.0433

0.0403

0.0352

0.0335

0.0324

0.0311

0.0283

0.0261

0.0244

0.0225 $\stackrel{6}{6}$

0.090

0.087

0.078

0.075

0.072

0.0705

0.0663

0.0630

0.060

0.053

Pressure 150 atm
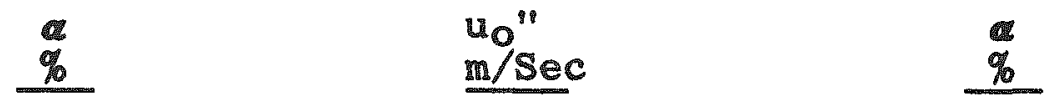

0.127

0.122

0.0234

0.0698

0.104

0.0210

0.0638

0.099

0.0200

0.062

0.086

0.0193

0.0605

0.0835

0.0185

0.058

0.076

0.0165

0.054

Pressure $190 \mathrm{~atm}$

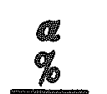

$u_{0}$ "

$\mathrm{m} / \mathrm{sec}$

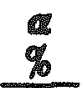

0. 128

0.121

0.0222

0.0197

0.0179

0.0161

0.105

0.099

0.091

0.0885
0.0796

0.0745

0.0683

0.0642 